\title{
The NIST Center for Neutron Research:
}

Over 40 Years Serving NIST/NBS and the Nation
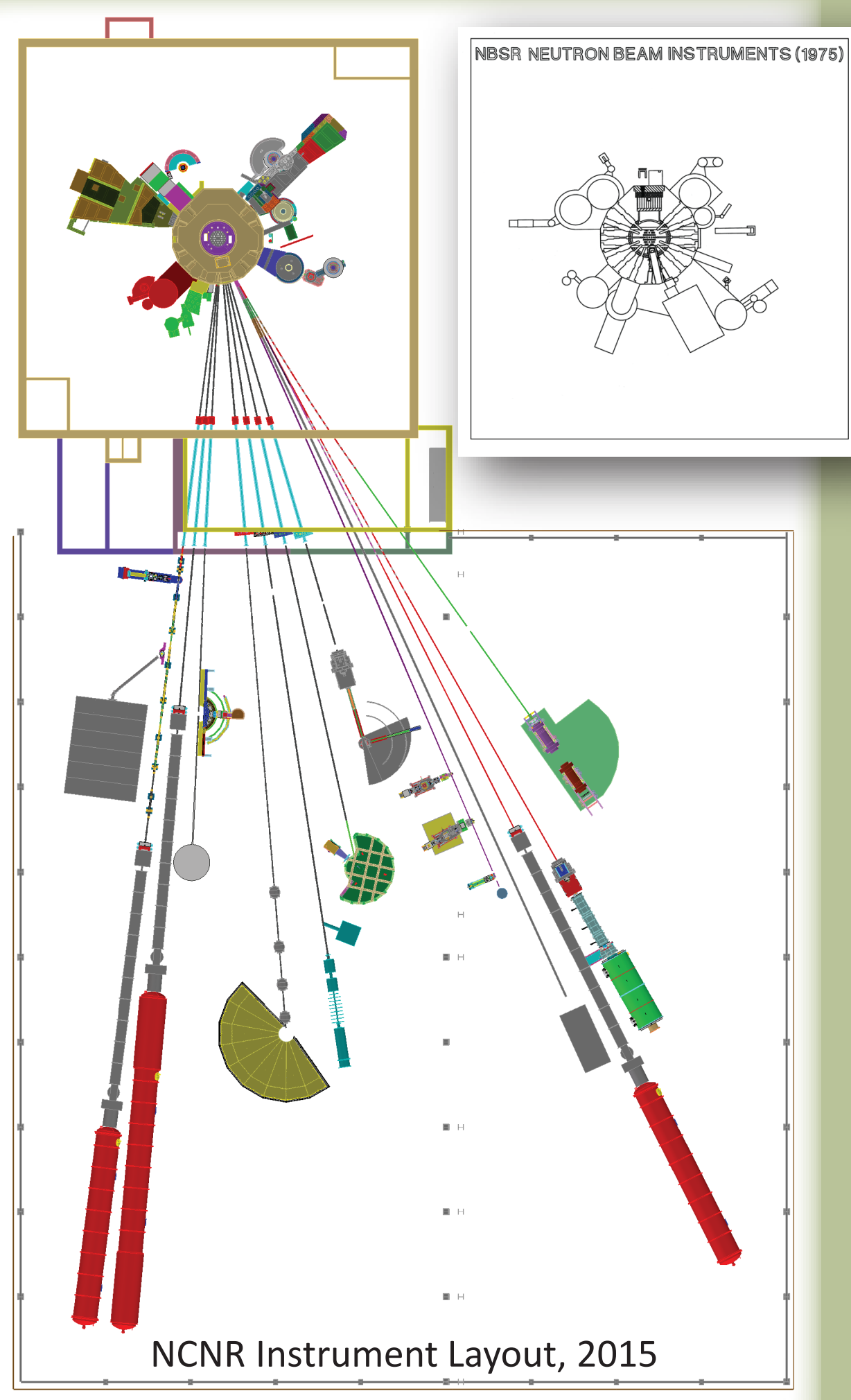

John J. Rush 
About the cover:

Pictured on the cover are two diagrams of the layout of instruments at the NIST Center for Neutron Research spanning 40 years of activity. On the right in black and white is the layout in 1975 in which the instruments using thermal neutrons were clustered around the reactor. On the same scale, the colored diagram depicts the instrument layout as it is planned for 2015, with instruments using cold neutrons located on guides emanating from the cold source housed in the "thimble" included in the original reactor design. Most of these instruments are located in the original guide hall building to the left of the "dots" running down the middle of the lower portion. The dots are the columns of the original wall before the expansion guide hall (to the right) was constructed in 2010.

About the authors:

Jack Rush is a NIST Senior Fellow (Emeritus) and was the leader of neutron scattering research at the NCNR for 35 years. He is currently an adjunct professor at the Materials Science and Engineering Department at the University of Maryland.

Ron Cappelletti, Professor of Physics (Emeritus), Ohio University, has worked as a physicist at the NCNR since 1999. Among other activities, he edits the NCNR Accomplishments and Opportunities annual report. 
Special Publication 1120

\title{
The NIST Center for Neutron Research: Over 40 Years Serving NIST/NBS and the Nation
}

\author{
John J. Rush ${ }^{1,2}$ \\ Ronald L. Cappelletti ${ }^{1}$ \\ ${ }^{1}$ NIST Center for Neutron Research \\ National Institute of Standards and Technology \\ Gaithersburg, MD 20899-6102 \\ ${ }^{2}$ Department of Materials Science and Engineering \\ University of Maryland \\ College Park, MD 20742
}

August 2011

National Institute of Standards and Technology

Patrick Gallagher, Director

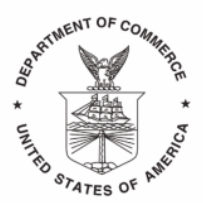

U.S. Department of Commerce

Gary Locke, Secretary 


\section{DISCLAIMER}

Certain Commercial entities, equipment, or materials may be identified in this document in order to describe an experimental procedure or concept adequately. Such identification is not intended to imply recommendation or endorsement by the National Institute of Standards and Technology, nor is it intended to imply that the entities, materials, or equipment are necessarily the best available for the purpose.

National Institute of Standards and Technology

Special Publication 1120

Nat. Inst. Stand. Technol. Spec. Publ. 1120, 70 pages

\section{CODEN: NSPUE2}

U.S. Government Printing Office-Washington: 2011

For sale by the Superintendent of Documents, U.S. Government Printing Office

Internet: bookstore.gpo.gov Phone: 1.866.512.1800

Fax: 202.512.2104 Mail Stop: SSOP, Washington, DC 20401-0001 


\title{
The NIST Center for Neutron Research: Over 40 Years Serving NIST/NBS and the Nation
}

\author{
Introduction
}

It is over 50 years since the decision to design and build the Neutron-Beam Split Core Reactor (NBSR) at the 1384 hectare (560 acre) site purchased in 1959 for the new location of the National Bureau of Standards (NBS) in Gaithersburg, MD. This brief history will attempt to place the NBSR and its evolution into the most heavily used and productive neutron source in the United States within the perspective of events of the last half of the twentieth century which greatly influenced the need for large facilities in American science and technology (and at NBS). While the scientific and engineering achievements of the NBSR will be covered in broad brush, no attempt will be made to write a summary of the enormous body of research at the NBSR, which has resulted in over 6000 archival papers and dozens of national research awards. We will largely rely on articles written by us and many others in special issues of the J. Res. Natl. Inst. Stand. Technol., and on the National Institute of Standards (NIST) Center for Neutron Research (NCNR) Annual Reports from the past 10 years, which give examples of research highlights at the NBSR, and will be included as references. While a number of individuals who were a large part of the historical development of the NBSR/NCNR will be mentioned, we regret that many others who made important contributions will not be, so that the length and flow of this informal history can be kept within bounds. In addition, the obvious central role that the Reactor Operations and Engineering staff has played in the success of the NBSR will not be described in any detail here. 


\section{The NBS Reactor}

Origins: The 1950's

The decision path toward the development of the NIST Center for Neutron Research began over 50 years ago, just before the Sputnik satellite launch accelerated the support of science and engineering in the U.S. It also came during a period of rapid change at the National Bureau of Standards (NBS) in the 1950's in which 2000 employees were transferred - mainly to the Department of Defense (DOD) - after the activities of NBS had been largely funded by Defense agencies and later by the Atomic Energy Commission (AEC) after World War II and during the Korean War period. Planning for a research reactor at NBS was already underway in early 1957, driven by NBS Director, Allen V. Astin. Another key supporter in 1958 was Acting Secretary of Commerce, Lewis Strauss, formerly Chairman of the AEC, who served through one budget cycle (for fiscal year 1960) in the 1958-59 period, before he was rejected as permanent Secretary by the Senate in August 1959, due to controversy over his role in the removal of Robert Oppenheimer's security clearance.

The 1950's were a golden period for the development of reactors for nuclear power, for nuclear submarines, for research and isotope production, and, of course, for nuclear weapons. During this period there was rapid progress in all areas of nuclear development. Key neutron cross sections were measured, the relevant properties of metals and materials were evaluated, and the development of instrumentation for neutron scattering research on materials reached a sophistication and scientific impact which was to generate a Nobel Prize for Clifford Shull and Bertram Brockhouse forty years later.

By the end of the 1950's research reactors had been constructed or were being designed or planned all over the United States, Canada, Europe, and Asia. In the Washington, D.C. area, a facility was already under construction at the Naval Research Laboratory, which was designed with a $10^{13} \mathrm{n} \mathrm{cm}^{-2} \mathrm{~s}^{-1}$ maximum flux, suitable for materials irradiations, isotope production and trace chemical analysis, and adequate for neutron diffraction applications. But such reactors were superseded in capability by research reactors already in place by 1960 at the Oak Ridge National Laboratory (ORNL) and Argonne National Laboratory (ANL) of the AEC, at Chalk River Laboratories in Canada, and in Great Britain and France. So NBS was faced with a decision: what kind of research reactor to build and for what purposes. It should be noted that at that time there was little appreciation among researchers at NBS (or at most other non-AEC Laboratories) of the power and applicability of neutrons. There was more knowledge and enthusiasm for the "high-power" electron accelerator being planned at the same time at NBS for nuclear and electron physics research, since two small accelerators already existed at NBS. 


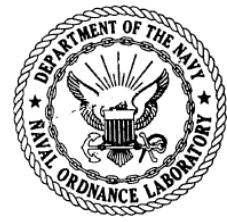

\section{U.S. NAVAL ORDNANCE LABORATORY WHITE OAK}

SILVER SPRING, MARYLAND

IN REPLY REFER TO:

$\mathrm{Q}: \mathrm{LRM}: \mathrm{ktm}$

9890

Ser. 5156

Dr. A. V. Astin, Director

7 oct. 1959

National Bureau of Standards

Washington 25, D. C.

Dear Dr. Astin:

The Naval Ordnance Laboratory has been following with particular interest the efforts of the National Bureau of Standards in regard to the procurement of a nuclear reactor. The reactor would serve a need existing in this scientific community for intense neutron sources.

The extent of our participation in the use of the proposed reactor was outlined in our letter of 11 December 1957. This estimate is a realistic one and constitutes an important need for this facility.

The purpose of this letter is to point out that our programs have been progressing in such a manner as to justify the forecast that we had previously made. We are actively using the Brookhaven facility but with definite plans of transferring the work to the NBS reactor when it becomes available.

This Laboratory would be pleased to assist in the procurement of the proposed reactor by providing scientific help in the form of either written proposals or testimony of experienced personnel concerned with this subject. We firmly believe that the reactor facility is needed for scientific work in this area.

Sincerely yours,

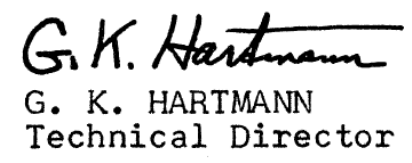

Copy to:

Dr. C. O. Muehlhause

National Bureau of Standards

A letter dated Oct. 1959 from the Technical Director of the Naval Ordnance Laboratory (NOL) offering strong support for a new research reactor at NBS. This was indicative of the enthusiasm for the NBSR among a number of Washington area government laboratories. A decade later NOL stationed Stan Pickart, Harvey Alperin and later Jim Rhyne at NBS and shared the cost of developing two spectrometers and a multispectrometer computer control system at the NBSR. 
By 1958 Allen Astin decided, after a lot of advice (including a set of recommendations by an NBS nuclear physicist, Randall Caswell in 1957) to go for funding for a high flux ( $>10^{14}$ neutrons $\mathrm{cm}^{-2} \mathrm{~s}^{-1}$ ) reactor to be built on the planned new campus of NBS in Gaithersburg, MD. In 1958, following a proposal by Nicholas Golovin, NBS Associate Director for Planning, Astin hired Carl O. Muehlhause, who had spent a number of years after World War II at the ANL and Brookhaven National Laboratories (BNL) in nuclear physics research, including reactor-related work. Carl had known Enrico Fermi and was personally acquainted with many of the major figures in American nuclear science at that time (Maurice Goldhaber, D.J. Hughes, Norman Ramsey, etc). By the end of 1958, Robert (Bob) Carter had been hired from Westinghouse and Harry Landon from BNL, both of whom had extensive research experience in neutron physics. Carter had also performed some of the first research worldwide (at the Brookhaven Graphite Reactor) in measuring phonons by neutron scattering in metal crystals. Muehlhause, Carter and Landon had a lot in common. They were all nuclear physicists. They had all served in the Navy during World War II, and they had all worked at BNL in the 1950's.

So the reactor team was set, and they started work on planning and designing the NBS reactor in an office on Van Ness Street at the old NBS site on Connecticut Avenue in Washington, D.C. In 1959, at the House Appropriations Committee hearings for the 1960 Budget, Astin informed the committee that he had formed a reactor planning group and projected a broad program of applications for the future reactor. The next year Astin obtained \$700K for reactor design, and a further \$8M was approved in FY 1962 for construction.



Left to right: Bob Carter, Carl Muehlhause and Harry Landon at the Van Ness Street Laboratories of NBS in 1962, before the construction of the NBSR started at the new Gaithersburg, MD site. 


\section{The 1960's: NBS Reactor Development and Science Beginnings}

The start of the NBS Reactor development occurred, as chance would have it, at the same time that the High Flux Beam Reactor (HFBR) at BNL and the High Flux Isotope Reactor (HFIR) at ORNL were conceived and constructed, and 5 years before the Institute Laue-Langevin (ILL) reactor project was agreed to by German Chancellor Konrad Adenauer and French President Charles DeGaulle to help cement German/French cooperation. These three U.S. facilities were to dominate U.S. neutron research into the 1980's. (It should be noted that powerful research reactors at U.S. universities were also developed during this period, most notably the Massachusetts Institute of Technology (MIT) reactor (1958) and the Missouri University Research Reactor (1966), which have made many contributions to neutron science and technology.)

The reactor design teams at BNL, NBS and ORNL in 1960 were each familiar with the path being taken by the other laboratories, and all had somewhat different missions in mind. By 1960 it was clear that the properties of the neutron offered powerful and unique advantages for nuclear and other fundamental physics studies, for neutron activation analysis, and especially for probing the structure and dynamics of materials and molecules. The very different sensitivity of neutrons to different isotopes (most notably hydrogen and deuterium), the neutron magnetic moment to probe atomicscale properties of magnetic materials, the deep and non-destructive penetration of materials by neutron beams, and the extraordinary potential use of neutrons for the study of atomic and molecular dynamics - all these properties promised an exciting future for using intense neutron sources in research.

In their response to the opportunities presented by intense neutron beams, the BNL/HFBR chose a new reactor concept for an under-moderated core, with neutron flux peaked in the reflector, which offered high fluxes to relatively small neutron beam tubes in the reflector. This reactor was designed at a power of $40 \mathrm{MW}$ (ultimately achieving 60 MW and unperturbed beam fluxes near $10^{15} \mathrm{n} \mathrm{cm}^{-2} \mathrm{~s}^{-1}$ ). The $100 \mathrm{MW}$ ORNL/HFIR was designed to produce transuranic isotopes in a very high intensity $\left(\approx 4 \times 10^{15}\right.$ neutrons $\left.\mathrm{cm}^{-2} \mathrm{~s}^{-1}\right)$ flux trap, but also offered very high fluxes to four beams.

The NBS team members, who were focused on serving both a large range of neutron scattering activities, as well as major efforts in neutron trace analysis, neutron standards and some isotope production, designed a modernized version of the ANL's CP5 reactor and the U.K.'s DIDO reactor, with a large core and $\mathrm{D}_{2} \mathrm{O}$ moderator and reflector. The uranium fuel elements were "split" with a central gap, so that nine very large thermal beam tubes (four $16 \mathrm{~cm}$ diameter and five $13 \mathrm{~cm}$ diameter) could be inserted radially to provide high intensity beams with low fast-neutron and gamma ray backgrounds to samples closer to the reactor core than in most reactors. Finally the NBS designers, perceiving the future importance of cold neutrons (with energies $<5 \mathrm{meV}$ ), based on recent work in England and France, installed a very large (56 cm diameter) "thimble" near the high flux region in the reactor to allow future installation of a cold neutron source. Conceived by 1961, this was the first large-volume cold neutron source designed into a research reactor. The reactor was planned for $20 \mathrm{MW}$ operation, but was licensed (in 1967) to operate for some time at $10 \mathrm{MW}$. Thus, the three major reactors started around 1960 were brought on line close together: HFBR (1965), HFIR (1966), NBSR (1969). 
Before the foundation was laid for reactor construction in 1962, the reactor group proceeded with another part of the plan laid out in 1958 by Nicholas Golovin and NBS Director Astin to start development of future neutron scattering efforts by arranging a joint Research and Development program with ANL. This effort would also include cooperative work, using ANL reactors, to test a $\mathrm{D}_{2} \mathrm{O}$ ice moderator for future cold sources at Argonne and NBS. One of the present authors, Jack Rush, a physical chemist straight out of graduate school at Columbia (who did his thesis work at BNL, thus adding another Brookhaven link) took this joint position and went to Argonne in 1962. During his years at ANL, Rush was able to develop and carry out new research efforts in the study of the dynamics of molecular solids and metal hydrides, which were later transferred to the NBSR, along with companion research using $\mathrm{x}$-rays and infrared and Raman spectroscopy. A number of key collaborations with ANL and BNL, along with universities and foreign labs were established during those years. Jack Rush and Don Conner, the leader of the Argonne neutron group, also did the research on neutron moderation in $\mathrm{D}_{2} \mathrm{O}$ ice at the Juggernaut Reactor at Argonne, which became the basis of the design of the first cold source at the NBSR.

\section{PLAN VIEW OF NBS REACTOR}

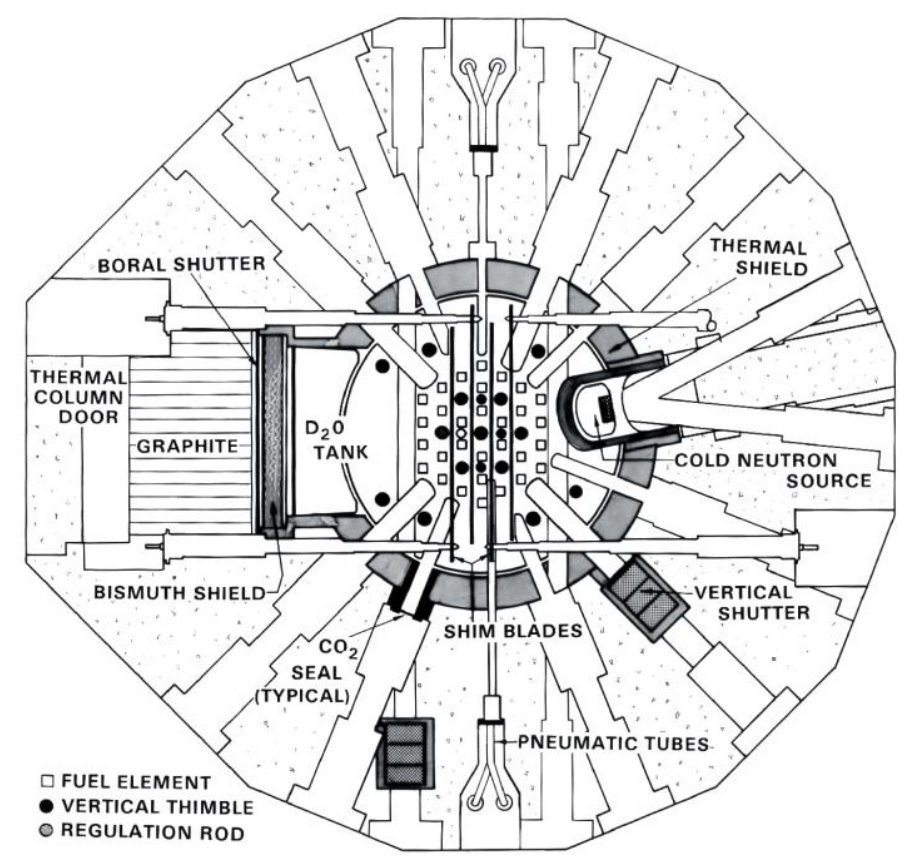

A plan view of the NBSR showing the reactor core, the large radial beams, and the location of the future large cold neutron source. 
In the period during the construction of the NBSR, Muehlhause, Carter and Landon had their hands full working with design and construction contractors (e.g., Burns and Roe) preparing reports for and answering myriad questions from the AEC regulatory authorities (and NBS management). They also worked extensively with other NBS groups and divisions (e.g., Analytical Chemistry) to plan future in-house research activities on a rather constrained budget. It is remarkable that this team of three, with some drafting and technician support, actually designed and brought on line a unique modern research reactor in about seven years amidst all the challenges they faced. There are few examples of such a feat in modern American science and engineering.

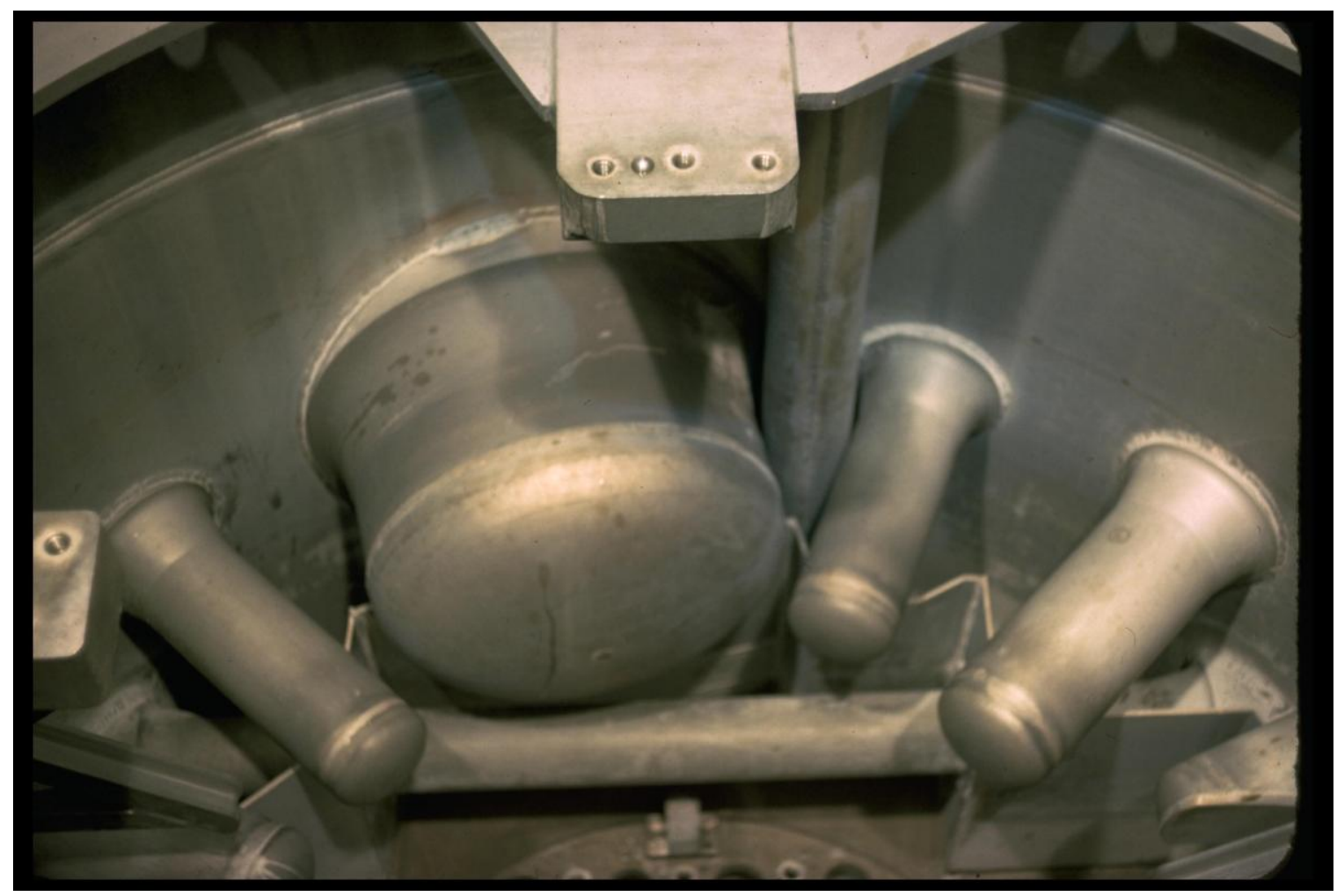

The core of the NBS reactor showing the large cold source "thimble" which was the key component of the nation's first cold neutron research facility. This picture and several others in this history are from a collection of early photos of the NMSR and its staff put together by Jim Torrance, long-time Deputy Chief of Reactor Operations. 
In 1966, the reactor group left the office of the NBS Director to become a division-level organization in the newly formed Institute for Materials Research (IMR). Carl Meuhlhause was appointed Director of the new Reactor Radiation Division, with Bob Carter and Harry Landon assigned, respectively, to plan and put together solid state physics (i.e., materials) and neutron physics efforts while the reactor was being constructed and commissioned between 1963 and 1969. Thus, in 1964 Tony Santoro and Marcello Zocchi were hired from the ISPRA European Research Laboratory in Italy to start a diffraction effort, and Ivan Schroder (a recent Columbia Ph.D. in physics, who also had done his thesis at BNL) was recruited to join Landon in neutron physics. Vernon Myers, a physicist from Penn State, was also brought on board to work on special projects with Muehlhause, along with Dave Goldman, a nuclear theorist from General Electric. And, in line with the original intent that the NBSR be a regional facility, agreements with the Naval Research Laboratory and the Naval Ordnance Laboratory were made, which established joint funding for four neutron diffractometers to be installed. These cooperative agreements enabled the NBSR to start building spectrometers, along with a state-of-the-art (at that time) computer system to operate the instruments and perform data analysis, at a time when federal budgets were being constrained by the Vietnam War.



An aerial view of the NBS reactor confinement building (at the rear) and the original office and laboratory buildings, circa 1970. 


\section{8-1970: Reactor Operation and a Reorganization}

After a long (and at times arduous) process, the Nuclear Regulatory branch of the AEC approved the operating license for the NBSR in 1967. Criticality was achieved on December 7, 1967. There was a sizeable crowd in attendance, including NBS Director Allen Astin, and a celebratory ceremony was held, with the key participants sharing a bottle of Chianti wine - similar to the festivities hosted by Enrico Fermi at the first reactor chain reaction at the University of Chicago in 1942. The nuclear engineer who led the team which brought the reactor to criticality was Tawfik Raby, who had been brought to NBSR from Allis-Chalmers Corp. as an experienced advisor in 1967, and subsequently agreed to become Chief of Reactor Operations, a position he would hold for over 30 years.

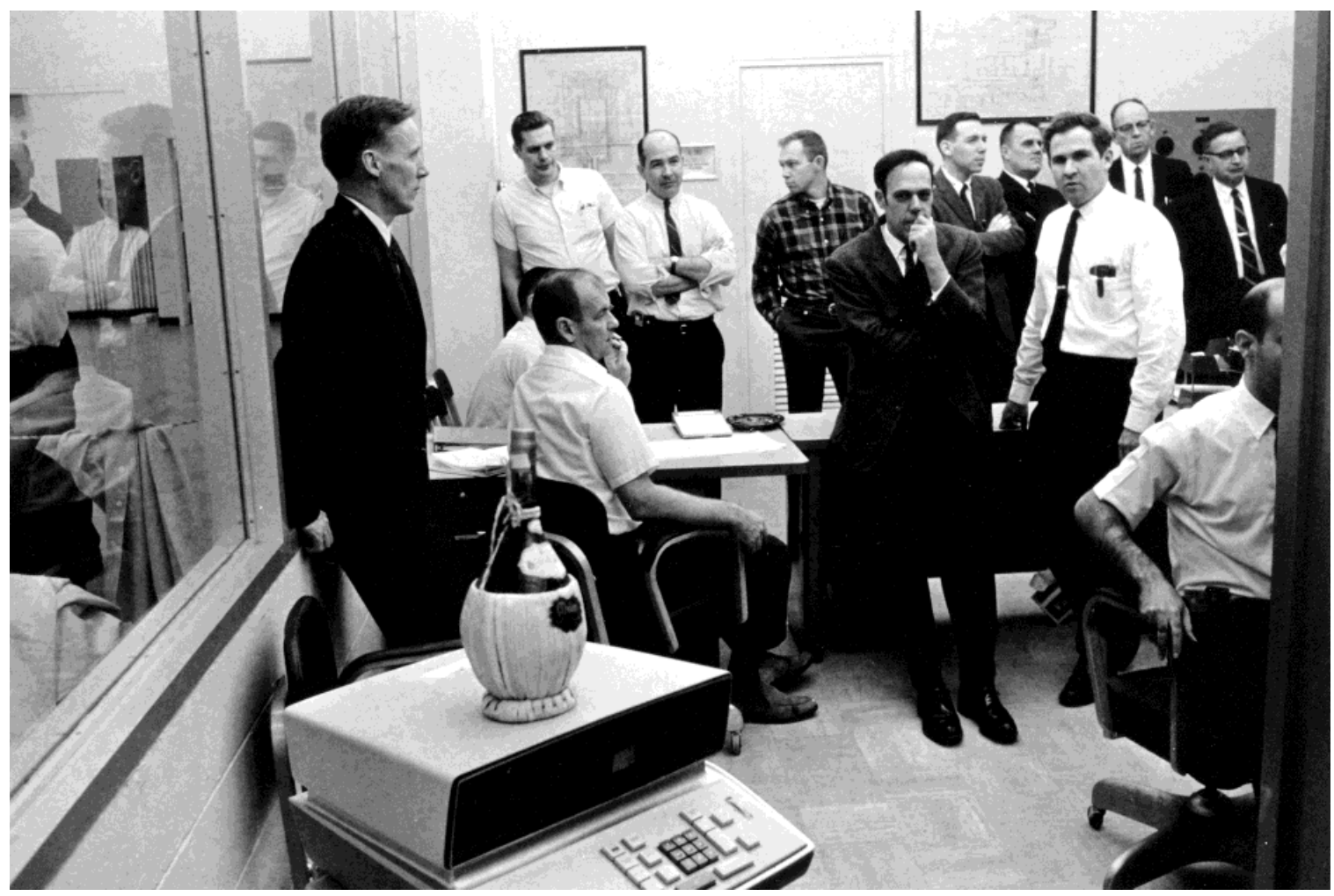

The NBS reactor goes critical, December 7, 1967. Muehlhause, Carter and Landon, and members of the reactor staff and AEC observers anxiously await achievement of criticality. 




Carl Muehlhause pours a cup of Chianti wine with NBS Director Allen Astin (left), a ceremonial bow to Enrico Fermi's celebration of the first controlled nuclear chain reaction at the University of Chicago, December 2, 1942.

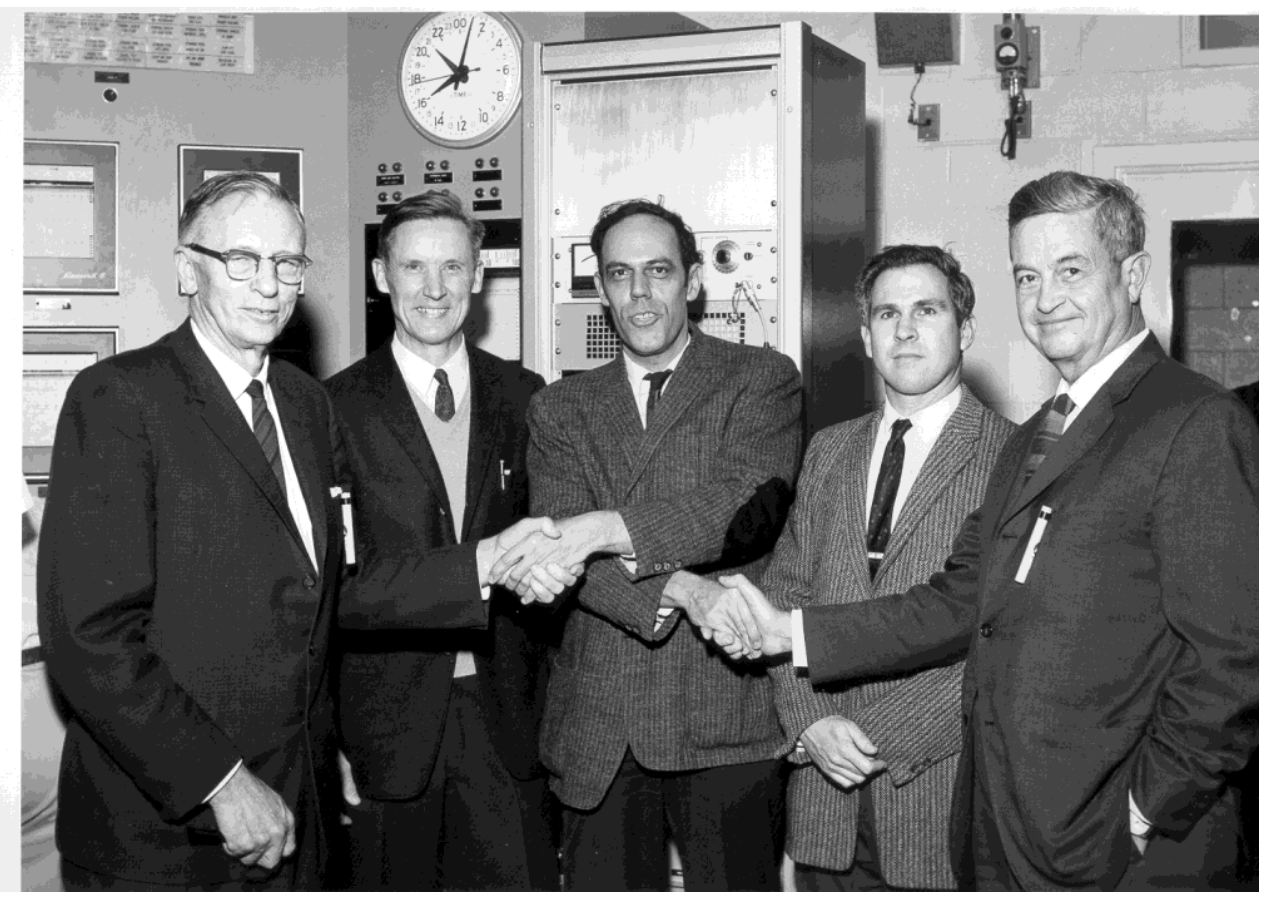

Five key players in the development of the NBSR: (left to right) Director Allen Astin, Harry Landon, Carl Muehlhause, Bob Carter, and Irl Schoonover, Deputy Director of the NBS. 


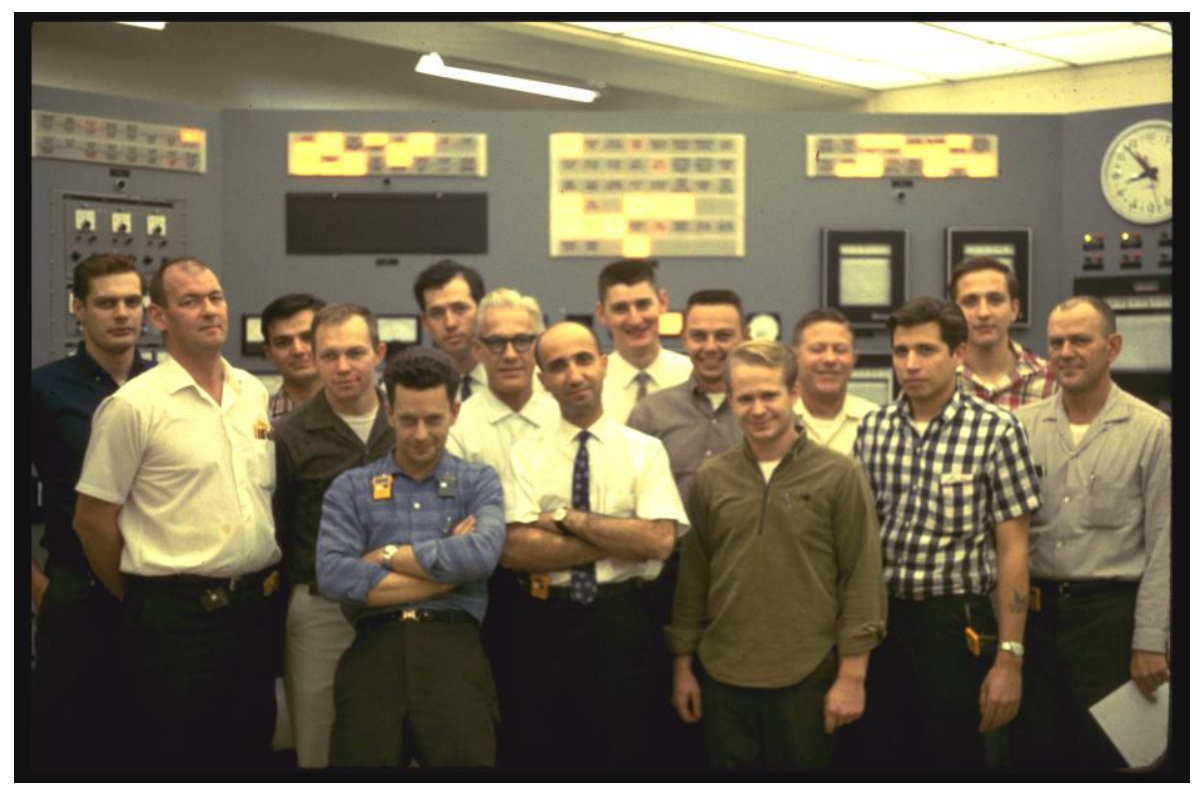

Tawfik Raby, Chief of NBSR Operations (center-front, with tie) and members of the original Reactor Operations staff in the late 1960's.

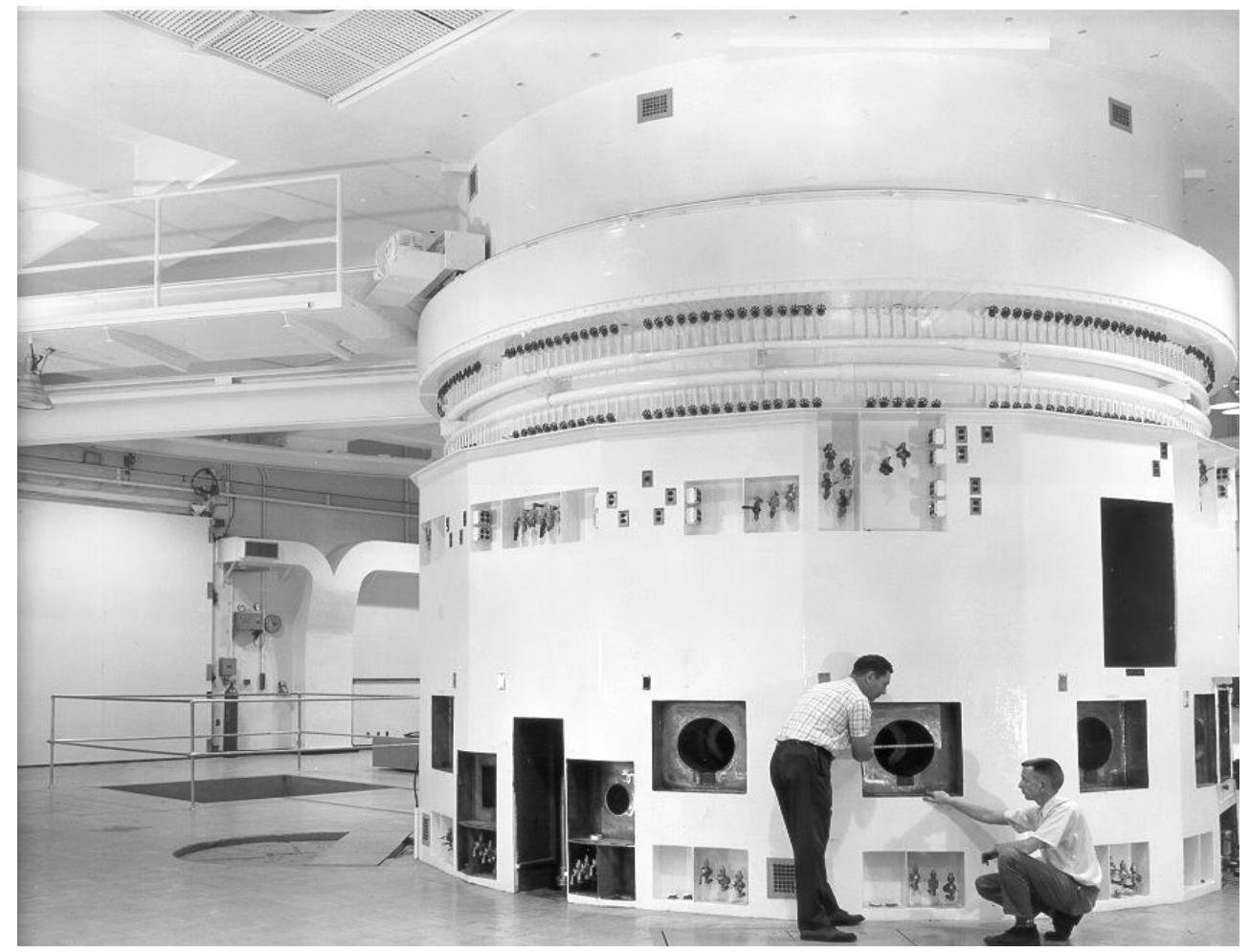

A view of the reactor floor in the late 1960's before installation of instruments. Fred Shorten (standing), a long time technical specialist at the NBSR, confers with reactor operator Dick Scheid. 
Shortly after the reactor went critical, Allen Astin made what was to be a fateful decision for the future of the NBSR and its leadership. Astin decided to remove the Reactor Radiation Division from the Institute for Materials Research (IMR) and the Radiation Physics Division from the Institute for Basic Standards (IBS) to create a new Center for Radiation Research (CRR). The basis for this decision was the judgment that it would be easier to manage, defend, and obtain additional funding for the two large regional facilities at NBS (the new $100 \mathrm{MeV}$ linear electron accelerator (Linac) had come on line in 1966) if they were combined. Carl Muehlhause was appointed as the Director of the CRR, Bob Carter became Division Chief of the Reactor Radiation Division (a position he would hold for 30 years) and Harry Landon was appointed Chief of the newly formed Nuclear Radiation Division. Jim Leiss was named Chief of the Linac Radiation Division, comprising Linac Operations and the non-neutron physics and instrumentation activities of the Center. The marriage of the two large facilities was less than successful, due to differences in approach, priorities and personalities between the old nuclear and radiation physics staff and leaders and the neutron research team at the NBSR. Then there was the clear difference in the main scientific directions of the facilities - radiation physics and standards for the Linac and neutron scattering from materials for the NBSR. This combination turned out to be unworkable.

In 1969 Lewis Branscomb, the head of the Joint Laboratory for Astrophysics (JILA) at Boulder, was appointed NIST Director by President Nixon. In 1970, he decided to undo the alliance of facilities in the CRR and transferred the NBSR back to the Institute for Materials Research under Jack Hoffman. A considerably smaller CRR under the leadership of Jim Leiss joined the Institute for Basic Standards under Ernie Ambler. This move left Carl Muehlhause without a suitable position, and effectively ended his career as a scientific leader. For personal reasons, Carl stayed on at NIST for more than a decade in a variety of advisory positions in the Institute for Applied Technology, with committee assignments and oversight of several applied research issues. Meanwhile, Harry Landon remained for a time as a division chief in CRR, but then joined the Environmental Protection Agency (EPA) to work on broad radiation safety issues until his retirement in the 1980's. 


\section{The 1970's: Developing Science and New Capabilities}

Even as the NBSR was caught in a bureaucratic whiplash, progress continued in developing a scientific staff and more instrumentation to meet new research challenges and opportunities. Bert Mozer joined the Solid State Physics Staff in IMR in 1968 from BNL, where his research had included neutron scattering studies on alloys and mass defects. Four neutron diffraction instruments, which were developed through the NBS cooperative agreements with the Navy Labs, were commissioned by 1970, and George Ferguson and Ted Prince from NRL and Stan Pickart and Harvey Alperin from the Naval Ordinance Lab (NOL) came to NBS as part of the partnerships - along with some technical support. Joint research included basic work on magnetic solids (for applications in sonar and other devices) and alloy hydrides and molecular crystals.

The early 1970's saw a rapid broadening of the science base at the NBSR with new alliances and collaborative efforts with U.S. and foreign labs and universities. Leo De Graaf from Delft University in the Netherlands was a guest scientist for two years and, along with Bert Mozer and Jack Rush (and Mike Rowe from ANL), helped initiate time-of-flight inelastic scattering research using a crystal/Fermi-chopper spectrometer with modest resolution. By 1972, a series of experiments on the structure and dynamics of simple liquids and on the rotational behavior and diffusion in molecular solids and metal hydrides were well underway in collaboration with BNL, ANL, ORNL, Delft, Catholic University, American University, and the University of Maryland.

\section{Agreement with the Army}

The last major research alliance with military labs, and the most important and long lasting, was implemented in 1970, just after Branscomb had transferred the NBSR back to the Institute for Materials Research. A cooperative research agreement was signed with the Army's Picattiny Arsenal to transfer its neutron research group which had a research program at the Watertown, MA Army Research Reactor to NBS to pursue joint research on materials and development of methods and instrumentation which would serve both NBS and army missions. Hank Prask, Sam Treviño, and Chang-Sun Choi became guest workers at NBS, in a program that was to last for 35 years. The agreement also included joint development of two of the first triple-axis spectrometers at the NBSR, the BT-4 and BT-6 instruments, along with technical support. The army group wove their research on explosive-related materials into the NBS efforts on molecular solids and later became leaders in the development of neutron residual stress and texture measurements at the NBSR. 


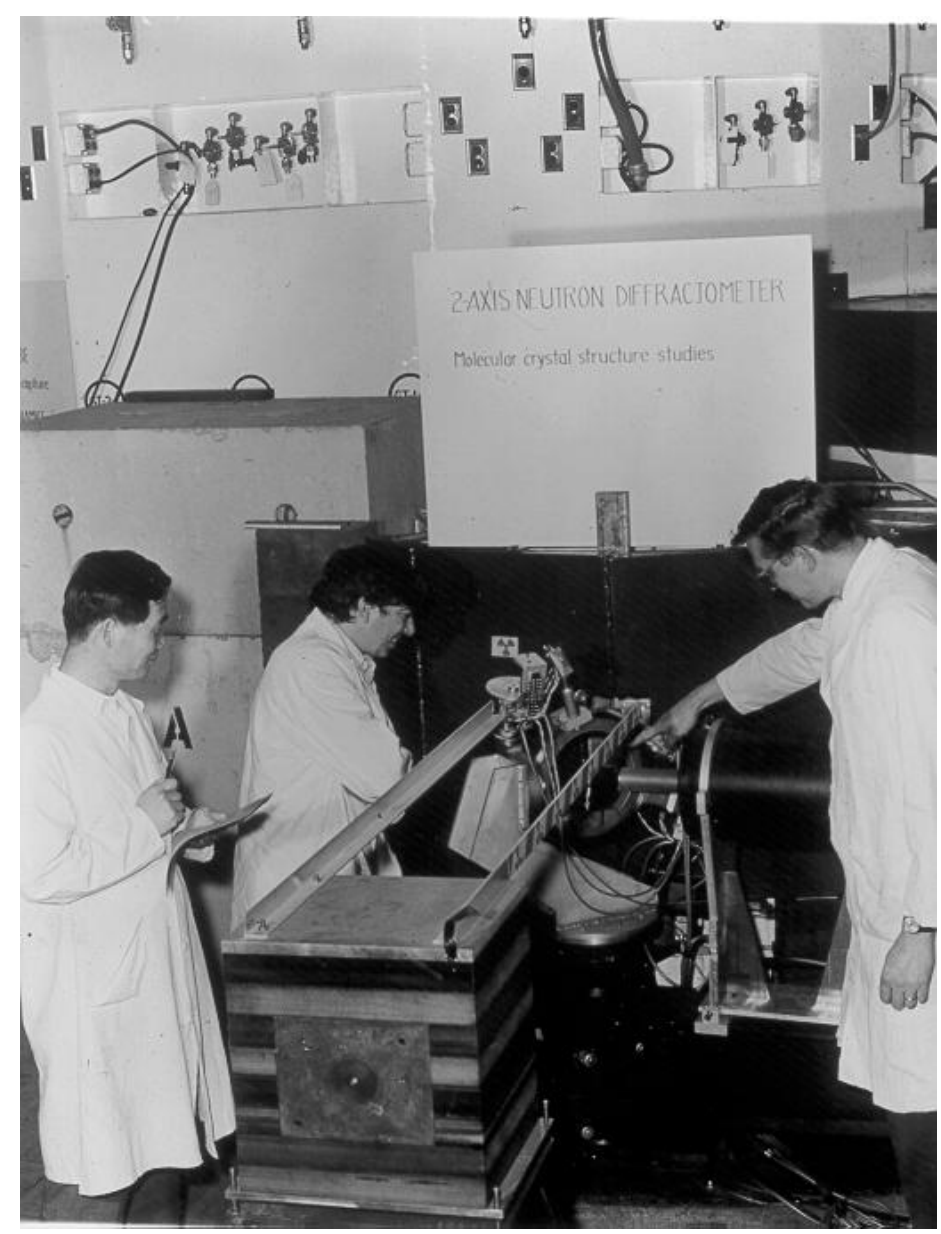

The Army Research Group from Picatinny Arsenal (left to right: Chang-Sun Choi, Sam Treviño and Hank Prask) working on one of the neutron scattering instruments jointly developed with NBS in the 1970's.

\section{The Arrival of Mike Rowe}

As mentioned above, Jack Rush kept strong interactions with ANL after he left in 1966 to come to NBS. His most notable colleague (and friend) from Argonne was Mike Rowe who came to the Solid State Science Division at ANL in the fall of 1966 after receiving his Ph.D. at McMaster University in Canada under Bert Brockhouse, who was later to receive a Nobel Prize for his pioneering research in neutron inelastic scattering. Jack and Mike started doing research together in the late 1960's, beginning a close collaboration which lasted over 35 years. In January 1973, Mike Rowe left Argonne and came to NBS, a transfer which was to help transform the future of the NBSR and its later expansion as an international research center. 


\section{Chemical Trace Analysis and Neutron Physics at the NBSR}

While the instrumentation and research efforts in neutron scattering were emerging after 1969, the very strong programs in analytical chemistry at the NBSR were a key to the early success of the reactor. In the 1960's NBS had hired Wayne Meinke, an international leader in nuclear based chemical analysis, to direct the large division of Analytical Chemistry at the NBS. Meinke and several colleagues (e.g., Phil LaFleur and Jim DeVoe) set about creating a broad program in neutron trace chemical analysis at the NBSR, which became one of the best efforts in this field. Activation analysis also became a core technique in certifying NBS Standard Reference Materials. These new capabilities helped attract a number of government agencies to establish programs at the NBSR. The FDA (purity of food and drugs), FBI (crime investigation), Smithsonian Institution (archeological research), and Geological Survey (mineralogical analysis) all initiated projects at the NBSR by the early 70's. Two of the programs (FDA and Smithsonian Institution) continue today, almost four decades later.

During the 1970's, the NBS Center for Radiation Research also maintained a small group at the reactor dedicated to neutron physics research and radiation standards and dosimetry, in cooperation with the Navy, AEC and a number of universities. This was to be the basis of a greatly expanded effort in future decades.

\section{Biology and Polymers in the '70's}

The application of neutron scattering, mainly Small Angle Neutron Scattering (SANS), for studies of the structure of polymers and other macromolecular and complex fluids started mainly in Europe in the late 1960's and then exploded on the scene at ILL in France in the 1970's. European SANS studies provided the experimental basis for Paul Flory's Nobel Prize on Polymer Structure in 1974. Over the next five years efforts in "soft-matter" research were initiated at the NBSR and at BNL and Oak Ridge. Charles Han, of the NBS Polymer Division, and Bert Mozer built a single detector small angle scattering spectrometer on the BT- 5 beam hole at the NBSR and carried out early experiments on the structure of block co-polymers and elastomers in 1977. The BNL SANS was commissioned in the late 70's and coupled to the HFBR cold neutron source in 1982. In addition, Oak Ridge won a close National Science Foundation-competition with BNL and NBS in 1978 to construct the first long $(25 \mathrm{~m})$ SANS in the U.S. and operate it as a user facility starting in 1980. Even with these developments, the U.S. remained far behind Europe in SANS studies of polymers and complex fluids, which had become the fastest growing field in neutron scattering. 


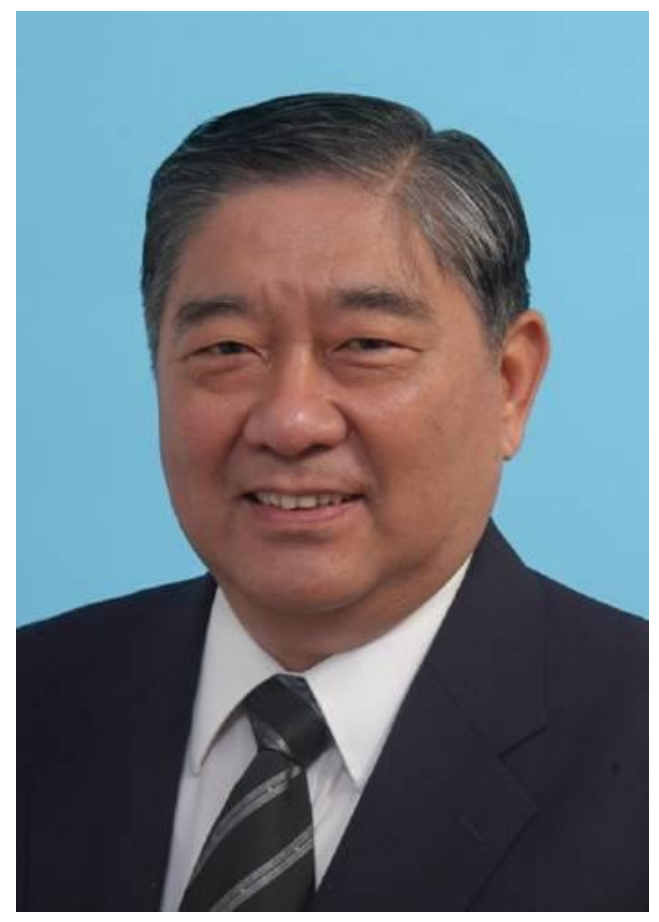

Charles Han, the first of many key scientists in the NBS/NIST Polymers Division who have helped stimulate polymer and other soft matter research at the NBSR for over 30 years.

During this period both BNL and NBS, with support from the National Institutes of Health (NIH), also initiated efforts in protein crystallography with neutrons. Alex Wlodawer came to NBS after a post-doc in Structural Biology at Stanford to lead the new NBS program.

\section{Rapid Growth of Research in Materials and Chemical Physics}

During the 1970's, Mike Rowe and Jack Rush collaborated on wide-ranging studies of dynamics and diffusion in metal hydrides, including the first phonon-dispersion curves for these materials. They also focused on the study of orientational disorder and phase transformations in inorganic and molecular solids. In both these areas, NBSR efforts achieved international leadership. This research ultimately involved dozens of U.S. and foreign collaborators, a great number from Germany, initiated by a twenty year association with Dieter Richter, who became a major leader in European neutron science. 


\section{NBSR NEUTRON BEAM INSTRUMENTS (1975)}

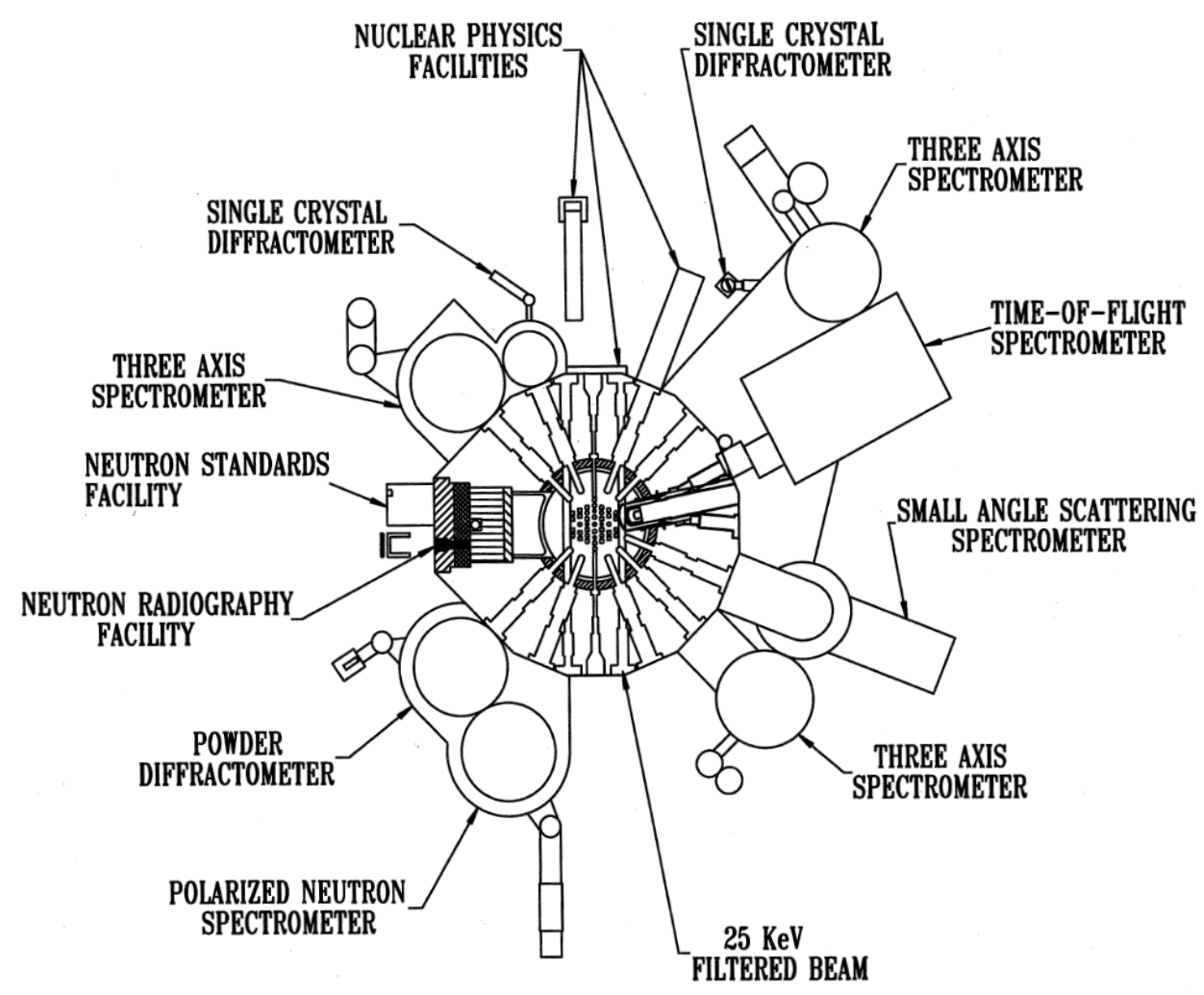

By 1975 NBS and its collaborators had developed an array of neutron scattering and other neutron beam instruments at the NBSR. A plan view of this instrument suite is shown above.

During the last half of the '70's the role of the NBSR in research on magnetic materials expanded as Jim Rhyne left the Naval Ordnance Laboratory (which later became the Naval Surface Weapons Center) to join NBS and carry out an active program in rare-earth magnetic materials and amorphous magnets. In the same period, Jeff Lynn came to the University of Maryland from Brookhaven and initiated broad research in magnetic and superconducting materials, which continues to this day. Both Jeff and Jim initiated dozens of collaborations with laboratories and universities from all around the world. 


\section{Twenty Megawatts and the Beginning of Cold Neutrons}

In the late 1970's, two successes were achieved which were to be the cornerstone of the accomplishments of the next decade as the NBSR became home to the nation's first cold neutron research facility.

In the early fall of 1976 prospects for the NBSR did not appear to be favorable. With the 1976 election approaching, the Ford Administration considered cutbacks at a number of government agencies, including NBS. One of the proposed cuts would have shut down or severely curtailed the NBSR. Fortunately, many of the reductions were withdrawn, including curtailing the reactor, and events took a decided turn for the better.

Also in 1976, Bob Carter was chosen as a Commerce Science Fellow at the Energy Research and Development Agency (ERDA). In the mid 1970's the AEC had split into ERDA, which was to become the Department of Energy (DOE) in the Carter Administration, and the Nuclear Regulatory Commission (NRC), in order to separate advocacy and oversight responsibilities. Jack Rush was appointed Acting Division Director for a year, and had to participate in the FY ' 79 budget process as part of the IMR under Jack Hoffman and his staff, which included Curt Reiman and Ian Bartky. With encouragement from Reiman and Bartky (and Jack Hoffman), the Reactor Radiation Division proposed an initiative to double the power of the NBSR to $20 \mathrm{MW}$. Rush presented the initiative in March 1977. It was well received in a vote by the NBS science and engineering managers (although less so by the Director, Ernie Ambler) and was included in the FY' 79 Budget Submission to the Department of Commerce (DOC). A key endorsement came from the Assistant Secretary of Commerce for Technology, Jordan Baruch, and the power increase ultimately was funded for $\$ 670,000$, including design and capital improvements. This was a key event for the future of the reactor, and likely made all later success possible.

When he returned from his "Com-Sci", Bob Carter combined the $20 \mathrm{MW}$ power increase tasks with the necessary planning to relicense the NBSR. The power increase (and relicensing) ultimately took place in 1985, delayed somewhat by the impact of the Three-Mile Island incident in 1979 on the staff of the NRC.

The second boost for the fortunes of the NBSR came as a result of the approval in FY '79 by Congress of a budget initiative to create a "Competence Fund" to assure that NBS was able to keep its staff and capabilities abreast of new ideas and opportunities in science and engineering. This new program came on the heels of the close competition between Brookhaven, Oak Ridge and NBS for an NSF-supported modern SANS facility to address the expanding European lead in Small Angle Scattering instrumentation for the study of the nanoscale structure of "soft" matter (polymers, complex fluids and biomolecular assemblies) and of inorganic and metallic materials. A Reactor Radiation Division proposal to create an $8 \mathrm{~m}$ SANS at the NBSR, supported by Jack Hoffman and aided by the future prospects of $20 \mathrm{MW}$ and a large cold neutron source, received one of the first competence awards $(\$ 300 \mathrm{~K}$ a year) in 1979 . These funds allowed the hiring of Charlie Glinka, previously a post-doc at the NBSR, who was charged with SANS development and later led the efforts which made NIST/NBS one of the leaders worldwide in SANS research in many scientific areas. Also hired was Norm Berk, a physicist who joined the NBSR from NYU and provided the NBSR with important theoretical contributions in SANS and reflectivity methods and in materials physics. 


\section{The 1980's: From SANS to the Cold Neutron Research Facility (CNRF)}

As the 1980's began, there were positive developments at all of the major U.S. neutron sources. Though a National Academy of Science (NAS) neutron study in 1977 (and the Carter Administration) had not endorsed the development of $\mathrm{a} \approx 0.2 \mathrm{MW}$ pulsed neutron source at Argonne, ANL was building a smaller version which was to become in 1981 The Intense Pulse Neutron Source (IPNS), the first full neutron user facility in the U.S. At the same time Los Alamos was proposing a 0.1 MW pulsed neutron source to replace the Weapons Neutron Facility at the Los Alamos Meson Factory (a 1 MW proton accelerator), a project which was to have its ups and downs for the next 20 years. The HFBR at Brookhaven continued to be an international center of excellence for neutron science, particularly for neutron scattering studies in solid state physics. Prospects were even brighter as BNL installed a small cold neutron source in 1980 and increased power from $40 \mathrm{MW}$ to $60 \mathrm{MW}$ in 1982. Productivity at the Oak Ridge High Flux Reactor increased significantly in 1981 as the NSF-supported SANS instrument was added to the first-rate scattering efforts in magnetism, metal physics, and other areas (including, of course, high neutron flux isotope production).

At NBS the development of the $8 \mathrm{~m}$ SANS on the large reactor beam thimble brought expanded science opportunities and users starting in 1981, particularly for the study of polymers. The promise of $20 \mathrm{MW}$ power and a possible cold source offered a brighter future.

The fact remained, however, that U.S. neutron research lagged in critical areas with respect to Europe. The French/German/British ILL was the dominant force in neutron science, particularly for cold-neutron research, and the new modern Orphée Reactor commissioned in France in 1982, along with the decision to build a major 0.2 MW spallation neutron source (ISIS) in Great Britain, were clear evidence of a continuing European advantage. Meanwhile in the same period a small, innovative pulsed neutron facility (KENS) was built, and an advanced $20 \mathrm{MW}$ research reactor was under development in Japan.

\section{The role of the $8 \mathrm{~m}$ SANS}

As did the NSF-supported SANS at Oak Ridge, the NBS 8 m SANS opened up new areas of research both for NBS scientists and for the many researchers from around the U.S. who came as users. This was particularly true in polymer and complex fluid research, and here it became clear that NBS had an "ace-in-the-hole" - the Polymer Division, which was the best organization of its kind among U.S. government laboratories. Charles Han and later Wen-Li Wu, along with an outstanding group of NBS/NIST post-docs and visiting scientists, carried out a broad range of research on polymers, polymer blends, complex fluids and other "soft-matter" systems. Scientists from other divisions at NIST also participated in SANS research, including Richard Fields from the Metallurgy Division, who became actively engaged in the microstructure of metals and ceramics. Later, a number of Ceramics Division scientists, including Gabrielle Long and Andrew Allen, were active in materials microstructure studies, which continue to this day. 


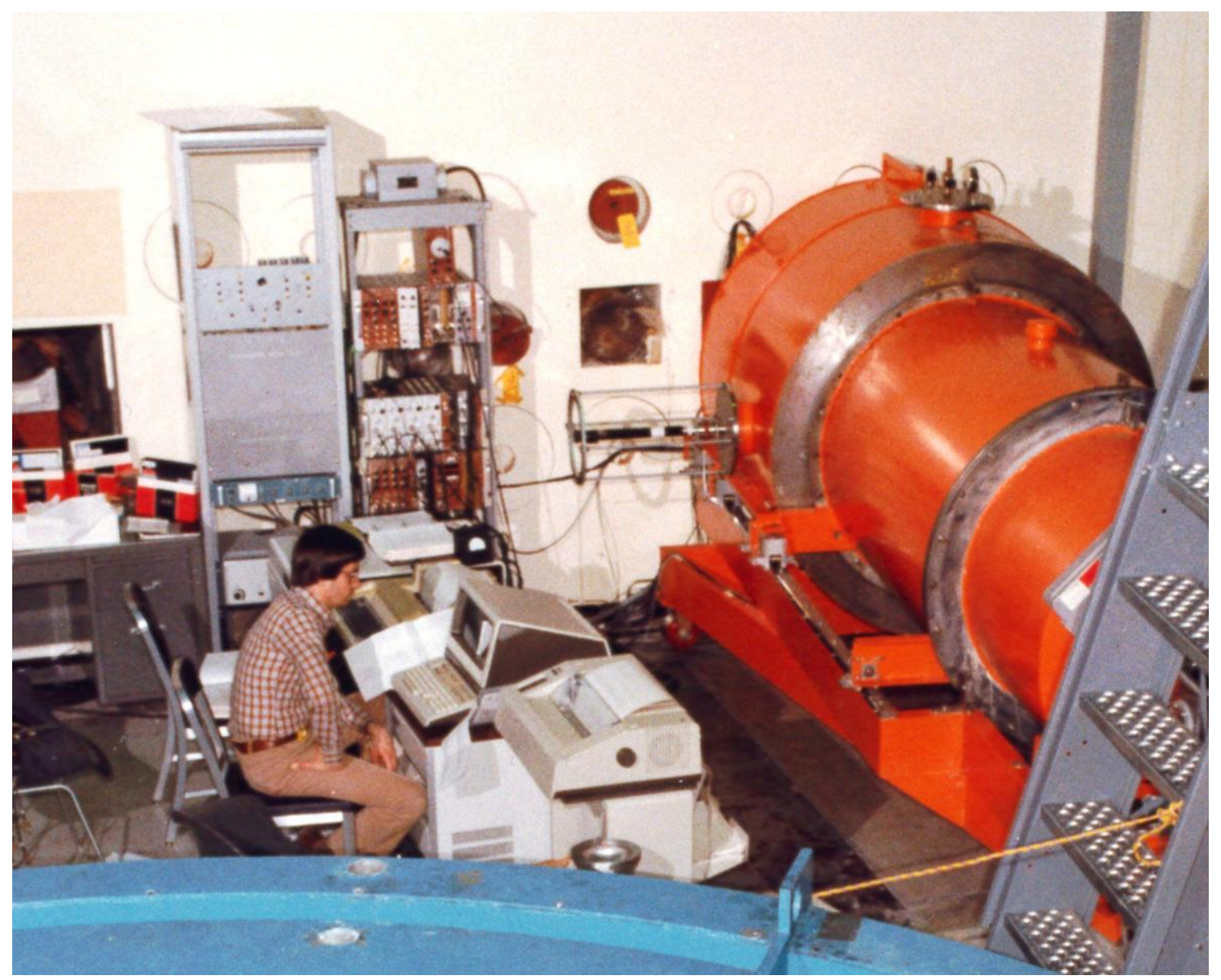

The original 8 meter SANS instrument commissioned in 1981, taking almost every inch of space available in the NBSR confinement building. Seated at the instrument station is Charlie Glinka, the leader in the development of all the NIST SANS facilities.

\section{Thermal Neutron Research during the 1980's}

In 1988 the name of the institution was changed from NBS to NIST. We shall use NBS/NIST to designate the name during the 1980's. While the $8 \mathrm{~m}$ SANS was opening up areas of nanostructure research with cold neutrons, physics and chemistry research on solids using thermal neutrons continued to expand at the NBSR. Extending the work initiated in the 1970's, Jim Rhyne and Jeff Lynn and their colleagues carried out a rich array of research on magnetic systems, including rare earth compounds, amorphous magnets and spin glasses, and magnetic multilayers. This work was carried out with many collaborators from around the country and from abroad. By this time the NIST/NBS arsenal of instruments included 3 triple axis spectrometers for investigating phonons and magnetic excitations, and new diffraction instruments for powder diffraction, protein crystallography, and crystallographic texture measurements. There was also a fruitful series of studies of diffraction on ceramics, catalysts, and other materials with Bob Roth and colleagues from the Inorganic Materials Division and many outside collaborators. The Be-filter spectrometer (later adding a graphite filter option for 
better resolution) developed by Mike Rowe and Jack Rush provided a highly sensitive instrument for measuring density of vibrational states between $20 \mathrm{meV}$ and $200 \mathrm{meV}$ for studies of hydrogen-rich molecular solids and metal-hydrogen systems. The flat-cone diffractometer, developed by Ted Prince, Tony Santoro, and Alex Wlodawer was one of the first instruments in the world for neutron protein crystallography. Summary articles on the neutron diffraction efforts at NBS/NIST from the late 1960's to 2001 can be found in the special issue of the J. Research of NIST (Vol. 105, No. 6, 2001).

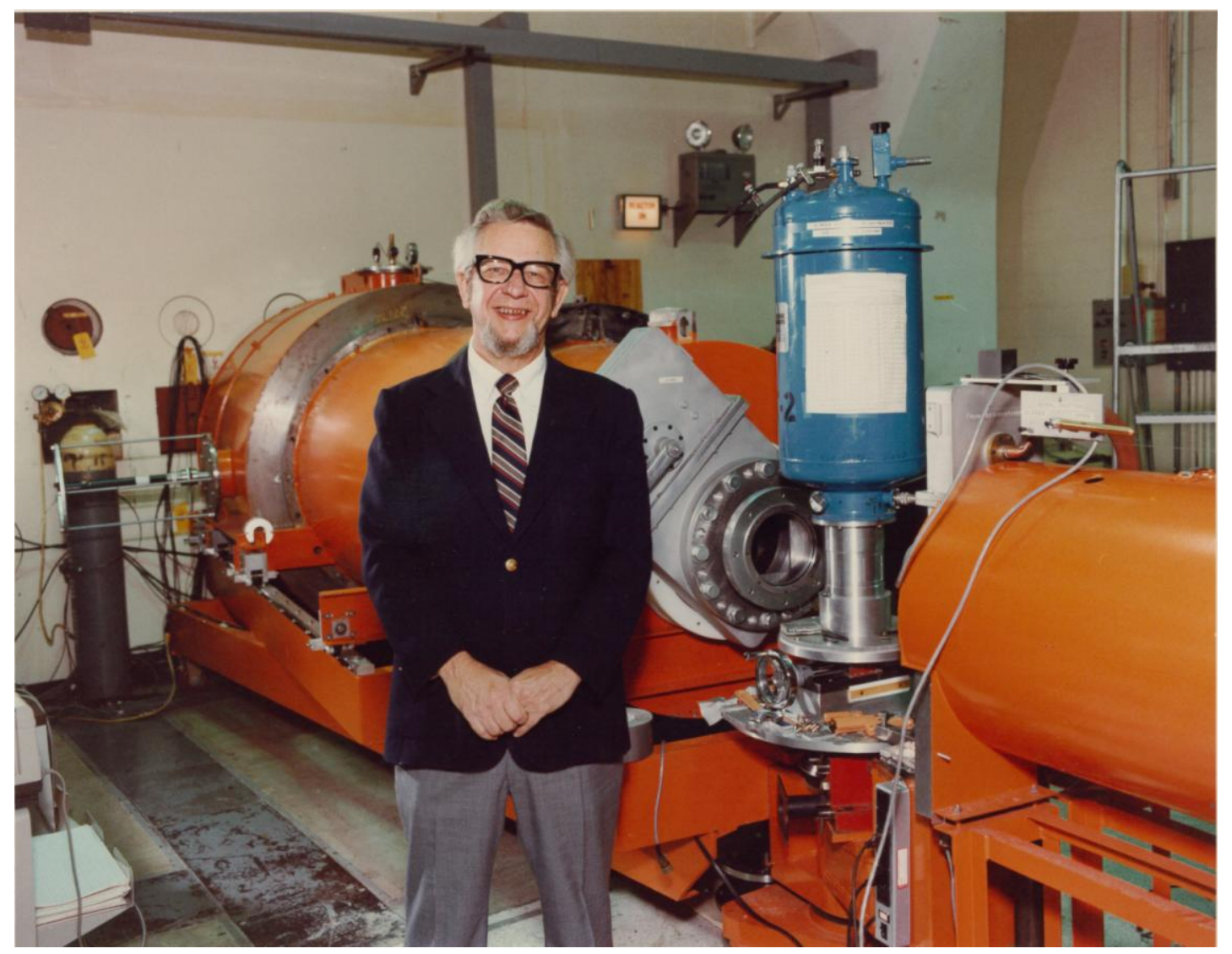

John D. (Jack) Hoffman, Director of the Institute for Materials Research and later of the National Measurement Laboratory at NBS. Here we see Jack at the NBSR shortly before his retirement from NBS in 1982 standing by the 8 meter SANS instrument.

The NBSR scientific staff and their growing cast of collaborators contributed very important work in high $T_{\mathrm{c}}$ superconductors after the discovery broke in 1986. Tony Santoro, Jim Rhyne, Jeff Lynn and their colleagues provided key results on the structure and fundamental excitations of these new materials. The overheated competitive environment between scientists and organizations in those days is exemplified by the fact that the NBSR was required to provide testimony in a superconductor patent contest between Bell Labs, IBM and NRL.

The 1980's also saw a number of important new applications in neutron scattering at the NBSR, including extensive research with Rick Cavanaugh, Dick Kelly and Ted Madey of the NBS/NIST Surface Science Division on the spectroscopy and bonding states of hydrogen and molecules on nanoparticulate metal catalysts; a broad effort with 
Hartmut Zabel and his students from the University of Illinois on the structure and dynamics of metals and molecules in graphite intercalation compounds.

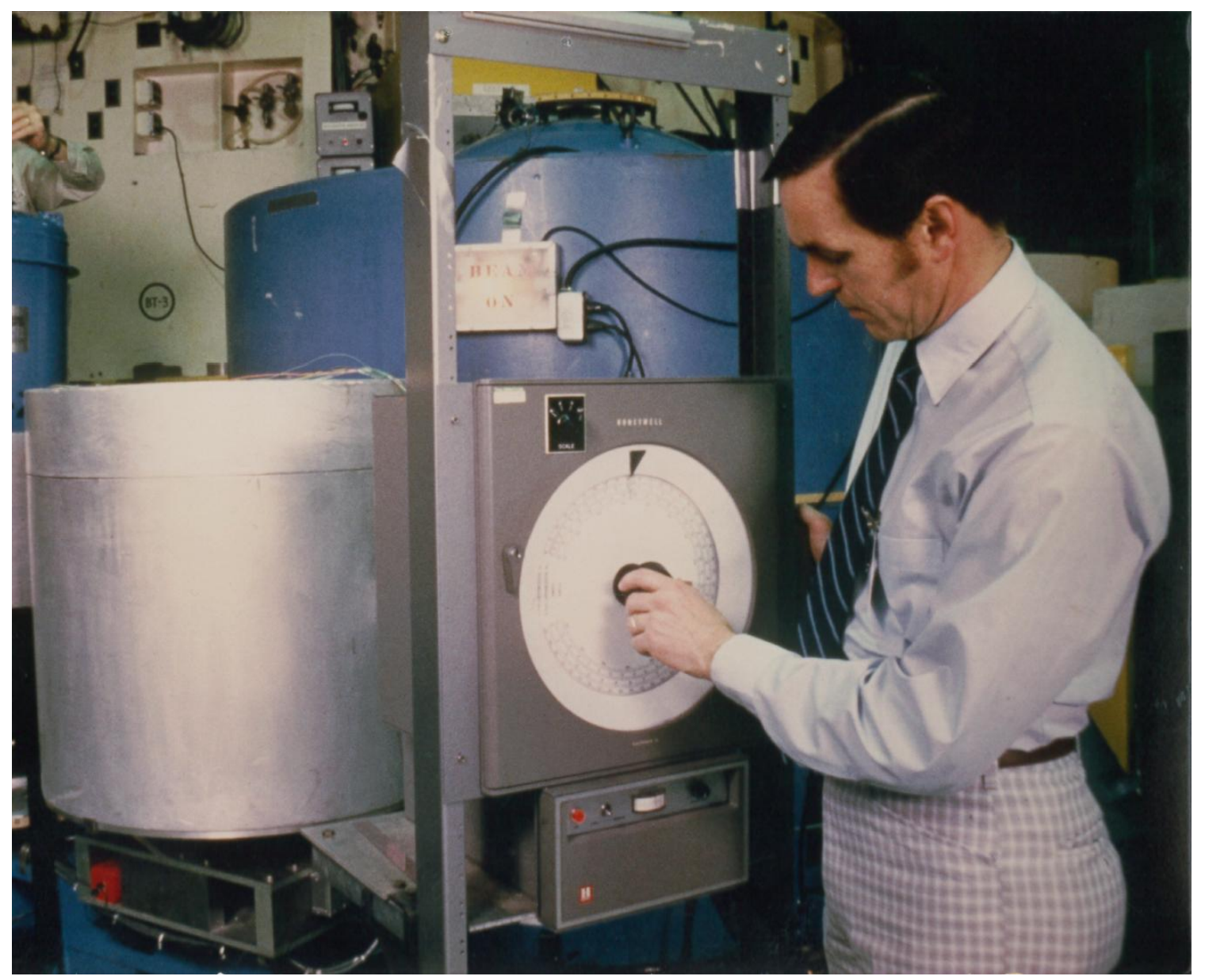

Dick Kelly preparing an experiment on the neutron spectroscopy of molecules bound on a catalyst, at the BT-4 Be-filter-analyzer spectrometer in 1981.

Finally the 1980's saw the development and expansion of new neutron methods at the NBSR for the measurement of residual stress and texture in structural materials and products, and neutron reflectometry for probing the structure of surfaces and interfaces in polymer and liquid films and magnetic multilayers. The use of neutron diffraction for the study of texture and residual stress was pioneered at the NBSR in the late 1970's by Harvey Alperin from the Naval Ordnance Laboratory and his colleagues in the Army Group (Choi and Prask), particularly the very important concept of residual stress vs. depth measurements. This led to a vigorous program at the NBSR with many crucial applications in military systems and civilian products. Flourishing residual stress efforts emerged at many other neutron centers around the world. In this same period, the Neutron Methods Group of the NIST/NBS Analytical Chemistry Division led by Ron Fleming and a cadre of young chemists and physicists developed what would become world-leading efforts in non-destructive depth-profiling of critical elements (e.g., boron, lithium, nitrogen, ${ }^{3} \mathrm{He}$ ) in thin films using high-intensity neutron beams, and neutron 
prompt-gamma analysis of a number of elements (most notably hydrogen) in materials and products. These methods provided new capabilities for highly sensitive elemental analysis with key applications in semiconductors, nuclear systems, metallurgy, catalysts and energy storage.

\section{The Cold Neutron Research Facility: A Tortuous Journey}

The move toward a cold neutron future for the NBSR occurred in an unexpected way in FY 83 when Bob Mehrabian, the newly appointed Director of the Center for Materials Science (CMS), asked the divisions in the Center to contribute new ideas for a long range plan for CMS. Charlie Glinka was asked to prepare a plan for the Reactor Radiation Division, and Mike Rowe suggested a short section proposing the development of a cold-neutron facility based on the ability to install a very large cold-neutron source in the NBSR to provide beams to many new instruments. Mehrabian was highly enthusiastic about this proposal (and its $\$ 25 \mathrm{M}$ price tag) and took it directly to the NBS Director, Ernie Ambler. The cold neutron facility was indeed submitted in the Dept. of Commerce budget for FY '85, and an intense series of interactions, formal and informal, took place with NBS management, the Office of Science and Technology Policy (OSTP) and congressional staffers during the spring, summer and fall of 1983. Things looked promising, since the Reagan Administration, which had taken office in 1981, favored projects large and small which supported basic research.

Hopes for an FY' 85 decision, however, were diminished by the reality that at that time a number of government agencies and their laboratories were proposing major new projects - many of them focused on the "materials" research area (i.e., condensed matter physics, chemistry, materials science and engineering and biology). The Presidential Science Advisor, George (Jay) Keyworth, reacted to the logjam of proposals by setting up one of the most influential Science and Technology Committees in recent history to make recommendations for the future development of large U.S. facilities for research on materials. Frederick Seitz, the former Director of the National Academy of Sciences, agreed to chair this committee in late 1983 and Dean Eastman, a leader in research at IBM, was chosen as his deputy. The members of the committee were selected from a range of universities, industries and government laboratories to evaluate about a dozen proposals (including the NBSR proposal) with a total cost of several \$B, which had emerged from a number of national laboratories and several universities. Jack Rush, who had recently chaired a National Research Council/NAS panel on the status of U.S. Neutron Sources, was chosen as a member of the "Seitz-Eastman" Committee. Mike Rowe presented the NBS Cold Neutron proposal to the committee in March 1984. 
After a number of meetings, workshops and deliberations, the Committee in the summer of 1984 chose to recommend a number of projects and ranked them in two categories; 1.) Major New Facilities, and 2.) New Capabilities at existing facilities. The NBS Cold Neutron Research Facility (CNRF) received the top recommendation in category 2 (along with the HFBR guide hall project at Brookhaven). Ultimately, six of the projects recommended by the Seitz-Eastman Committee were developed at a cost of $\approx$ $\$ 4 \mathrm{~B}$.

The Seitz-Eastman recommendation was a shot-in-the-arm for the Cold Neutron Facility, and the decision was made to include a request for full funding again in the FY '86 budget. Enthusiasm and support were high, with the Deputy Secretary of Commerce, Clarence Brown, particularly favorable to the project, and the NIST/NBS Director, Ernie Ambler solidly onboard. In addition, somewhat to the surprise of NIST/NBS management, $\$ 1.5 \mathrm{M}$ per year was approved in the NBS FY ' 85 budget to support the installation and operation of the first $\left(\mathrm{D}_{2} \mathrm{O}\right.$ ice $)$ cold source for the NBSR. Rowe and Rush took on the roles of salesmen and tour guides to facilitate the enthusiasm and interest that continued to grow for the NBSR project. Darrell Reneker, the Acting Director of the Center for Materials Science at that time, described Jack Rush's approach in this period as that of a "revivalist preacher", which wasn't too far off the mark.

In 1985, Exxon Research and Development Corp., knowing the increasing importance of SANS in the science and technology of polymers and other soft matter, agreed to fund one-half of the cost of a state-of-the-art SANS instrument in the new guide hall. Also in 1985 Lyle Schwartz, who had been the Director of the Center for Materials Research at Northwestern University, came to the NBS as the new Director of the Institute for Materials Science and Engineering (IMSE). Lyle, who was an expert in diffraction techniques and had done research in neutron diffraction and SANS, was also very supportive of the Cold Neutron project.

\section{$\underline{\text { Political Troubles Emerge }}$}

The apparently smooth path for budget approval of the CNRF ran into unexpected problems, most notably the clash between the Reagan Administration and the Congress on the fate of the NIST/NBS Building Technology and Fire Science programs. The Administration wanted to phase out the NIST/NBS efforts in these areas, and rely on the private sector to fill their role. The Democrats and some Republicans on the Hill were adamant that these programs be maintained. In fact visits to the NBSR by congressmen and their staff confirmed this. Thus, the Cold Neutron Initiative in the FY' 86 Budget was rejected by Congress, largely as a quid pro quo for the attempt by the Office of Management and Budget to eliminate the Building and Fire Science programs in the same budget. There seemed to be no give on either side that would change things in the FY'87 budget. 


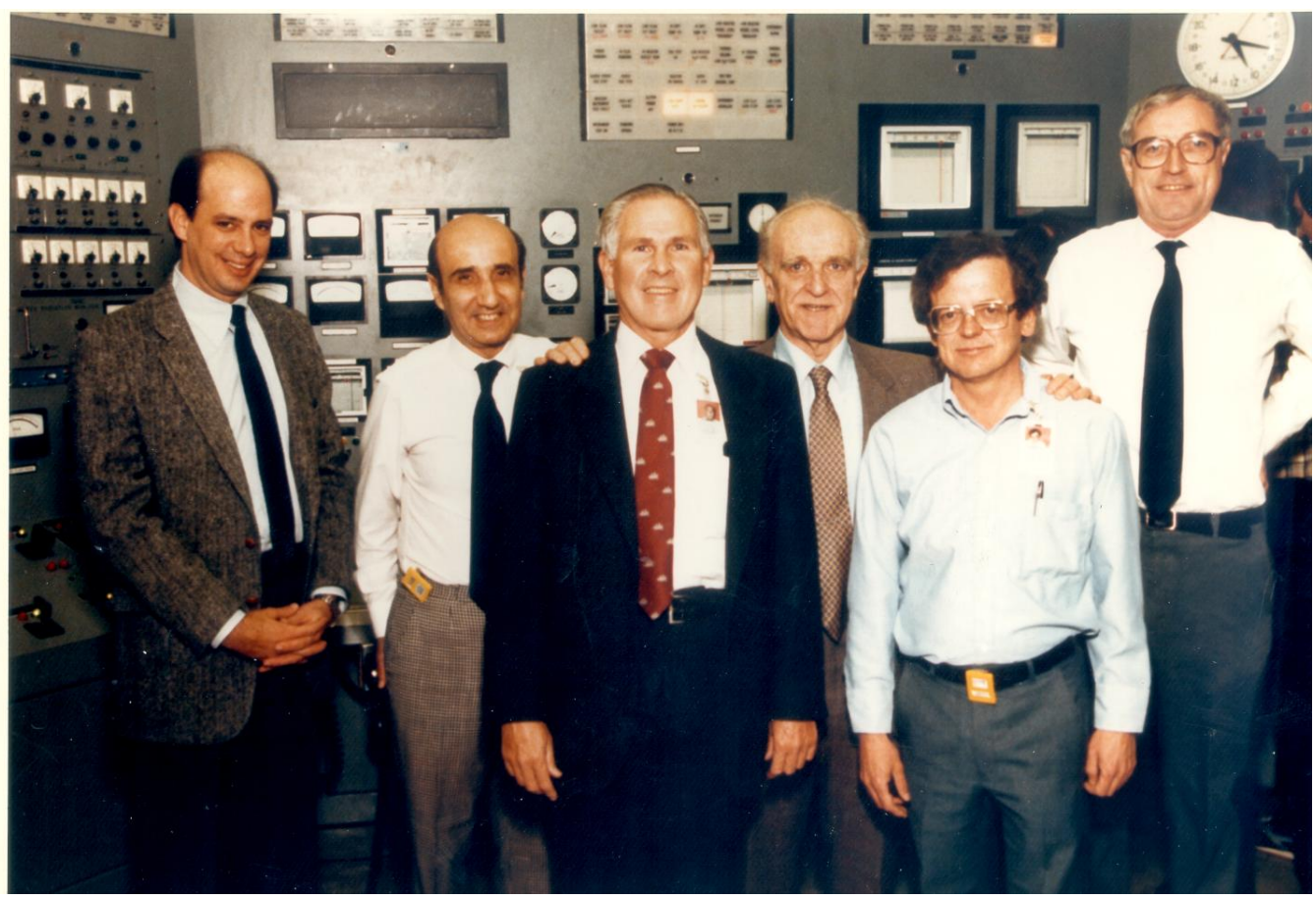

Celebrating the increase in power to $20 \mathrm{MW}$ at the NBSR in 1985. From left to right are Ray Kammer, NBS Deputy Director; Tawfik Raby, Bob Carter, NBS Director Ernie Ambler, Mike Rowe and Jack Rush.

Meanwhile as the budget battles continued, Bob Carter was leading the effort to use the FY ' $85 \$ 1.5 \mathrm{M}$ increase well. With help from the engineering and scientific staff, he successfully developed, installed and tested the large $\mathrm{D}_{2} \mathrm{O}$ ice cold source by 1987 , and coupled it to the $8 \mathrm{~m}$ SANS to greatly increase cold neutron intensities for all experiments. Carter, Tawfik Raby, and the NBSR engineering staff also completed the increase of the power of the NBSR from $10 \mathrm{MW}$ to $20 \mathrm{MW}$ in 1985.

\section{$\underline{\text { The Final Path to Success }}$}

During FY '86 the prospects for the Cold Neutron Research Facility remained uncertain, so that less expensive options were considered (for a smaller cold-neutron guide hall and fewer instruments). Ray Kammer, who was then Deputy NIST/NBS Director, remained firm on pursuing the full project, as did the Commerce Department. Finally, in November 1986, a deal was struck with Congress to approve funding of the Facility at $\$ 6.5 \mathrm{M}$ a year for five years. Thus in early 1987 , the NBSR received the first year funding for the Cold Neutron Research Facility, which was to comprise 7 neutron guide tubes (with the largest guide-tube area of any cold neutron facility up to that time), 15 new cold-neutron instruments, and a large guide hall/office/laboratory complex to serve hundreds of research participants a year. At the beginning of 1987, Mike Rowe agreed to lead the Cold Neutron Project, which included the construction of the Guide Hall Facility, and the design and development of the guide tube array and the new cold neutron instruments. 


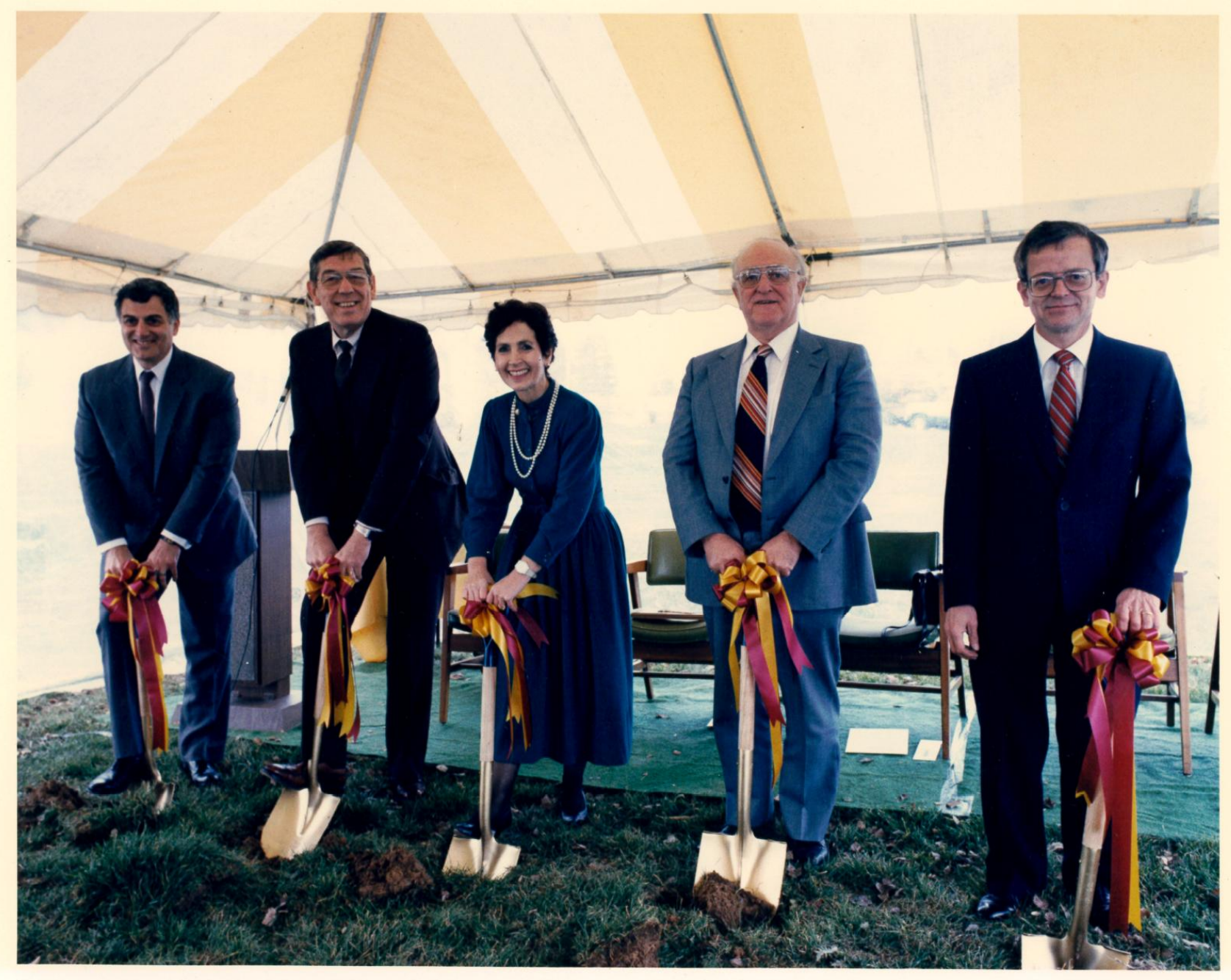

Officials at the groundbreaking ceremony for the cold neutron guide hall in November 1987. Left to right: MSEL Director Lyle Schwartz, DOC Deputy Secretary Clarence (Bud) Brown, Rep. Connie Morella (R-Md), NBS Director, Ernie Ambler, and Mike Rowe. 
IV From the CNRF to the NIST Center for Neutron Research

\section{$\underline{\text { Staffing up for a Cold-Neutron Future }}$}

One of the most exciting aspects of the success of the Cold Neutron Initiative was the opportunity to add new scientific and engineering staff to carry out the instrumentation development and to prepare for the new opportunities in science to be opened up by a world-class cold neutron capability. So, between 1986 and 1989, the neutron research group at the NBSR led by Jack Rush attracted a number of the future scientific leaders of the NCNR: Chuck Majkrzak from Brookhaven, Dan Neumann a fresh Ph.D. from the University of Illinois, Sushil Satija from the U. of Delaware, John Copley from McMaster University in Canada, Terry Udovic, an NBS post-doc from the U. of Wisconsin, Julie Borchers, a post-doc from U. of Illinois, Boualem Hammouda from U. of Missouri and Susan Krueger, an NBS scientist who had been a student of Jeff Lynn at the U. of Maryland, among others.

To help carry out the enormous engineering tasks, Ivan Schroder was recruited from the Center for Radiation Research to design and lead development of the neutron guide tube network. Schroder had been the first in the U.S. to test a guide tube in a reactor, when as a graduate student, he and Klaus Fiebiger, a German colleague, inserted a nickel-coated copper tube into the BNL Graphite Reactor and measured the emerging neutrons.

Young engineers including Don Pierce and Christof Brocker were also hired to help design and construct the cold neutron instrumentation. In addition, Bob Williams was designated leader of an expanding group of technical support personnel, and later was succeeded by George Baltic in that role. Gayle Greene, a computer scientist, became an essential resource to provide and maintain operational software for our neutron scattering spectrometers. Finally, recognizing the need to meet the computer-based requirements of the next-generation instrumentation being developed and of the sophisticated communication and information systems to serve the expected influx of neutron users, young scientists with outstanding computer skills were recruited, including Przemek Klosowski from the University of Notre Dame, and later Nick Maliszewskyj from the University of Pennsylvania, and Alan Munter from the University of Illinois. 


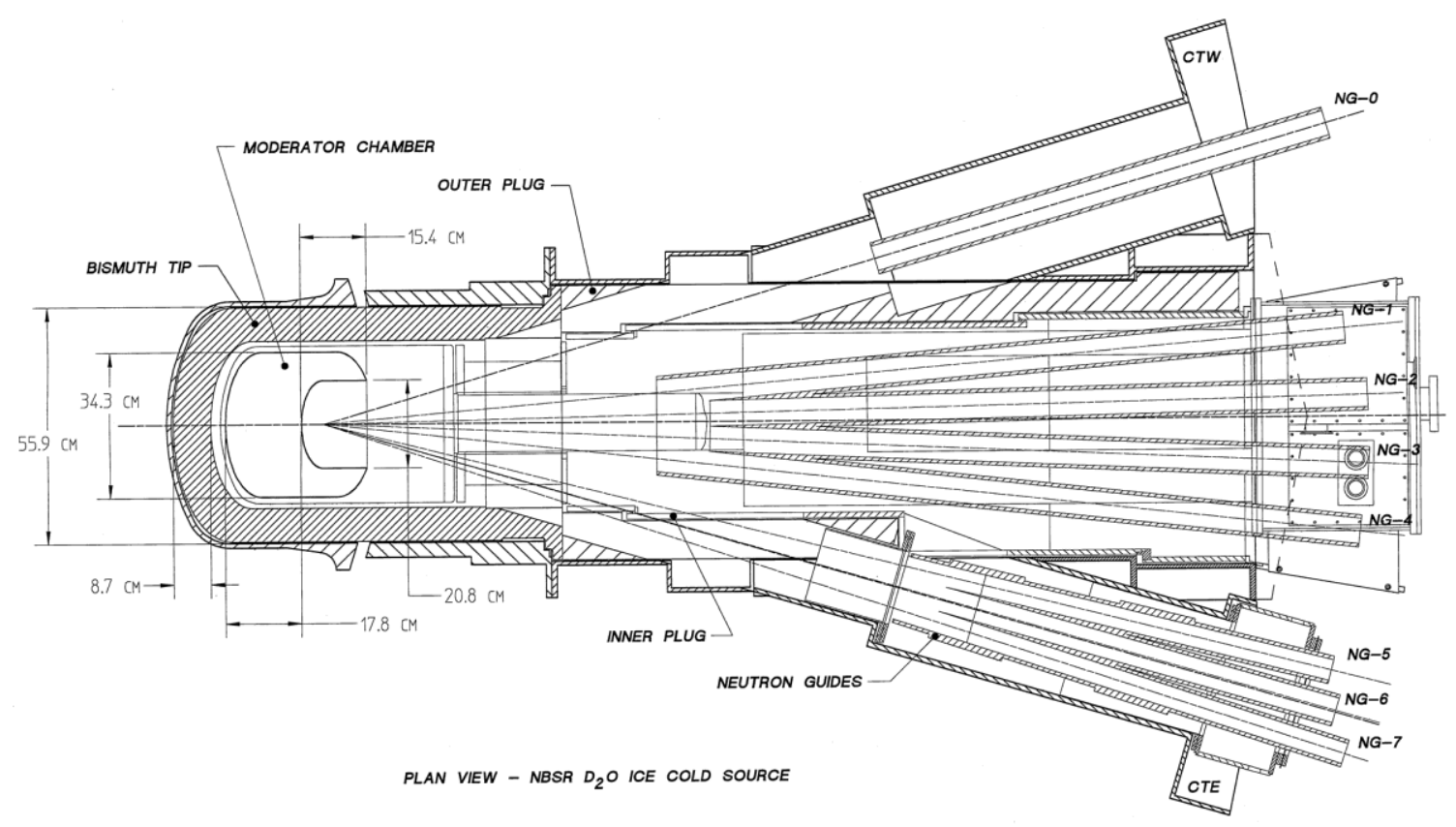

Plan view of the original large $\mathrm{D}_{2} \mathrm{O}$ ice cold neutron source at the NBSR. Also shown emanating to the right is the network of seven guide tubes, which carried cold neutrons into the guide hall.

\section{New Instruments, New Research Alliances}

Design work on the cold-neutron guide hall had been initiated in 1986, so that when the Congress provided construction funds in FY '87, the NBSR team was able to be off and running. The Guide hall building and the lab and office wing were completed in 1989. 


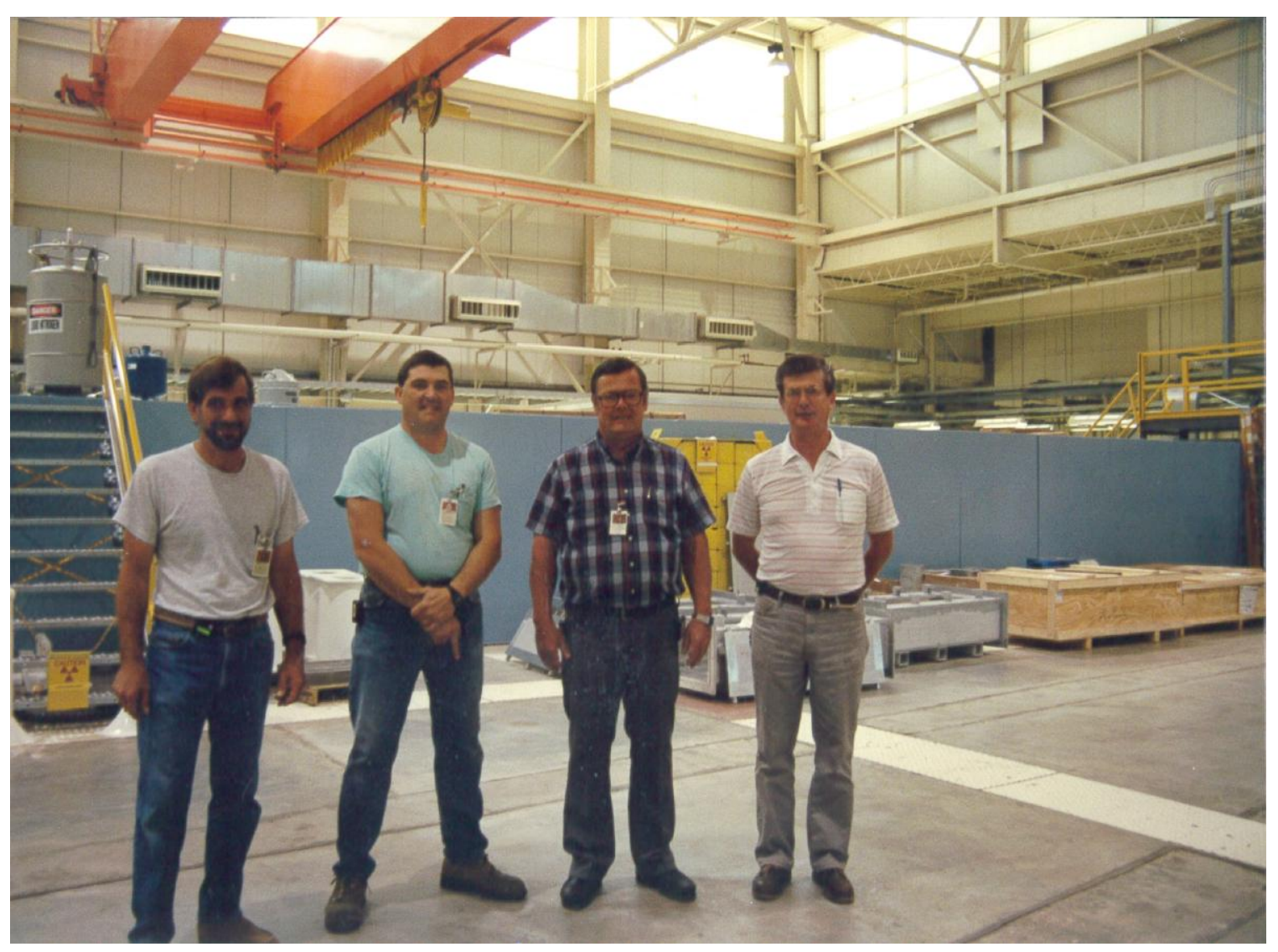

Members of the NBSR technical staff in the cold neutron guide hall, circa 1990. Right to left: Wayne Knill, Bob Williams, the first leader of the neutron technical staff, George Baltic, who succeeded him as leader, and Mike Rinehart.

Also in 1989 there was a significant "passing of the guard", as Bob Carter retired as division chief after 31 years at NIST/NBS and Mike Rowe agreed to take his place. A series of annual lectures was instituted that year to celebrate Carter's long leadership of the NBSR. The speakers were major figures in American science and technology, including two Nobel Prize winners. 


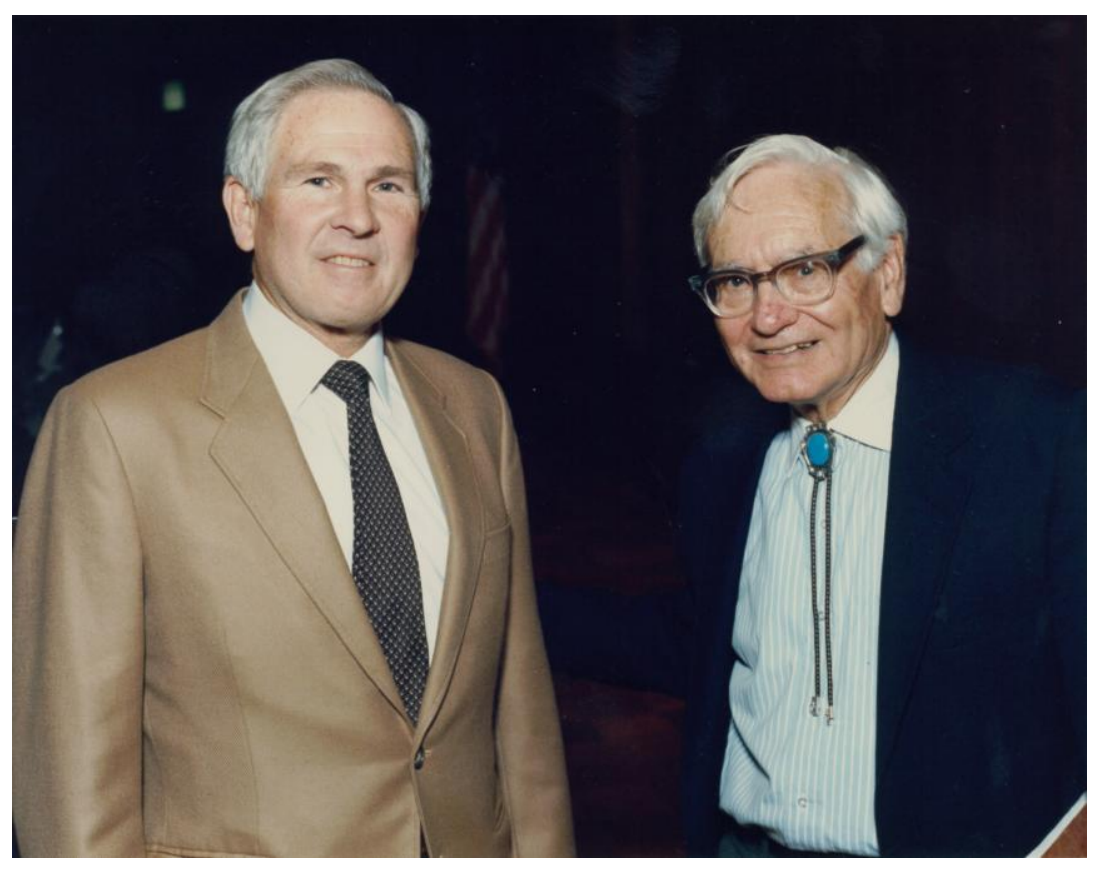

Bob Carter pictured here with Alvin Weinberg, former director of Oak Ridge National Laboratory, who delivered one of the annual Carter lectures initiated after Carter retired in 1989.

The first instrument (the existing $8 \mathrm{~m}$ SANS) was placed on a guide tube in 1990. The $30 \mathrm{~m}$ Exxon/NIST SANS was completed in 1991, and immediately superseded other U.S. SANS machines and became an enormous success, particularly for soft matter research. Sunil Sinha, a long-time colleague of many at the NBSR, led a talented team of Exxon researchers in an active, highly productive research effort. This became one of the best neutron programs in industrial research ever carried out. The Center for Interfacial Engineering at the University of Minnesota joined the Exxon/NIST partnership, led by Professor Frank Bates, a major user of NIST SANS instruments. This partnership continues in place, twenty years later. 


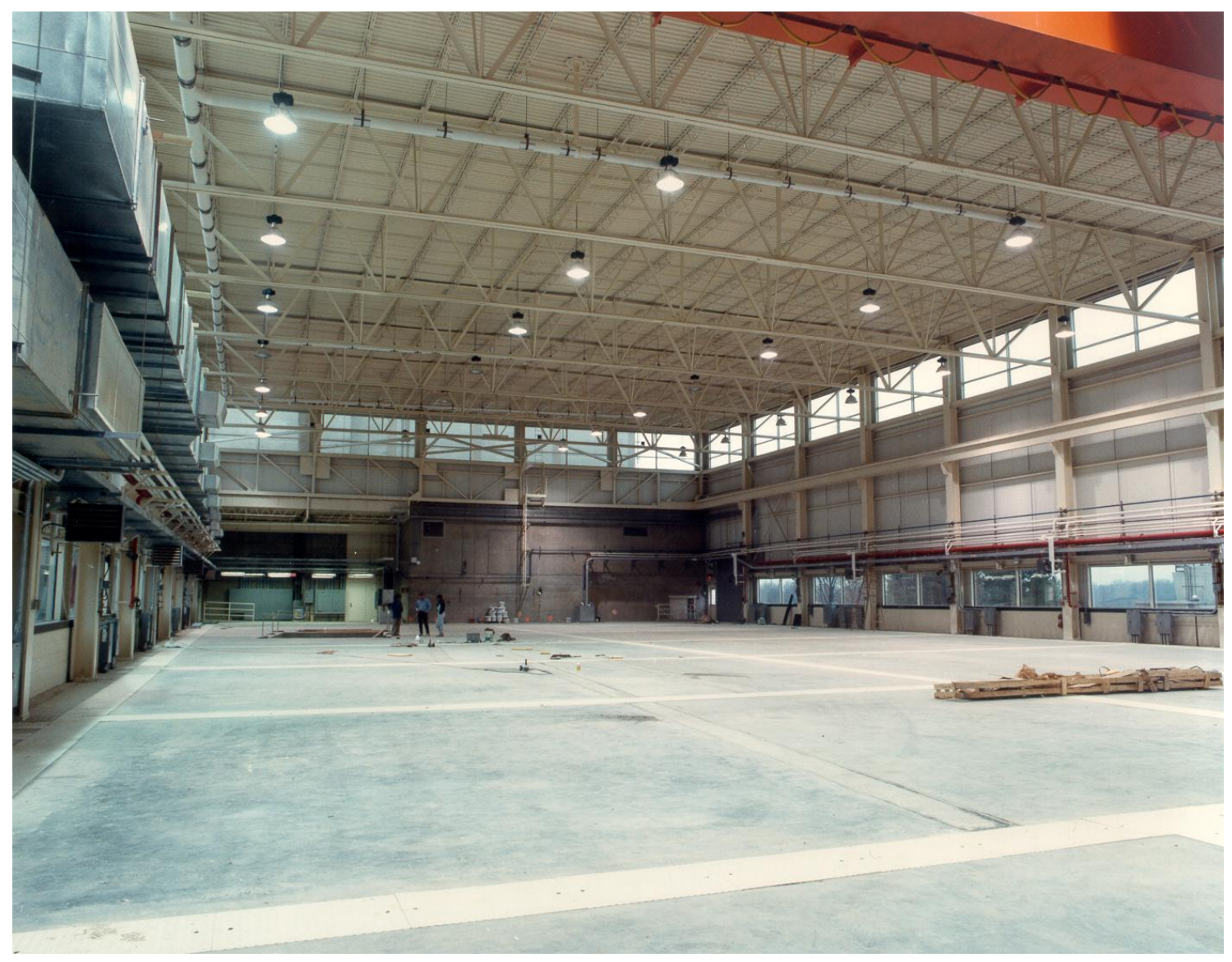

View of the empty cold neutron guide hall in 1989 as the installation of neutron guide tubes and instrumentation was about to begin.

During the 1990's work continued on the full development of cold-neutron instruments. As the instrumentation suite took shape, the number of instrument-based cooperative agreements and programs also grew. The NIST Quantum Metrology Group set up two cold neutron beam lines, initiated by Dick Deslattes and Geoff Greene and later led by Dave Gilliam and Muhammad Arif, which included a unique neutron interferometry station (greatly aided by Sam Werner of the University of Missouri) and a facility for fundamental neutron physics experiments. The Neutron Methods group in Analytical Chemistry installed ground-breaking cold neutron instruments for prompt gamma analysis (of hydrogen and other critical elements) and for neutron depth profiling.

Also in the early 1990's, the IBM Laboratory in San Jose, CA formed a Participating Research Team (PRT) with NIST to develop a horizontal-beam coldneutron reflectometer for studies of soft-matter thin films and liquid surfaces. IBM's Tom Russell was the leader of this effort. Tom had been one of the early players in exploiting neutron reflectometry in the study of polymer thin films at the IPNS (with Gian Felcher) and then with Chuck Majkrzak who developed a vertical reflectometer on a thermal neutron beam line at the NBSR, in 1987. This instrument performed extremely well and became the basis for the highly successful cold neutron vertical reflectometers built by Chuck and his colleagues in the cold neutron guide hall in the 1990's and 
beyond. Between 1987 and the early 1990's, a number of young scientists came to NIST, including post-docs Anne Mayes and Spiros H. Anastasiadis from IBM, and NIST postdocs Julie Borchers (previously mentioned) and John Ankner from the University of Illinois. They helped launch what became the best neutron reflectometry research effort in the world. In 1993, the IBM/NIST instrument (the IBM role lasted about seven years) came on line and with further improvements remains a highly productive instrument to this day. The development of NIST reflectivity (and SANS) capabilities was aided by key theoretical contributions by Norm Berk.

The 1990's also saw the initiation of a long-term research effort with Richard Livingston of the Federal Highway Administration on the structure and hydration processes in cements. This program includes the participation of the NIST Building Materials Division and the Ceramics Division, along with university partners.

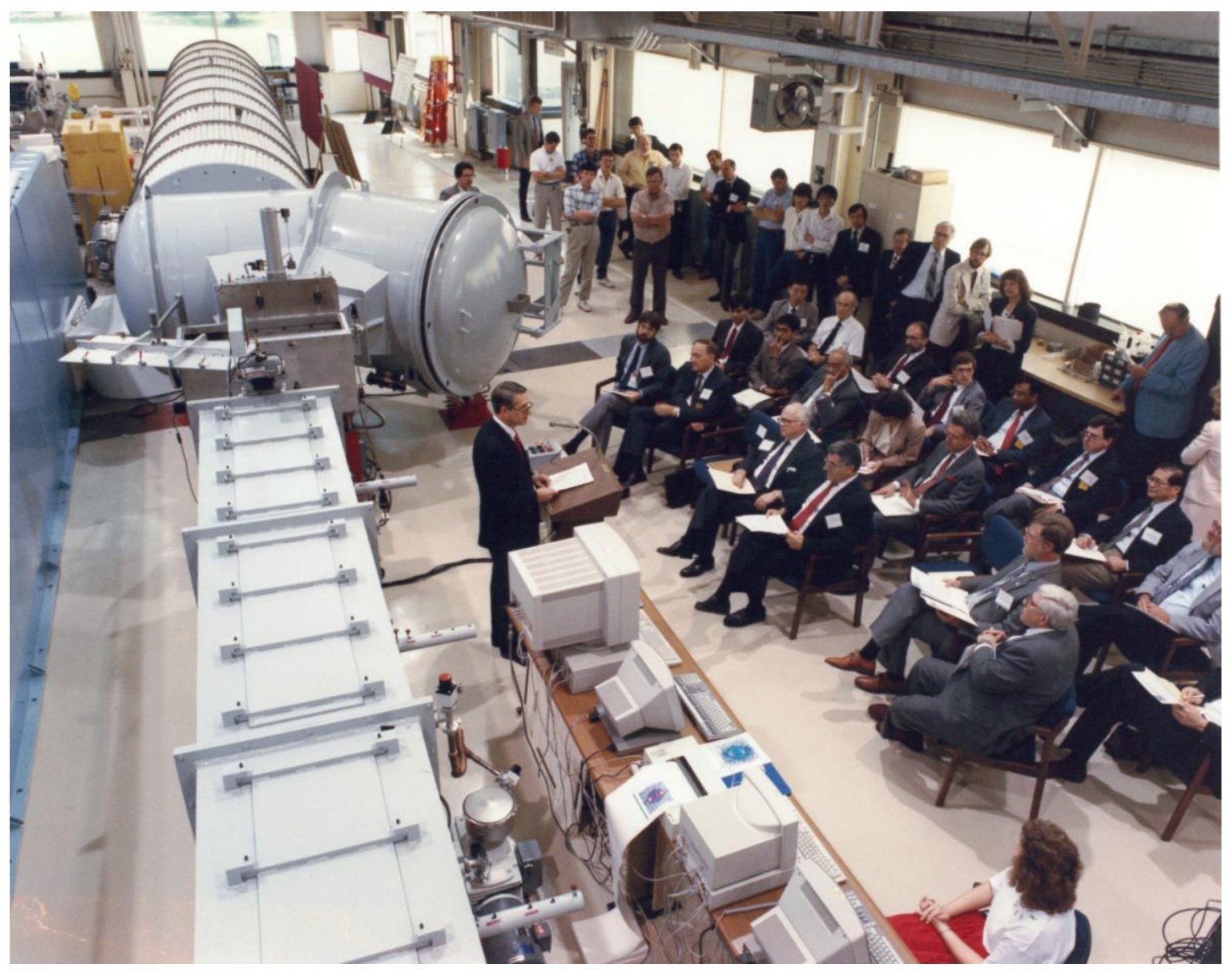

Robert White, DOC Assistant Secretary for Technology speaks at the dedication in 1991 of the NIST/Exxon/U. of Minnesota 30 meter SANS facility, first new instrument installed at the CNRF. Prof. Frank Bates representing the Minnesota contingent sits at the far left of the first row. 
The ability to carry out the development of the CNRF was greatly enhanced by close cooperation with universities in the middle Atlantic region, most notably the University of Maryland. Joint efforts with Maryland started early on in the 1970's and involved collaborative research with both the physics and chemistry departments at the university. Jeff Lynn's arrival at College Park as a professor of physics in 1976 has already been mentioned. Jeff played a pivotal role in administering Maryland/NIST joint research. As the pace of events leading to the CNRF quickened, a major cooperative research agreement was established, which joined NIST experience and expertise in the neutron field with the broad capabilities and perspective of the University, to advance neutron research and engineering for the national community. A significant fraction of the engineers, neutron instrument scientists and visiting researchers who have made the CNRF (and the NCNR) a major success were recruited and developed through this Maryland/NIST Agreement. University of Maryland graduates and the dozens of key NCNR scientists and engineers over the years who worked under the Agreement, include Charlie Glinka (the long-time leader of the SANS program and instrumentation), Susan Krueger (senior scientist for biostructure research at the NCNR, who has facilitated much of the biological SANS effort at NIST), Don Pierce (leader of instrumentation engineering), Seung-Hun Lee (currently a professor of physics at the U. of Virginia), Qingzhen Huang, the NCNR's most prolific crystallographer, Craig Brown (a recipient of a Presidential Early Career Award for Scientists and Engineers in 2009), Mark Green (current Leader of the NCNR Crystallographic team) and Richard Ibberson (acting leader of the Research Facilities Operations Group). When Jeff Lynn came to NIST in 1993 to lead the Condensed Matter Physics effort at the NCNR, Professor Rob Briber of the Materials Science and Engineering Department at Maryland took over as Principal Investigator for the Maryland/NCNR Agreement, and has greatly broadened the scope of the program in the area of research and instrumentation for soft matter science.

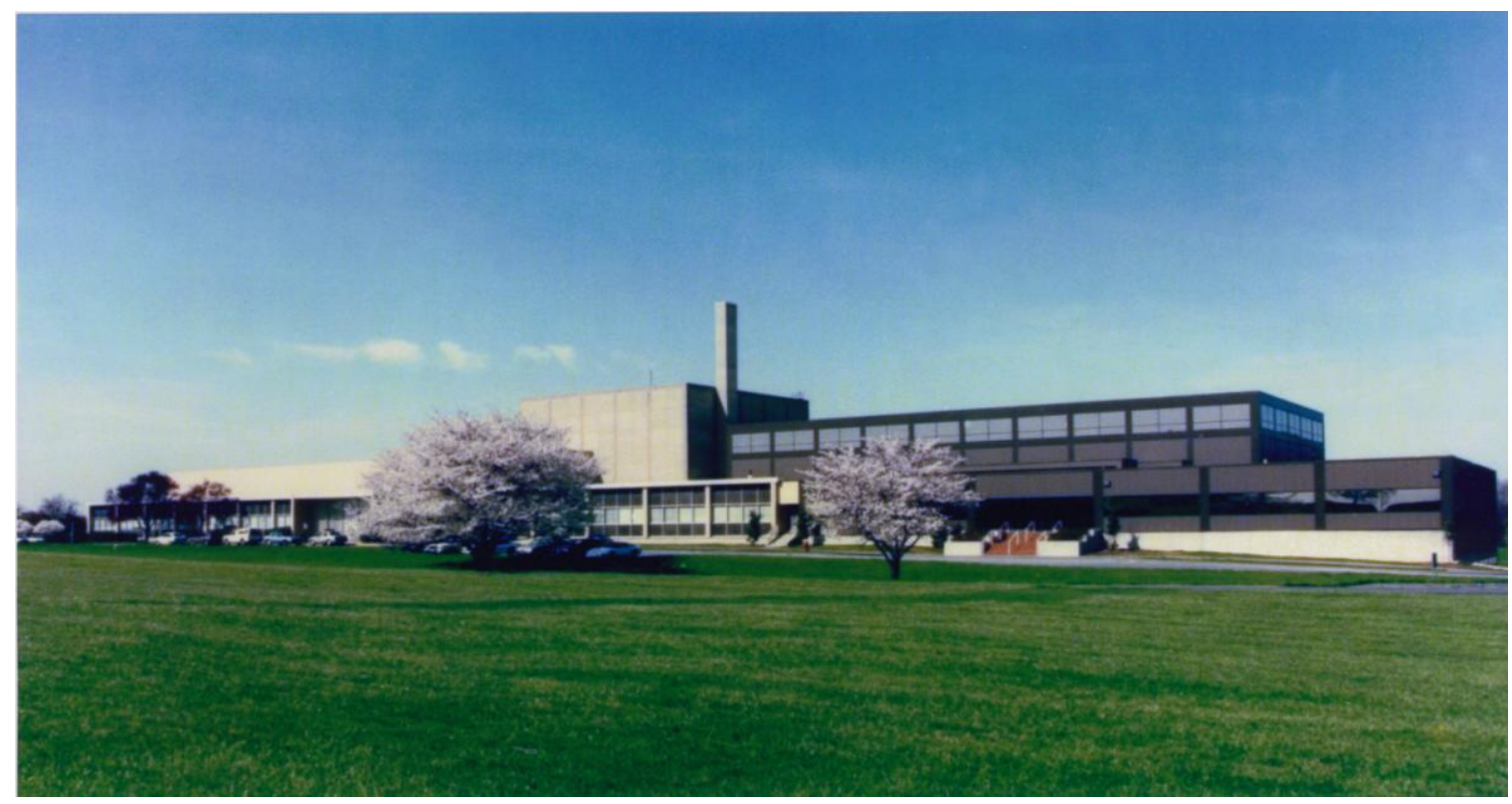

Springtime view of the expanded NBSR with the guide hall and the new office/laboratory complex on the right, circa 1992. 
It should also be noted that a strong NCNR association with Johns Hopkins University emerged in the 1990's with the arrival of Collin Broholm in the Physics Department. This new alliance was to yield major benefits in both physics research, and in the development of next generation cold-neutron instrumentation.

Another strong collaboration was established in the 90's with the University of Pennsylvania, which involved cooperative ventures in materials science and theory (with Jack Fischer and Taner Yildirim), and biological structure and modeling (with Mike Klein and Kent Blasie). These research efforts provided one of the key themes in research at the NCNR in the years to come: research on materials and biological systems which directly couples neutron scattering measurements with modern theory and modeling. In particular, this research approach brought Taner Yildirim to the NCNR. Yildirim has led an extremely productive research program on a wide range of functional materials, including high- $T$ c superconductors, magnetic systems, modern carbons, and new framework materials for energy storage. Taner is the current leader of the Theory and Modeling team at the NCNR. The combination of molecular modeling with neutron measurements of biomolecular structures also remains a core research theme at the NCNR.

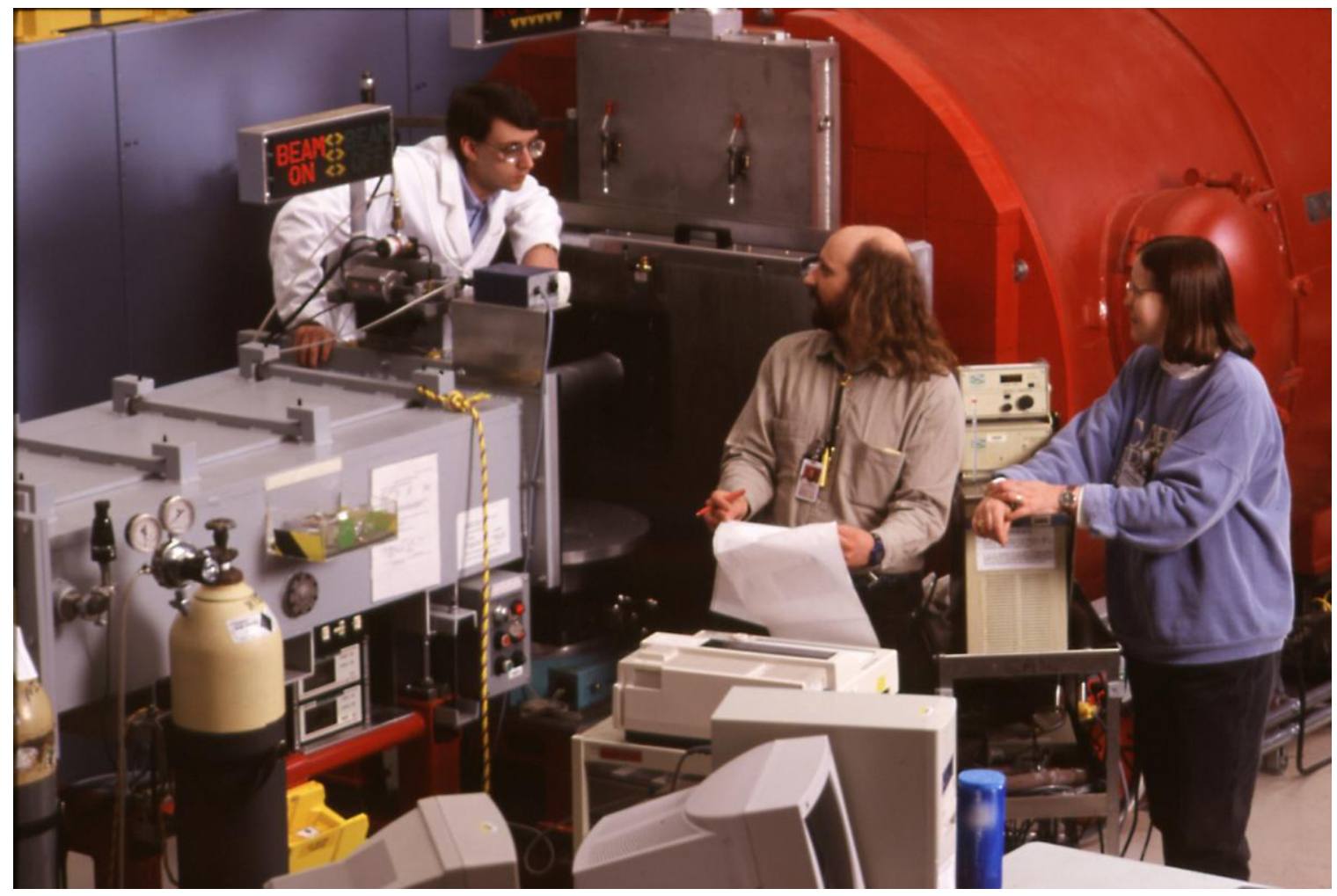

Left to right: Steve Kline, Paul Butler (who later succeeded Charlie Glinka as leader of the NIST SANS facilities) and University of Tennessee Professor Lee Magid perform a measurement on the NIST/Exxon/Minnesota 30 meter SANS. 
The most important external alliance with other government agencies that developed in the early years of the CNRF was the creation with NSF of the Center for High Resolution Neutron Scattering (CHRNS) in 1989. CHRNS was initiated with two instruments, a $30 \mathrm{~m}$ SANS machine and the first state-of-the-art cold neutron triple axis spectrometer in the United States, whose development was led by Chuck Majkrzak and later by Collin Broholm. This center of excellence has expanded over 20 years to become the foremost resource in the United States for cold neutron scattering research, ultimately including the six best U.S. spectrometers for small angle neutron scattering and high resolution neutron spectroscopy. The first CHRNS instruments came on line by 1995, and were highly successful in attracting new U.S. researchers and new science.

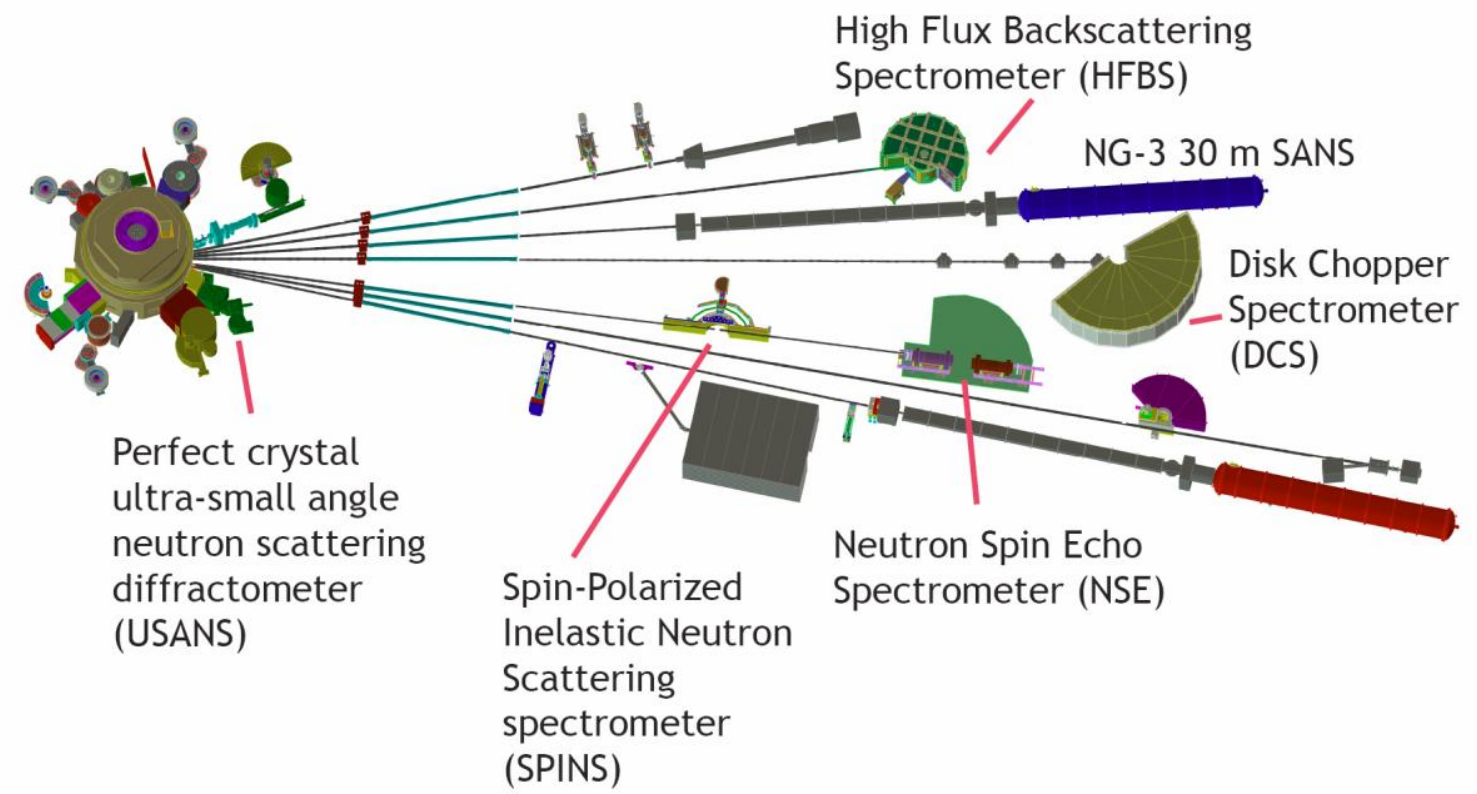

Schematic array in 2002 of the instrumentation suite at the NCNR. The six cold neutron instruments which comprised the NSF/NIST Center for High-Resolution Neutron Scattering (CHRNS) at that time are pointed out.

\section{The U.S. Neutron Research Environment (1987-1999)}

Unfortunately, the positive progress at the CNRF and the rapid expansion of new cold neutron users at NIST/NBS was not accompanied by similar progress at other U.S. neutron sources. The proposal to create a guide hall at the BNL HFBR in the late 1980's was not approved. Even worse, technical and political problems over the next decade led to an uneven operating schedule for both the BNL and ORNL research reactors, and the 
power at both facilities was reduced, from $100 \mathrm{MW}$ to $85 \mathrm{MW}$ at HFIR and $60 \mathrm{MW}$ to 30 MW at HFBR. The operation and performance at the Los Alamos Neutron Scattering Center (LANSCE) was promising, but also problematical during this period.

There were some positive developments at the DOE laboratories, however. Following the recommendations of the Seitz-Eastman Committee in 1984, ORNL developed by 1987 a proposal for a powerful new research reactor, the Advanced Neutron Source (ANS), which was to include two large cold neutron sources, six times the available neutron flux of the ILL in France, and over 40 beam stations for neutron scattering and other activities, including isotope production. NIST scientists were actively engaged in the National Steering Committee for this new facility over the years (Jack Rush was chairman for six years). The influential Kohn Panel, which was appointed by the DOE in 1992 to survey the DOE neutron facilities and opportunities and make recommendations for a new neutron source, gave the ANS proposal its highest rating and paired it with a pulsed spallation source for sequential development. The ANS project was cancelled in early 1995 primarily because of increased cost estimates (almost \$3B), ironically only three months after Shull and Brockhouse received the Nobel Prize in Physics for their development of neutron scattering in the 1950's (at research reactors). Two years later Congress approved funding (ultimately $\approx \$ 2 B$ ) for the Spallation Neutron Source (SNS) at Oak Ridge. NIST scientists have been very active on committees related to the development of the SNS and at existing DOE neutron facilities. During the 1980's and 1990's a number of DOE scientists and leaders have provided valuable advice and assistance to the NCNR, including, e.g., Mike Wilkinson from ORNL, John Axe from BNL, and Roger Pynn from LANL.

A bright and consistent light among the DOE facilities during this period was the IPNS at Argonne, which operated as a user facility. The IPNS achieved very successful research efforts in powder diffraction, neutron reflectivity and neutron spectroscopy, but was not successful, however, in obtaining new funding from the DOE to increase its neutron fluxes and capacity.

In 1999 the U.S. neutron field suffered a major blow when the DOE decided to shut down the HFBR at BNL, its premiere neutron source, mainly due to political pressure. In response, the NCNR formed a "scientific alliance" with the Brookhaven neutron scattering group in 2001 to carry out joint research with BNL in materials physics. While the NBSR was able to serve some of the needs created by the slowdown or shutdown of the DOE reactors (e.g., the MIT program in magnetism and superconductivity of Bob Birgeneau and his students and post-docs), the NCNR's capacity could not fill the neutron gap that occurred. Thus, during the 1990's (and beyond) the NIST facility was the only internationally competitive force in the U.S. neutron scattering, while the national community awaited the SNS at Oak Ridge and improvements that were to come at the HFIR reactor and LANSCE. (e.g., see the 2002 OSTP "Report on the Status and Needs of Major Neutron Scattering Facilities and Instruments in the United States".) 


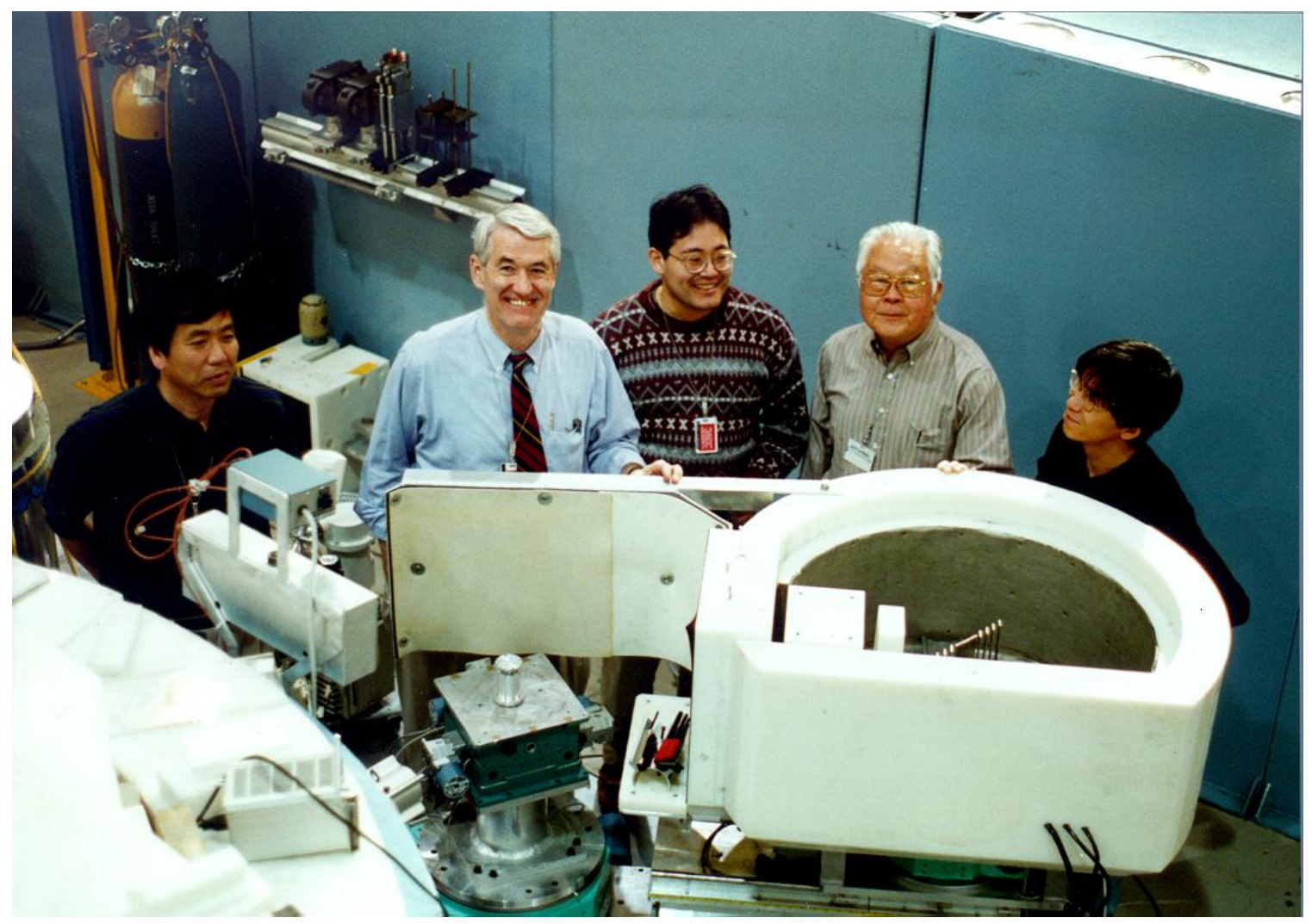

Professor Bob Birgeneau from MIT and physicist Gen Shirane from BNL (second and fourth from the left) and colleagues at the SPINS facility. Birgeneau and Shirane, along with students and collaborators were among those who carried out much of their neutron research on magnetism, superconductors, and ferroelectrics at the NCNR when the Brookhaven reactor was curtailed and then shut down.

\section{$\underline{\text { A New Cold Source and Completion of Neutron Instrumentation }}$}

While the large $\mathrm{D}_{2} \mathrm{O}$ ice cold source which became operational in 1987 was a success, it was clear that the cold neutron flux could be greatly improved by development of a large area liquid hydrogen source. Under the direction of Mike Rowe, Robert Williams, Paul Kopetka and other engineering staff members designed a next generation hydrogen source in the early '90's and brought it on line in 1995. The results were as predicted and were spectacular. The neutron flux at the end of the 7 guide tubes (beam lines) was increased by a factor of 6 , which greatly upgraded the performance of all the cold neutron instruments in the guide hall, and immediately put NIST in the ranks of the world's best facilities for neutron research. 


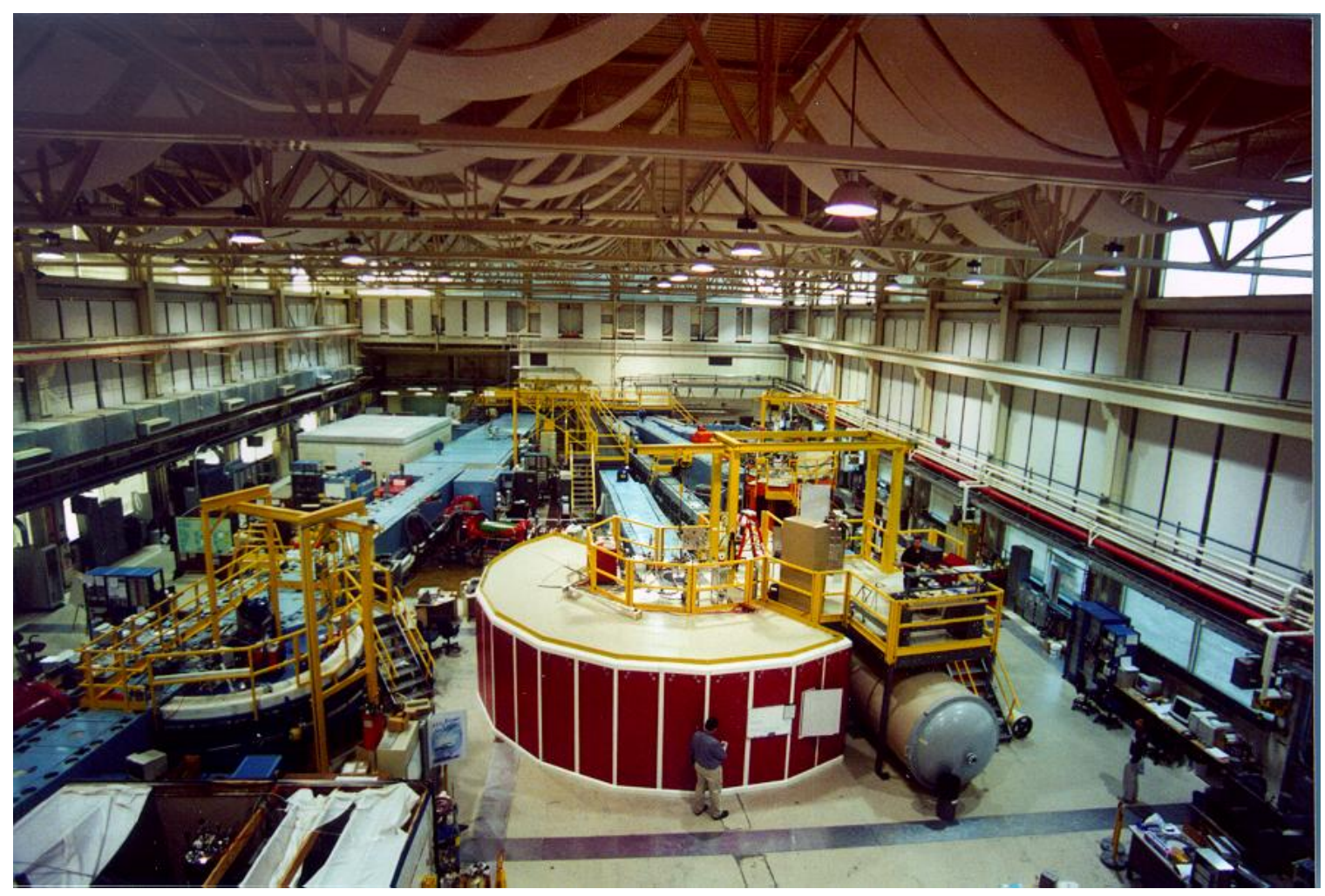

An interior view of the neutron guide hall (circa 2000) with an array of cold neutron instruments in full operation.

During the 1990's the complete suite of cold-neutron user instruments came online, including the Disk-Chopper Spectrometer (DCS), which has enjoyed great success, the high flux backscattering Spectrometer (HFBS) using the phase-space chopper concept, which achieved the highest flux on sample among backscattering instruments worldwide, and a state-of-the-art vertical-beam cold-neutron reflectometer. Dan Neumann, Peter Gehring, Christof Brocker, Robert Dimeo and Andreas Meyer (a postdoc from Münich) combined on the HFBS; John Copley and Jeremy Cook were leaders of the DCS effort; and Chuck Majkrzak created a major success with the vertical beam reflectometer. Finally, in the late 1990's another partnership was formed, Cold Neutrons for Biology and Technology (CNBT), funded by NIH and NIST, and led by Professor Stephen White of the University of California at Irvine and key professors from the University of Pennsylvania, the University of Pittsburgh, and Johns Hopkins University. The centerpiece of CNBT was a new Advanced Neutron Diffractometer/Reflectometer (AND/R) which, along with high resolution SANS, was aimed at joint research on the structure of biological surfaces and interfaces and bioassemblages. Chuck Majkrzak and Susan Krueger from NCNR and Anne Plant from the Biotechnology Division were the key players for NIST, with Klaus Gawrisch a NIH participant. In the same period, Jack Rush, Charles Han of the Polymer Division and Gary Gilliland of the Biotechnology Division were awarded a 5-year "Competence" award by NIST to pursue novel approaches in soft matter research using the new collection of cold neutron instruments, combined with molecular dynamics simulations. 


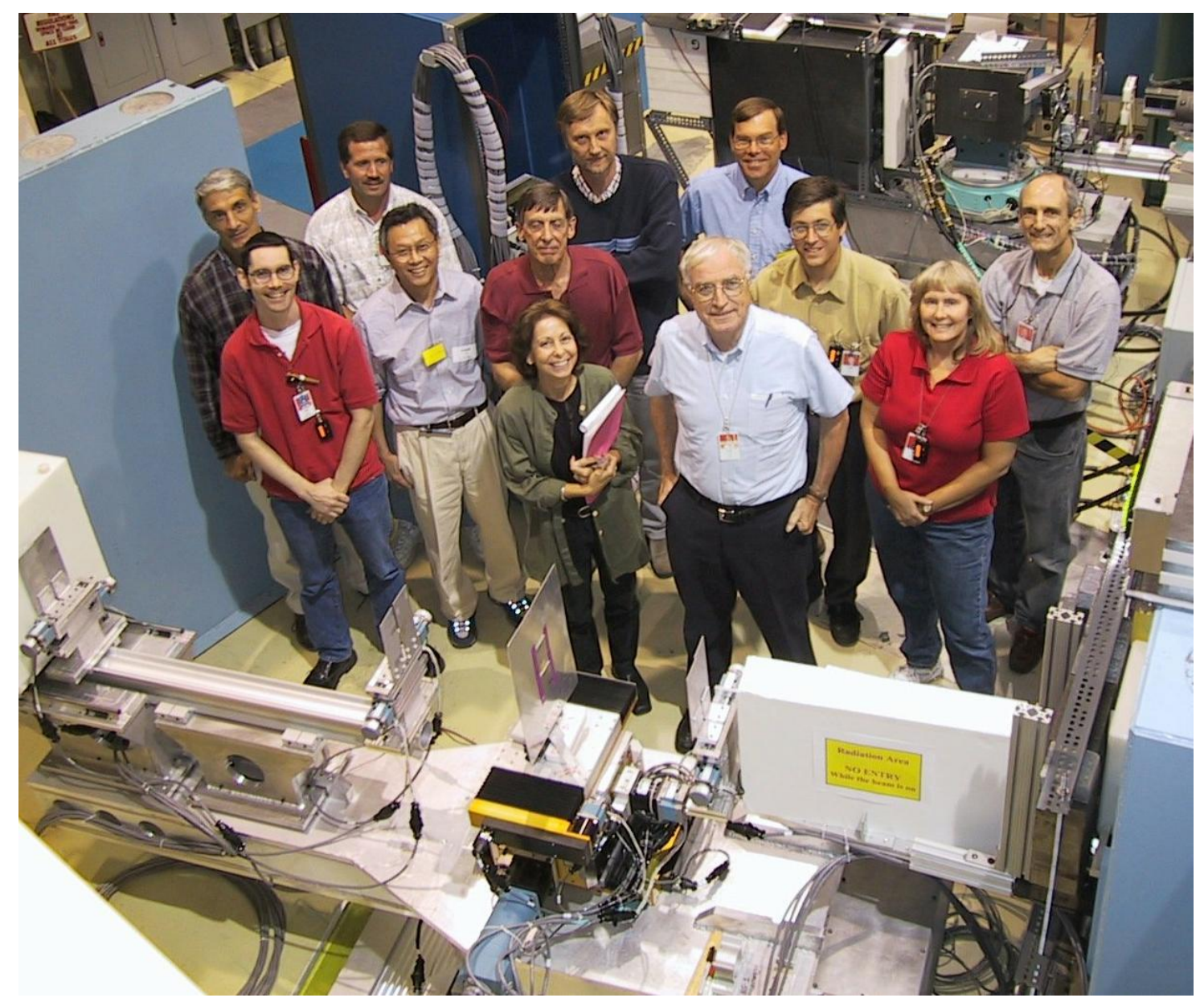

Members of the team of scientists and leaders from NIST, the University of California at Irvine, and a number of other universities at the newly commissioned Advanced Neutron Diffractometer/Reflectometer (AND/R). The instrument, dedicated to studies of biological surfaces and interfaces, was the centerpiece of the Cold Neutrons for Biology and Technology partnership.

Parallel advances in instrumentation and new science were also carried out on thermal neutron beams at NCNR during the 1990's. In 1992 a 32 detector, highresolution neutron powder diffractometer was commissioned with 3 focusing monochromators to provide variable resolution and a wide wave vector $(4 \pi \sin \theta / \lambda)$ range. 


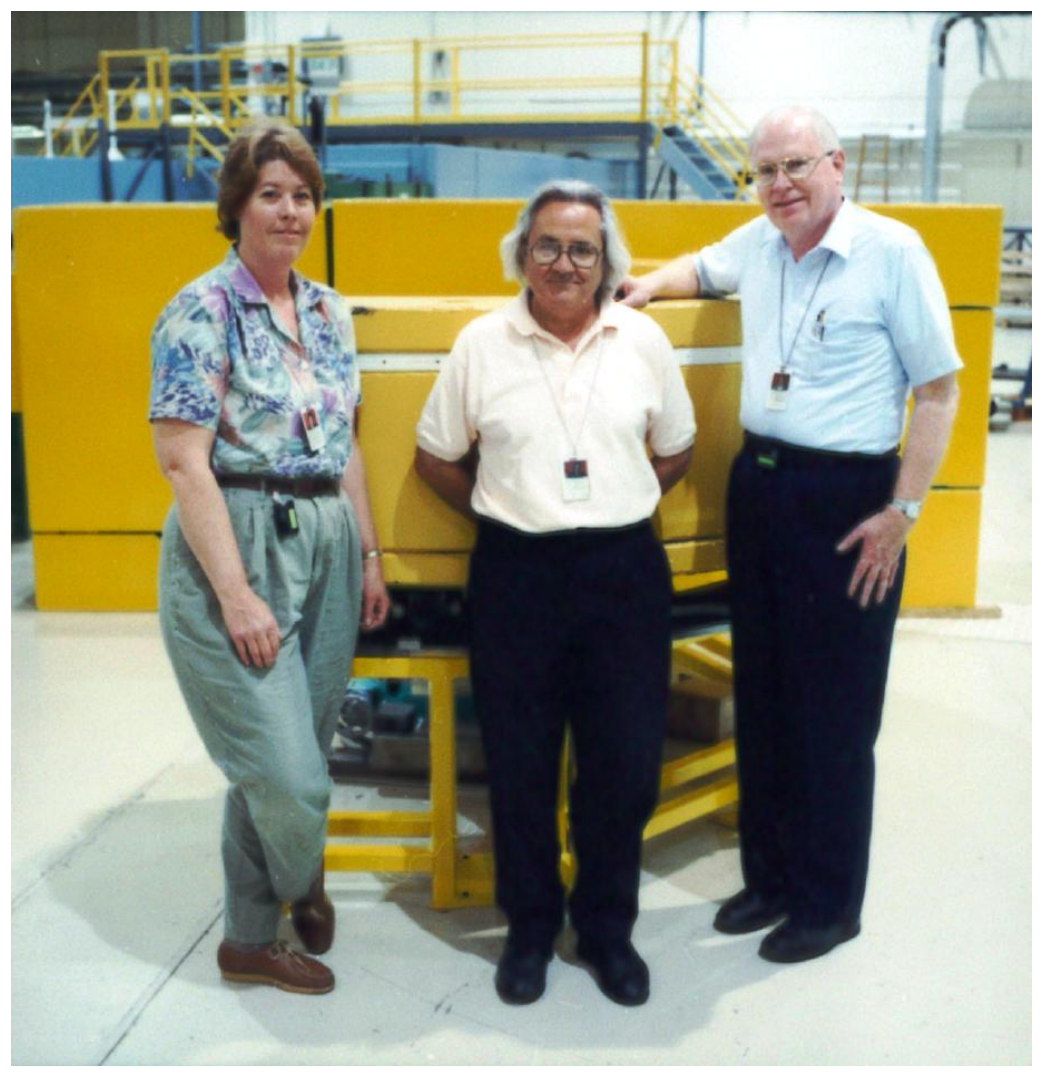

Left to right: Judy Stalick, Tony Santoro, and Ted Prince at the 32-detector array for the high resolution powder diffractometer, which greatly advanced materials structure research at NIST, circa 1992.

This instrument, developed by the diffraction group (especially Ted Prince) and later improved by Brian Toby and Judy Stalick, immediately expanded research on the structure of a wide variety of materials and attracted users from all around the U.S. In 2000, the filter-analyzer neutron spectrometer (FANS) was upgraded with a new cooled multidetector analyzer to create an increase in intensity by a factor of 20 for studies of the vibrational spectra of all classes of materials. This instrument, initially developed in cooperation with Penn and the University of California at Santa Barbara, with partial NSF support, provides a highly sensitive neutron vibrational spectrometer for small samples and low concentrations of hydrogenous species. Terry Udovic and Dan Neumann were leaders of this development. In 1996 under the leadership of Paul Brand, a materials engineer from Holland, an advanced double-axis diffractometer for residual stress, texture and single crystal analysis (DARTS) was commissioned. This instrument represented a culmination of the leadership role played by NBS/NIST and Army colleagues starting in the 1970's in the development of these engineering methods for both industrial and military applications. Its development led to a new wave of technologically important studies of residual stress and texture, ranging from pipelines, to tank cars, to automotive components. 

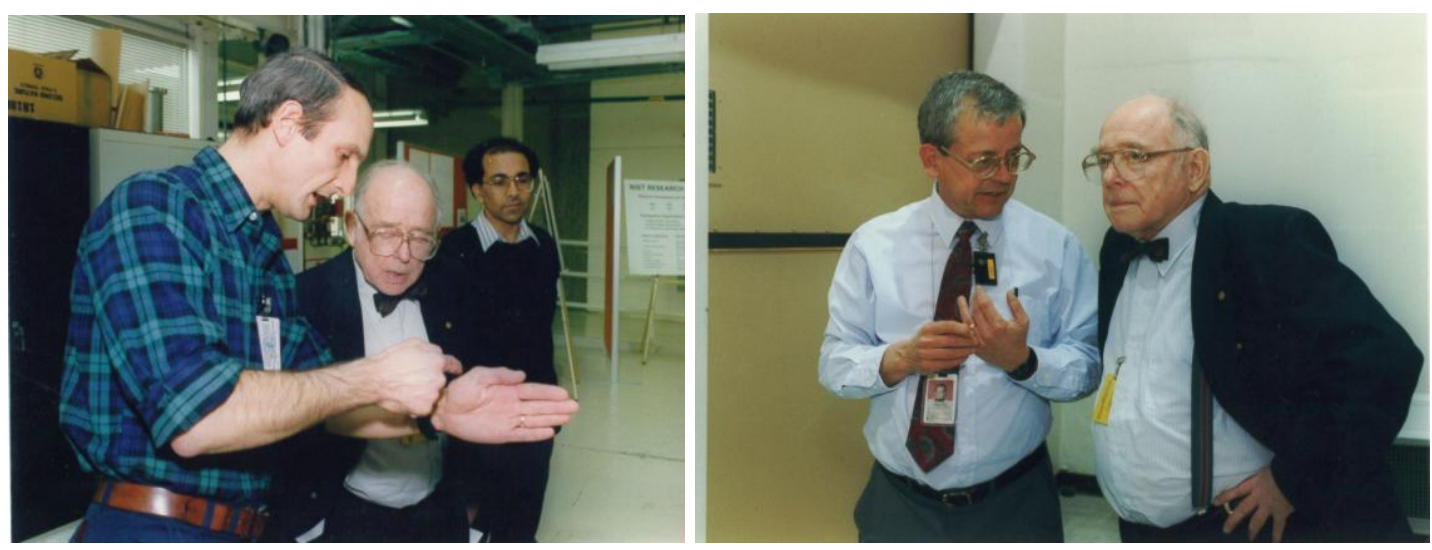

Cliff Shull, Nobel prize winner in 1994 for the development of neutron diffraction, visited the NBSR in 1995. Here he discusses NIST facilities and research with Chuck Majkrzak and Sushil Satija (left) and with Mike Rowe (right.)

As the NCNR approached the new century, it was nearing its capacity as a national user facility, which had transformed U.S. capabilities in cold neutron research, and quadrupled the number of participants at NIST to 1,750 per year, while rapidly expanding applications in many disciplines, with extraordinary impact on soft matter science and technology.

\section{Advances at the Turn of the Century}

By the year 2000, as the number of participants in research at the NCNR was continuing to grow, a new generation of instrumentation was being designed or commissioned. AND/R was under construction, as was the Johns Hopkins University/NIST/NSF Multi Axis Crystal Spectrometer (MACS), a next-generation facility for high intensity cold neutron studies of materials dynamics, led by Professor Collin Broholm. In addition, a state-of-the-art thermal neutron triple-axis spectrometer, which included a large double-focusing monochromator and several multidetector/analyzer systems, was being designed under Jeff Lynn's leadership. And the Physics Laboratory was engaged in developing the Neutron Imaging Facility (NIF), a new capability for neutron imaging of hydrogenous systems and components such as fuel cells.

Also in 2001 NIST/NBS celebrated its $100^{\text {th }}$ year as the nation's first federal physical science and engineering laboratory. The NCNR had become an important part of the NIST story, and Jack Rush was invited to give a lecture on the history of the NCNR at the special session of the 2001 March Meeting of the American Physical Society commemorating the NIST/NBS Centennial. In the early years of the new century, the NCNR received a new boost as Mike Rowe, Robert Williams, and Paul Kopetka completed the commissioning of a second generation hydrogen cold source in 2003 with an improved reflector and optics, which yet again doubled the intensity of cold neutrons for all the instruments in the guide hall. 

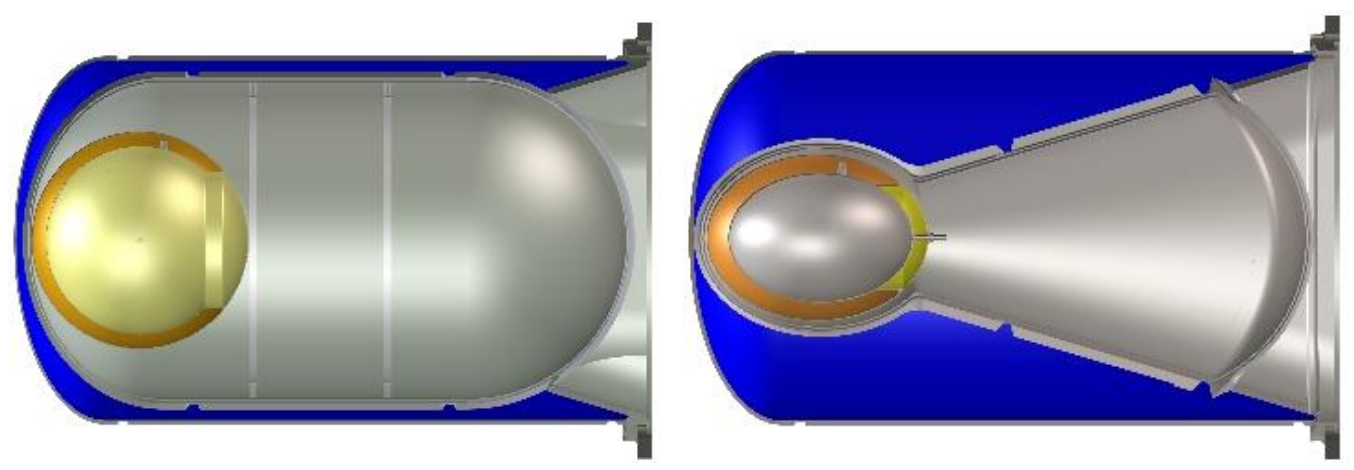

Schematic views of the hydrogen moderator cold neutron sources, which replaced the original $\mathrm{D}_{2} \mathrm{O}$ ice moderator. The original hydrogen source installed in 1995 increased cold neutron intensities by a factor of six. The second improved source (right) doubled available intensities in 2003.

\section{$\underline{\text { New Leadership Emerges }}$}

As the CNRF expanded rapidly in the 1990's, it became obvious that facility and science management needed to be updated to adjust to this growth and the complexity it engendered. So the Neutron Condensed Matter Science Group led by Jack Rush was divided into teams to reflect the great diversity of scientific efforts and instrumentation responsibilities at the NCNR. Team leaders were appointed to oversee Chemical Physics of Materials (Dan Neumann), Condensed Matter Physics (Jeff Lynn), Macromolecular and Microstructure studies-SANS (Charlie Glinka), Surface and Interfacial Science (Chuck Majkrzak) and (later) Crystallography and Diffraction Applications (Brian Toby). Pat Gallagher, who had come to the NCNR in 1993 as a post-doc instrument scientist, took over Mike Rowe's duties as Leader of Research Facility Operations, while Mike concentrated on his responsibilities as NCNR Director. At the same time, it became obvious that the great expansion of NCNR users required a professional system to evaluate and schedule the increasing number of research proposals and to publicize the increasing scientific accomplishments and information emerging from this research. Fortunately, during the 1990's Bill Kamitakahara from Ames Laboratory joined NCNR to take over proposal evaluation and scheduling, and in 1999 Ron Cappelletti, a professor of physics at Ohio University, agreed to join NCNR to coordinate scientific information activities. 


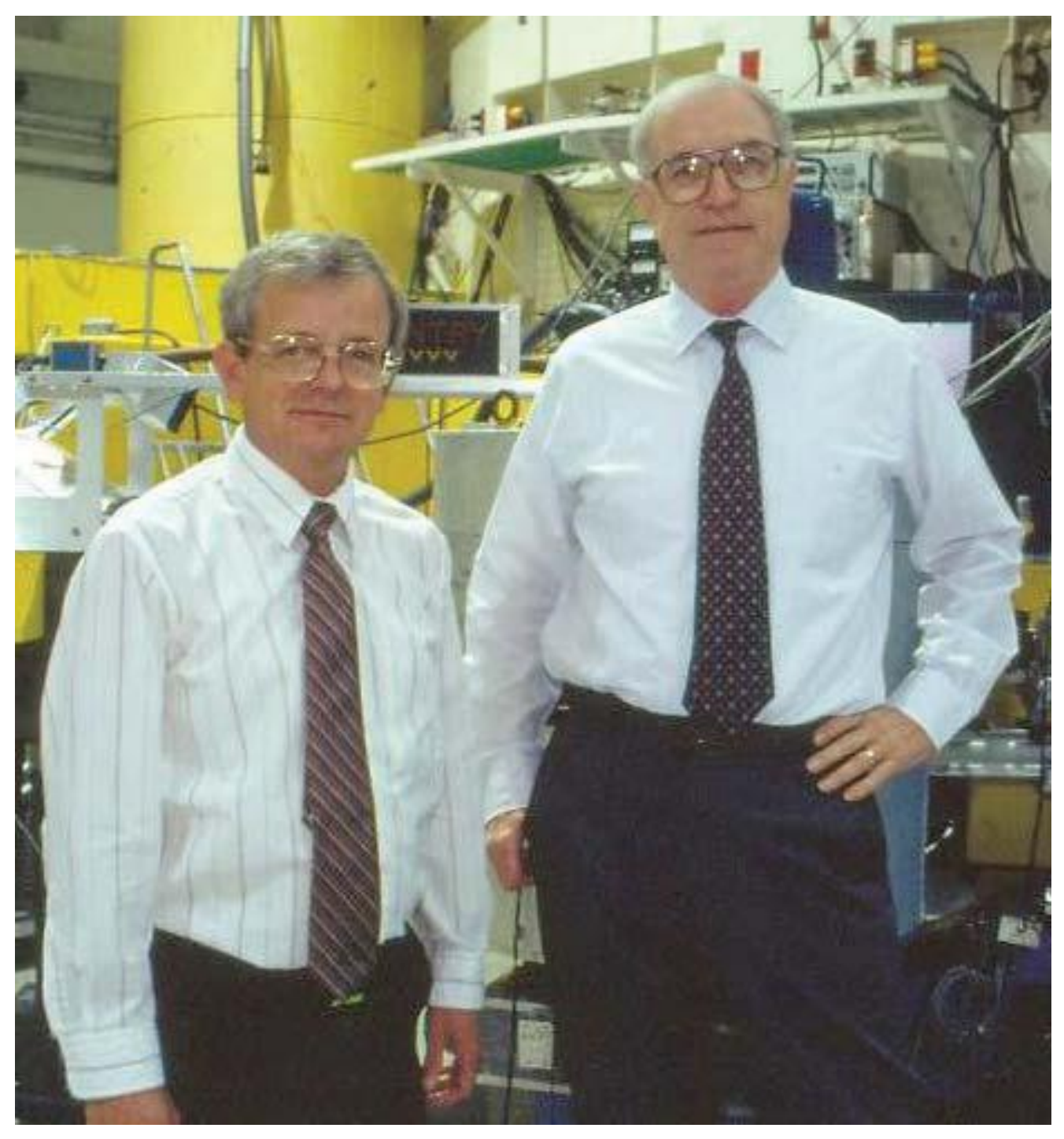

Mike Rowe and Jack Rush. A symposium honoring their leadership took place in 2005, shortly after both officially retired.

After the installation of the upgraded cold source in 2003, Mike Rowe decided to move toward retirement in 2004 and Jack Rush retired eight months later in January, 2005. This represented the end of their partnership in science and NCNR development, which had lasted over 35 years. Pat Gallagher, who had spent two very successful years on assignment to OSTP straddling the Clinton and Bush Administrations, was named Director of the NCNR in 2004 to replace Rowe. Dan Neumann replaced Rush as Leader of the large Science Group, which both carried out the broad NCNR science program and provided scientific and technical support and collaboration for users of the instrumentation of the NCNR. Rob Dimeo, who had come to NCNR as a neutron spectroscopist and instrument scientist for the HFBS (Backscattering spectrometer) and later led the development of the widely praised (and used) DAVE software system for analysis of neutron scattering data, replaced Charlie Glinka (who had filled in for Pat Gallagher) as Leader of the Facility Operations Group. Rob had also broadened his perspective in an assignment to OSTP before taking over as Group Leader. Finally, in 
2008 Pat Gallagher was appointed acting Director and later Director of NIST, and Rob Dimeo took his place as NCNR Director.

Both Mike Rowe and Jack Rush continue their service at the NCNR, Mike in a variety of engineering and advisory responsibilities and Jack as a researcher and adjunct professor under the University of Maryland/NCNR Cooperative Program.

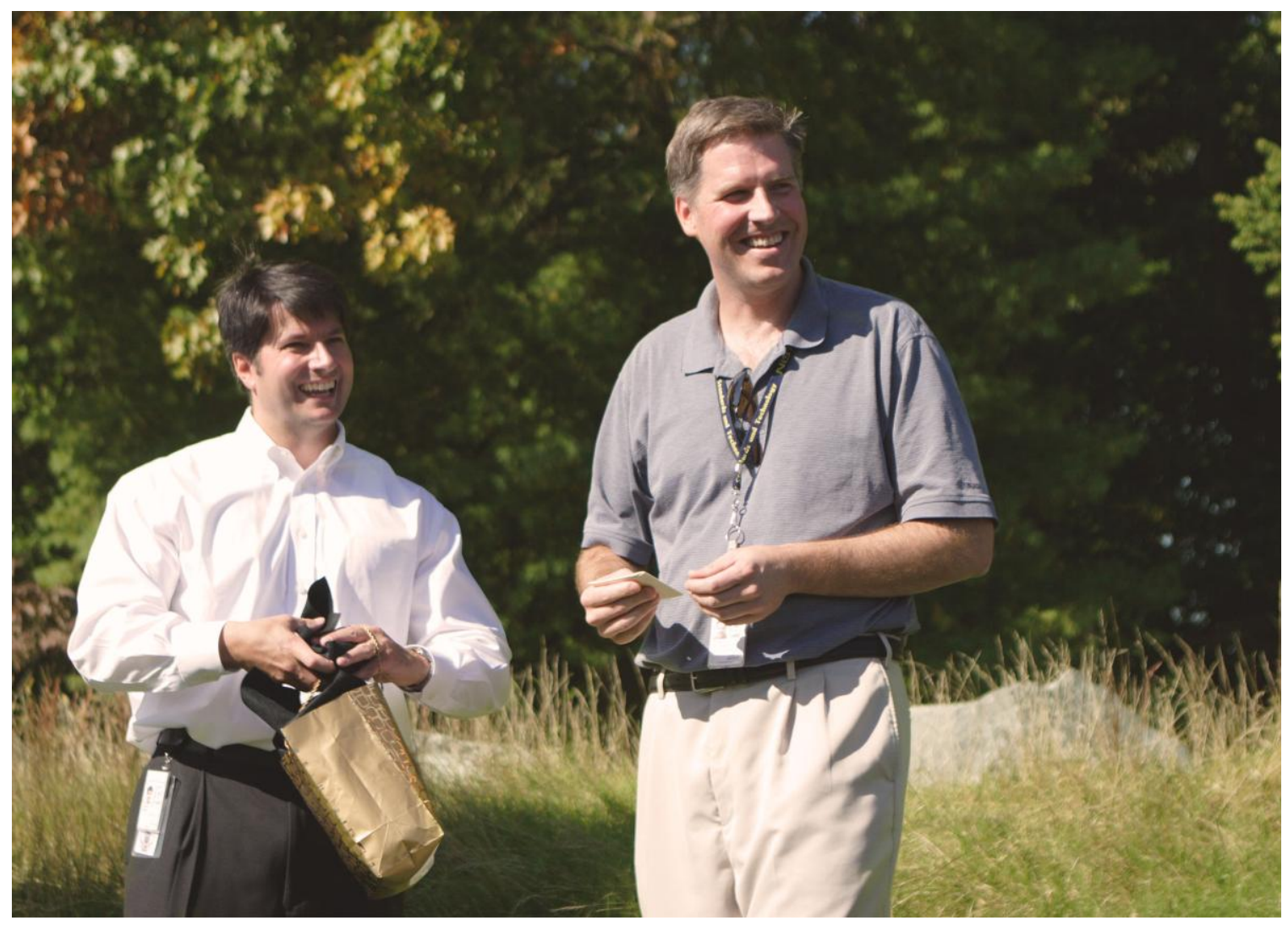

Rob Dimeo, current NCNR Director (left) and Pat Gallagher, previous NCNR director and now Director of NIST, at the groundbreaking ceremony of the second guide hall, October 2008. 


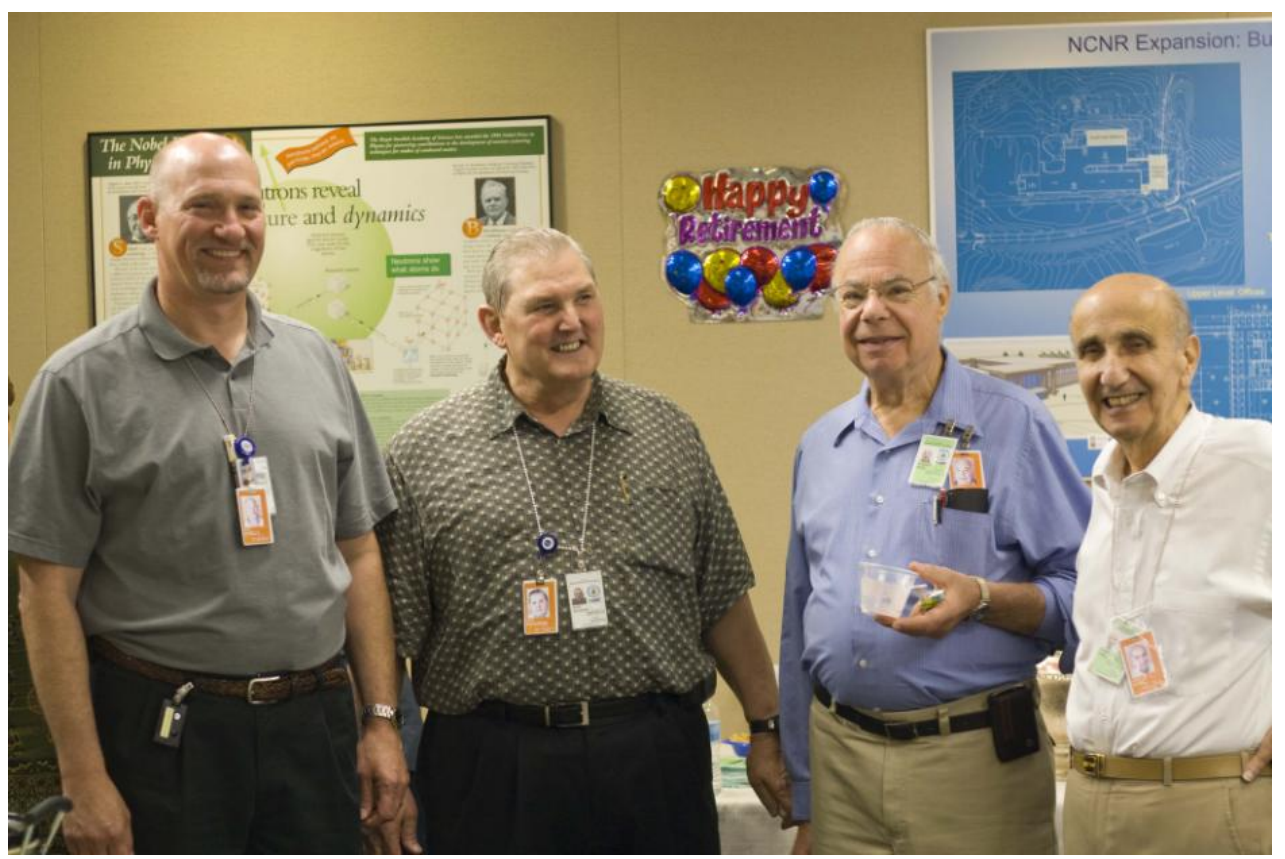

The leadership transitions at the NCNR also included changes in Reactor Operations and Engineering. Here we see Tawfik Raby, the original Chief of Reactor Operations (right) who retired as Chief in 2000 and was replaced over the past decade by (right to left) Sy Weiss, Wade Richards, and (in 2010) by Sean O'Kelly.

\section{The First Decade of the New Millennium}

The accomplishments of the past 10 years have expanded over broad areas of physics, chemistry, biology, materials science and engineering. Over 20 national awards have been received in the last decade related to work at the NCNR, as listed in the next section. Also notable was the establishment of major new cooperative research agreements with Indiana University (2005) on development of new instrumentation concepts and applications for cold neutron research and with the U. of Delaware (2007) on advanced metrology for structure and dynamics of soft matter.

Research over this period has led to 3000 publications and to major advances in many areas, including macromolecular structure, dynamics and interfaces; biological membranes; reflectometry methods; neutron imaging of fuel cells; the physics of new superconductors; correlated electron physics; frustration in magnets; and the structure and hydrogen dynamics in energy storage materials. The ten annual reports describing highlights of accomplishments at the NCNR in the last decade are included as references at the end of this brief history, and we urge the reader to consult those reports for a flavor of the achievements during this period.

A dramatic advance for the NCNR occurred in 2007, when Pat Gallagher was successful in obtaining DOC and Congressional approval for development of a second cold-neutron guide hall. Also in this decade three NCNR scientists became NIST Fellows - Jeff Lynn, Chuck Majkrzak, and Taner Yildirim. (Jack Rush had been named one of the original NBS Fellows in 1985.) 


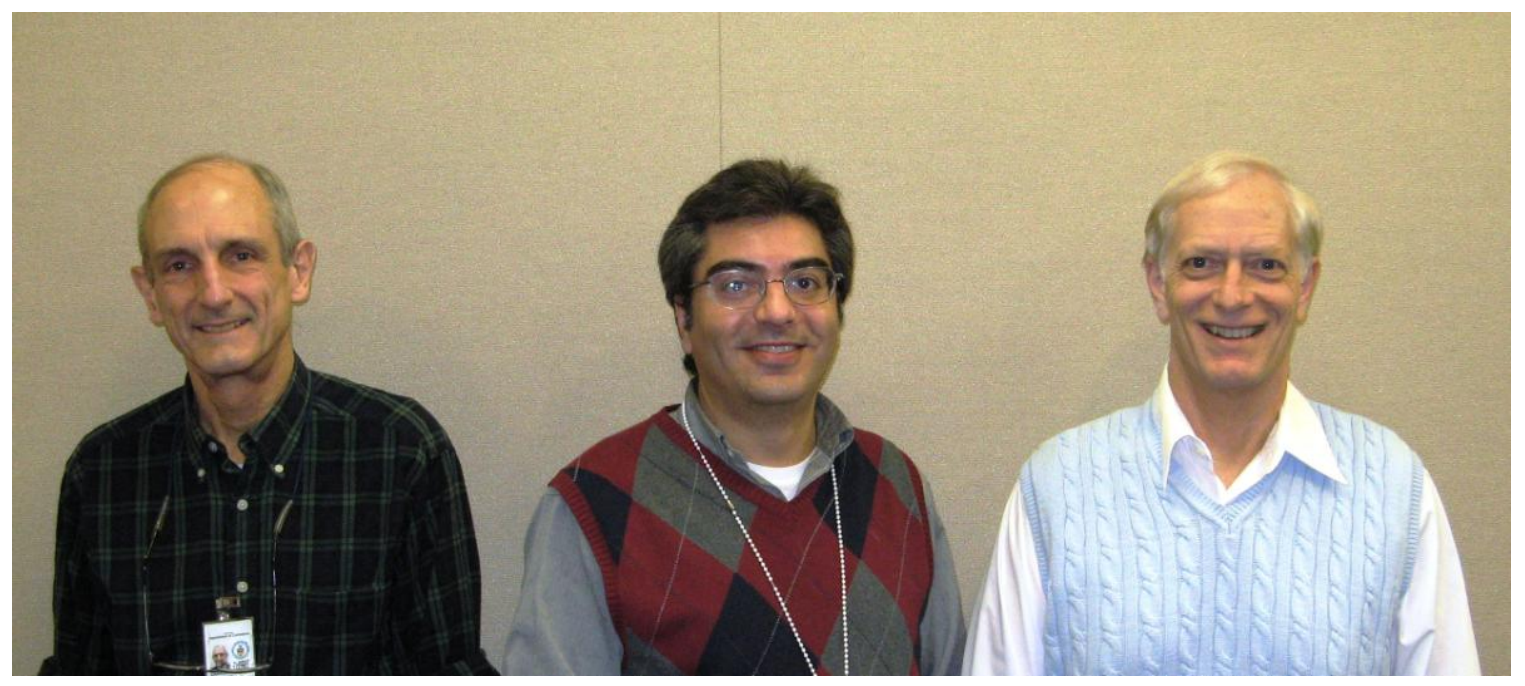

NCNR staff chosen as NIST Fellows during the last decade, from left, Chuck Majkrzak, Taner Yildirim, and Jeff Lynn.

\section{The NCNR: Measures of Success}

The scientific and engineering achievements exemplified above and in the references at the end of this brief history truly define the impact of the NBSR and NIST Center for Neutron Research in the past 42 years. But in this section we attempt to demonstrate in various ways the fruits of the research opportunities which the NCNR has provided for American science and technology (and for the international community). We also summarize the contributions of the NCNR to national needs for neutron measurement technology, in line with the mission of NIST.

\section{$\underline{\text { Research Participants and Publications }}$}

The scope and breadth of the service the NCNR has provided to the science and engineering community is demonstrated in the figure below, which displays the number of research participants for the facility over the past twenty years. These numbers represent the individual researchers (counted once) who come to the NCNR each year to perform neutron measurements, had direct daily access to the facility, or were co-authors of papers published in each year. These participants, who covered the fields of physics, chemistry, biology and materials science and a number of engineering disciplines, increased by a factor of more than 5 over 20 years. The number of participants in this period was far more than any other U.S. neutron facility. As shown in the insert, in 2010 these researchers came from over 250 technical organizations including 224 in the United States from 39 states and D.C. (representing 146 American universities, 46 corporations and 32 U.S. Government organizations). Over the years the number of industrial organizations using the NCNR has exceeded that for other neutron sources in the world, which is in line with the mission focus of the DOC and NIST. Other neutron facilities in Europe and Japan are also making great strides in this area. 


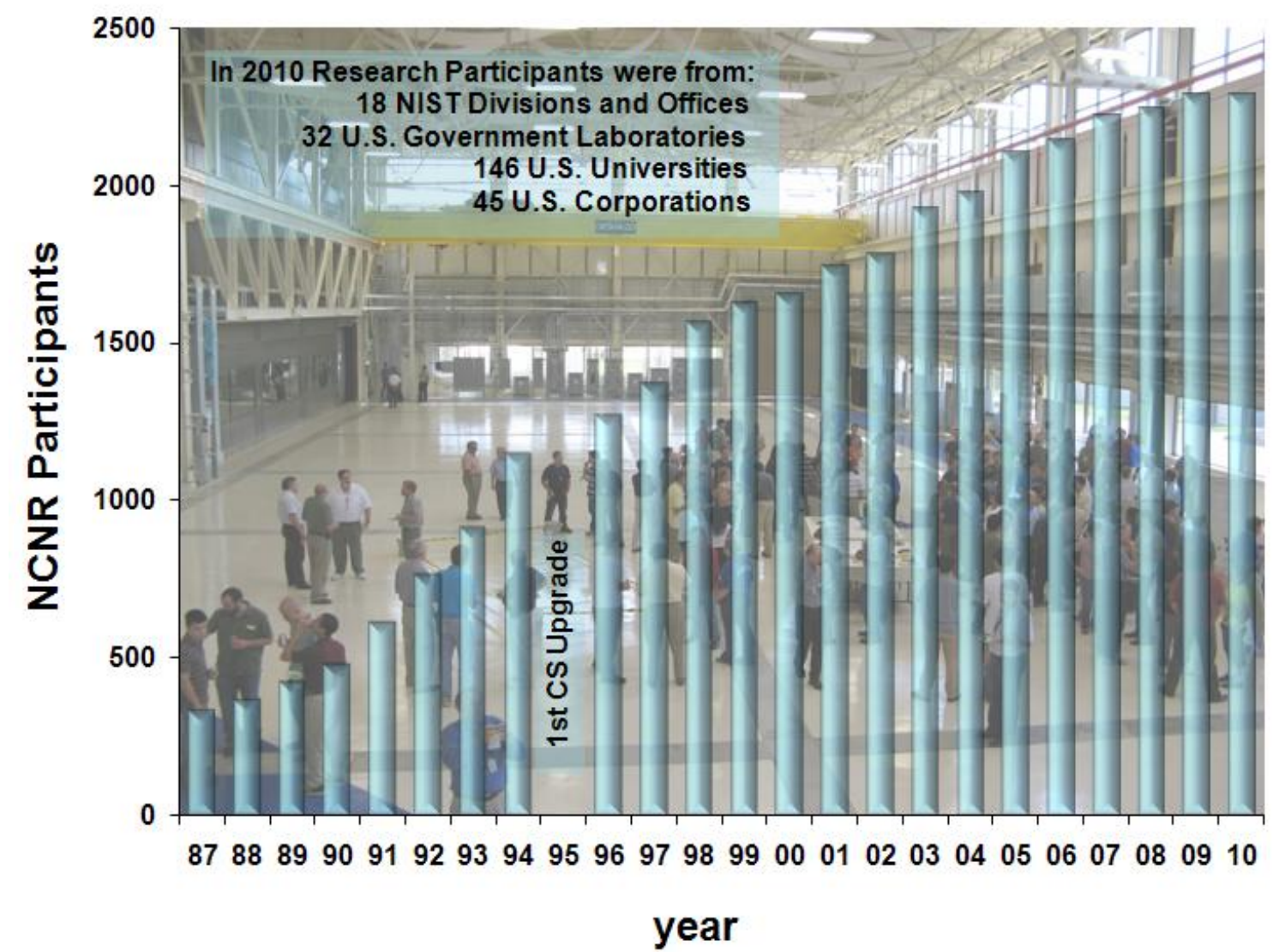

A plot showing the great increase in research participants at the NCNR since the cold neutron research facility was approved in FY 1987. A summary of the 224 U.S. organizations that used the NCNR in 2010 is shown as an inset. The recently completed second cold neutron guide hall space is shown in the background

Finally, as a measure of educational impact, NCNR has been a key national resource for graduate (and undergraduate) research. Many hundreds of PhD's have been granted based in whole or part on research at the NCNR, averaging about 40 per year in recent years.

One of the singular aspects of the success of the NCNR is the wide use of neutron measurements by other NIST laboratories and divisions in their own mission activities. Thus the NCNR in 2010 served the needs of 18 NIST divisions in many activities including polymer and biological structure, nanoscale structure of thin films, hydration of cements, residual stresses in metal and ceramic products, imaging of fuel cells, analysis of standard reference materials, and radiation standards.

A critical measure of the productivity of a research program or facility is the output and quality of research publications. Aside from many reports and special publications, the NCNR neutron facilities have produced over 6,000 archival publications, almost one-half of these in the last decade. In the last fifteen years the NCNR has been by far the most prolific of U.S. neutron sources. In the figure below, we show a comparison of the NCNR publication record for 2009 with the world's largest neutron facility, the ILL, which serves the wider European Community. The ILL has 40 
state-of-the art neutron beam instruments compared to the current number of 23 at the NCNR.

\section{NCNR Publications}

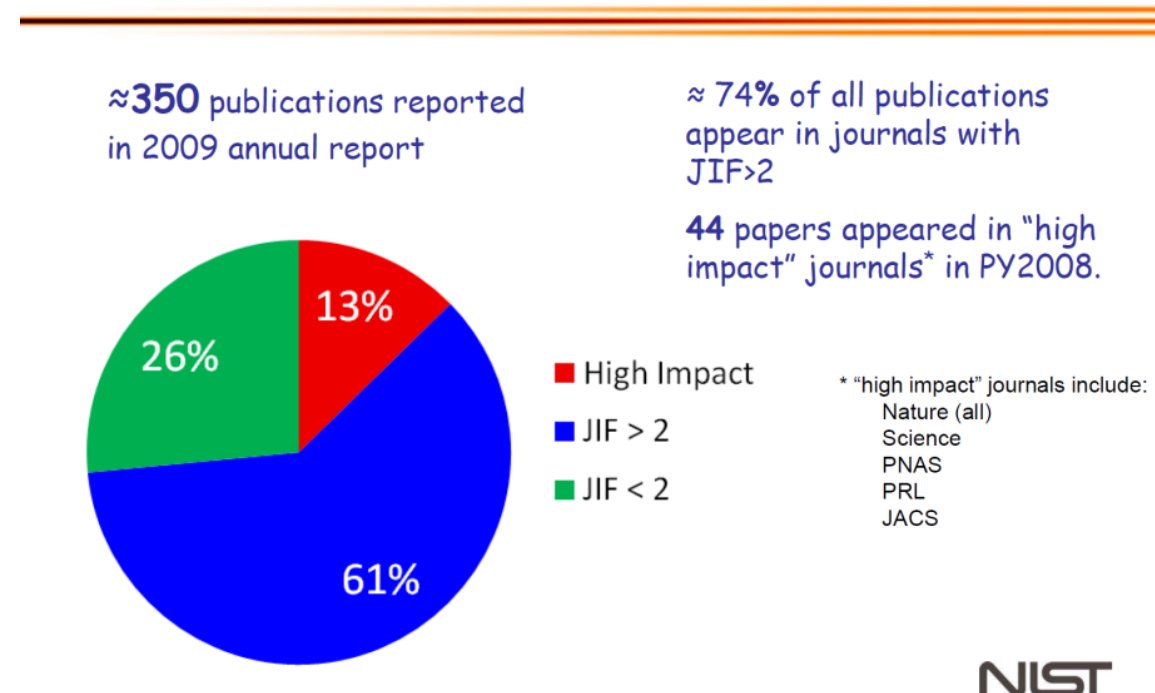

\section{Publications Reported by ILL}

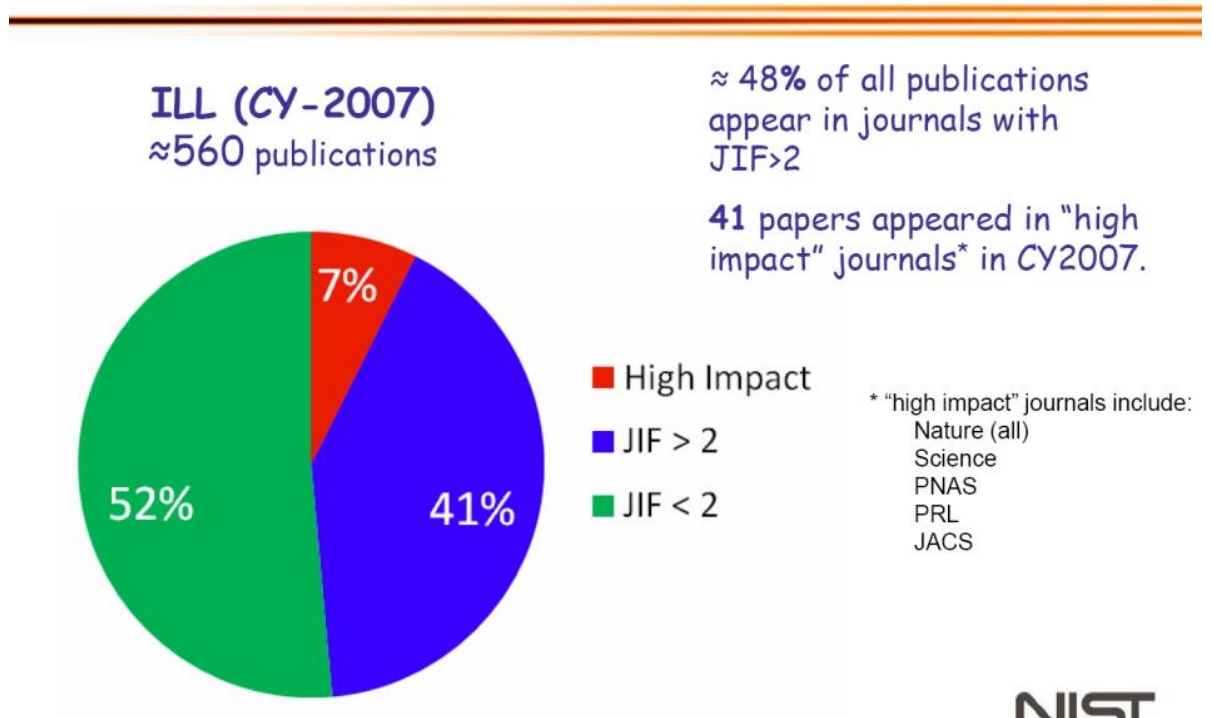

Summary of publication facts for the NCNR and the Institute Laue-Langevin at Grenoble. The NCNR had 23 operating neutron beam instruments in 2009 and ILL about 40. These data reflect the very strong position of the NCNR in recent decades in the number and impact of research publications per instrument when compared to the best neutron centers worldwide.

As shown in the figure, the total number of published papers per neutron instrument is about the same for NCNR and ILL. But the NCNR actually has a somewhat higher 
performance per instrument than ILL in research impact measures, including a similar number of papers in the highest impact journals and a higher percentage $(75 \%)$ of publications in journals with an impact factor greater than 2. Moreover, when expenditure per publication is included, the NCNR can be clearly identified as the world's most cost-effective neutron source.

It is worthwhile to note here that a critical factor in the success of the NCNR over the past 40 years is the outstanding record of the Reactor Operations and Engineering group. Except for scheduled reactor showdowns for power upgrades, cold source installations and large component replacements (e.g., heat exchangers and cooling towers), the NBSR staff has operated the reactor with close to $100 \%$ efficiency in scheduling and reliability.

\section{Awards Associated with the NCNR}

Another indication of the impact of the NCNR on U.S. Science and Technology is the recognition of the accomplishments of research participants by the national (or international) community. In this section we will summarize the external (to NIST) awards received by scientists and engineers for research and measurements related to neutron scattering at the NCNR. As can be seen from the list in the table below, over 30 national awards and prizes have been directly related to research at the NCNR (20 over the past decade) by a wide range of scientific and engineering organizations. Neutron research at NIST has also contributed to a number of other major awards over the years.

Major Scientific Awards for, or strongly influenced by, neutron research at the NBSR/NCNR

\begin{tabular}{llll}
\hline Year & Name & Award & Research Area \\
\hline 1984 & Charles Han, NIST & APS John H. Dillon Medal & Polymer Structure \\
1989 & Frank Bates, AT\&T & APS John H. Dillon Medal & Block copolymers \\
1992 & Alice Gast, Stanford U. & $\begin{array}{l}\text { Colburn Award (American } \\
\text { Inst. of Chemical Engineers) }\end{array}$ & Colloids and polymers \\
1997 & $\begin{array}{l}\text { Frank Bates, U. } \\
\text { Minnesota }\end{array}$ & APS Polymer Physics Prize & Structure of copolymers \\
1996 & Nitash Balsara, NYU Poly & APS John H. Dillon Medal & Properties of polymer blends \\
1998 & Eric Kaler, U. Delaware & ACS Award in Colloid and & Complex fluids \\
& & Surface Chemistry & \\
& & Spiros Anastasiadis, U. & APS John H. Dillon Medal \\
& & & $\begin{array}{l}\text { Structure and dynamics of } \\
\text { polymer solutions, melts and } \\
\text { films }\end{array}$ \\
\hline
\end{tabular}




\begin{tabular}{|c|c|c|c|}
\hline 1999 & Anne Mayes, MIT & APS John H. Dillon Medal & Polymer self-organization \\
\hline 1999 & Charles Han, NIST & APS Polymer Physics Prize & $\begin{array}{l}\text { Neutron scattering polymer } \\
\text { phase separation }\end{array}$ \\
\hline 1999 & $\begin{array}{l}\text { G. Robert Odette, U. } \\
\text { California, San Diego }\end{array}$ & $\begin{array}{l}\text { American Nuclear Society } \\
\text { Materials Prize }\end{array}$ & $\begin{array}{l}\text { Defects in pressure vessel } \\
\text { steels }\end{array}$ \\
\hline 2000 & Lewis Fetters, Exxon & APS Polymer Physics Prize & $\begin{array}{l}\text { Polymer entanglement, } \\
\text { miscibility and microphase } \\
\text { separation }\end{array}$ \\
\hline 2000 & Lewis Fetters, Exxon & $\begin{array}{l}\text { ACS Award in Applied } \\
\text { Polymer Science }\end{array}$ & $\begin{array}{l}\text { Polymer science and } \\
\text { applications }\end{array}$ \\
\hline 2004 & Mike Rowe, NIST & NSSA Clifford G. Shull Prize & Neutron scattering leadership \\
\hline 2004 & $\begin{array}{l}\text { Timothy Lodge, U. } \\
\text { Minnesota }\end{array}$ & APS Polymer Physics Prize & $\begin{array}{l}\text { Polymer chain diffusion and } \\
\text { dynamics }\end{array}$ \\
\hline 2005 & Chuck Majkrzak, NIST & ACA Warren Award & $\begin{array}{l}\text { Development and application } \\
\text { of neutron reflectometry }\end{array}$ \\
\hline 2005 & Tom Russell, U. Mass & APS Polymer Physics Prize & $\begin{array}{l}\text { Pioneering research on } \\
\text { polymer surfaces and } \\
\text { interfaces }\end{array}$ \\
\hline 2006 & $\begin{array}{l}\text { Sow-Hsin Chen, et al., } \\
\text { MIT, NIST }\end{array}$ & PNAS Cozzarelli Award & $\begin{array}{l}\text { Outstanding publication in } \\
\text { engineering and applied } \\
\text { science }\end{array}$ \\
\hline 2006 & Taner Yildirim, NIST & NSSA Science Prize & $\begin{array}{l}\text { Coupling of neutron } \\
\text { scattering and first-principles } \\
\text { theory }\end{array}$ \\
\hline 2007 & Robert Greenberg, NIST & $\begin{array}{l}\text { George Hevesy Medal } \\
\text { Award }\end{array}$ & $\begin{array}{l}\text { Applied nuclear and } \\
\text { radiochemistry }\end{array}$ \\
\hline 2007 & $\begin{array}{l}\text { Darrin Pochan, U. } \\
\text { Delaware }\end{array}$ & APS John H. Dillon Medal & $\begin{array}{l}\text { Physics of synthetic } \\
\text { polypeptides }\end{array}$ \\
\hline 2008 & Sow-Hsin Chen, MIT & NSSA Clifford G. Shull Prize & $\begin{array}{l}\text { Dynamical properties of } \\
\text { supercooled and interfacial } \\
\mathrm{H}_{2} \mathrm{O}\end{array}$ \\
\hline 2008 & $\begin{array}{l}\text { Tom Trabold, Jon } \\
\text { Owejan and Jeffrey } \\
\text { Gagliardo, (General }\end{array}$ & $\begin{array}{l}\text { Charles L. McQueen Award } \\
\text { (General Motors) }\end{array}$ & Neutron imaging of fuel cells \\
\hline
\end{tabular}




\begin{tabular}{|c|c|c|c|}
\hline & Motors) & & \\
\hline 2008 & $\begin{array}{l}\text { Frank Bates, U. } \\
\text { Minnesota }\end{array}$ & $\begin{array}{l}\text { NSSA Sustained Research } \\
\text { Prize }\end{array}$ & $\begin{array}{l}\text { Structure and } \\
\text { thermodynamics of polymer } \\
\text { fluids and copolymers }\end{array}$ \\
\hline 2008 & $\begin{array}{l}\text { Seung-Hun Lee, U. } \\
\text { Virginia }\end{array}$ & NSSA Science Prize & $\begin{array}{l}\text { Innovative studies of } \\
\text { frustrated magnetic systems }\end{array}$ \\
\hline 2009 & $\begin{array}{l}\text { Stephen White, U. } \\
\text { California, Irvine }\end{array}$ & $\begin{array}{l}\text { Avanti Award in Lipids } \\
\text { (Biophysical Society) }\end{array}$ & $\begin{array}{l}\text { Membrane structure and } \\
\text { protein insertion }\end{array}$ \\
\hline 2009 & Richard Lindstrom, NIST & $\begin{array}{l}\text { George Hevesy Medal } \\
\text { Award }\end{array}$ & $\begin{array}{l}\text { Radioanalytical measurement } \\
\text { science }\end{array}$ \\
\hline 2009 & Rolf Zeisler, NIST & $\begin{array}{l}\text { American Nuclear Society } \\
\text { Radiation Science and } \\
\text { Technology Award }\end{array}$ & $\begin{array}{l}\text { Neutron activation techniques } \\
\text { in research and SRM } \\
\text { production }\end{array}$ \\
\hline 2009 & Taner Yildirim, NIST & $\begin{array}{l}\text { Tübitak Award, Republic of } \\
\text { Turkey }\end{array}$ & $\begin{array}{l}\text { Special Award in fundamental } \\
\text { science }\end{array}$ \\
\hline 2010 & $\begin{array}{l}\text { Collin Broholm, Johns } \\
\text { Hopkins U. }\end{array}$ & $\begin{array}{l}\text { NSSA Sustained Research } \\
\text { Prize }\end{array}$ & $\begin{array}{l}\text { Correlated electron physics in } \\
\text { magnets, metals and } \\
\text { superconductors }\end{array}$ \\
\hline 2010 & Craig Brown, NIST & NSSA Science Prize & $\begin{array}{l}\text { Hydrogen-framework } \\
\text { interactions in metal-organic } \\
\text { frameworks }\end{array}$ \\
\hline 2010 & Hui Wu, NIST & $\begin{array}{l}\text { Sidhu Prize, Pittsburgh } \\
\text { Diffraction Society }\end{array}$ & $\begin{array}{l}\text { Structure of energy storage } \\
\text { materials }\end{array}$ \\
\hline
\end{tabular}




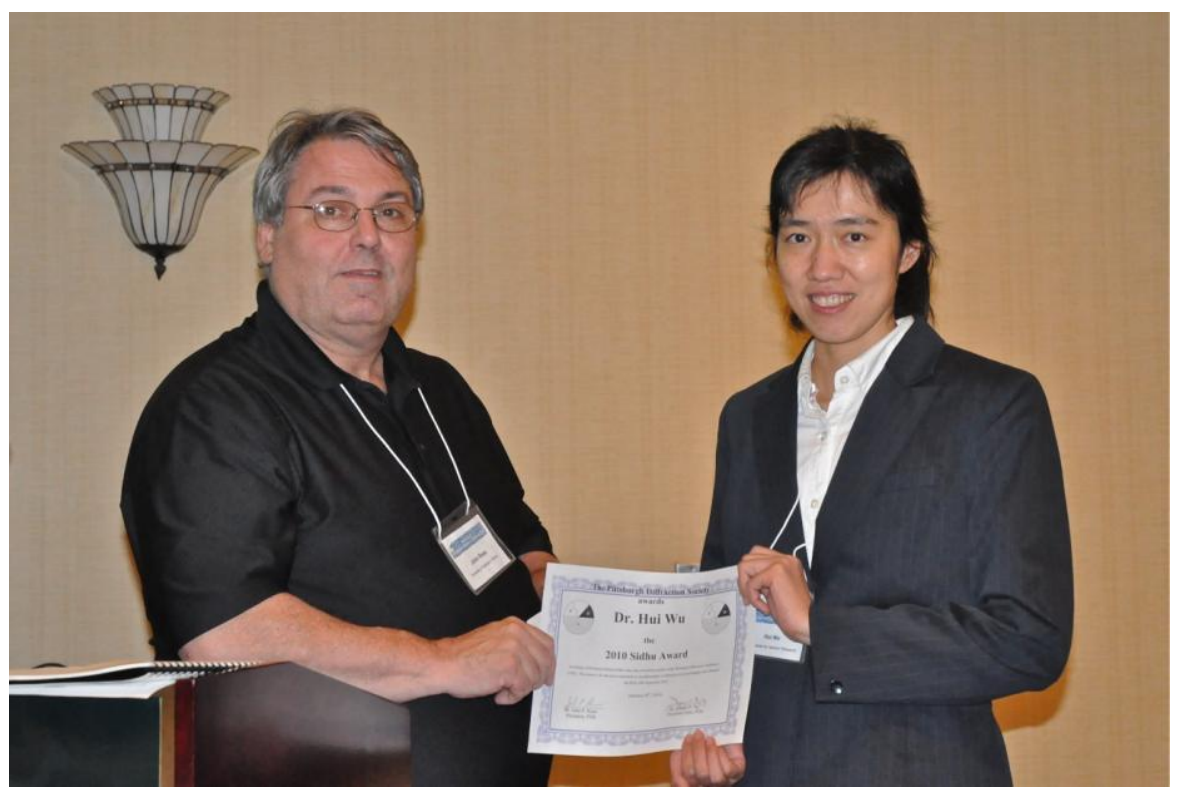

Hui $\mathrm{Wu}$, right, a research scientist in the joint U. of Maryland/NCNR neutron research program, receives the 2010 Sidhu Prize from John P. Rose, president of the Pittsburgh Diffraction Society. Dr. Wu was recognized for her outstanding research at the NCNR on the structure and properties of materials for energy storage.

It is notable that seven out of ten major prizes of the Neutron Scattering Society of America (NSSA) since 2004 have been awarded for research and scientific leadership at the NCNR. In the last decade many awards for outstanding research have also been given to graduate students and post-doctoral researchers performing research at the NCNR (including awards from the APS, ACS and Sigma Xi, and the NSSA). In addition, well over 100 NIST and Department of Commerce Awards have been granted for achievements at the NCNR, including six NIST annual Stratton Awards for excellence in research. 


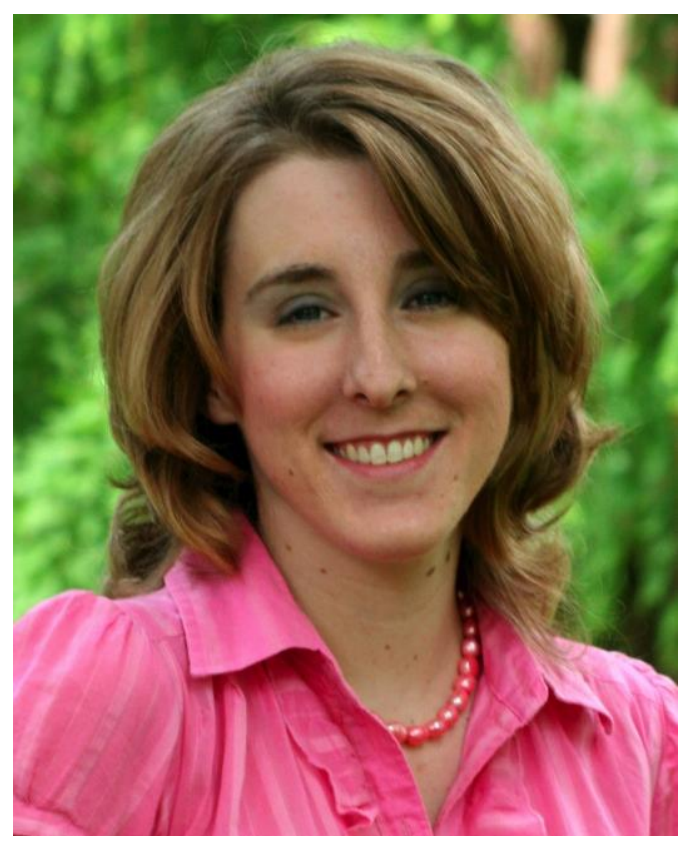

New faculty member Susan Fullerton Shirey of Notre Dame received the 2009 Frank J. Padden, Jr. Award from the American Physical Society for "excellence in polymer physics research" for her doctoral dissertation work at Pennsylvania State University. This award is one of a large number received by students and post-docs for research performed at the NCNR.

\section{Neutron Measurement Science and Technology}

By providing state-of-the-art neutron measurement capabilities over the decades to thousands of researchers from U.S. universities, industries and government organizations, the NCNR has obviously played a vital role in helping carry out the mission and goals of NBS/NIST. In this section we summarize a number of the unique contributions of the NCNR to the development of neutron measurement methods to advance science and technology, some of which have been mentioned earlier in this historical review. The NIST advances in neutron measurement techniques cover a wide variety of fields and applications and have involved the participation of a number of divisions at NIST, as well as many outside collaborators.

Perhaps the most important growth area for neutron scattering over the past 30 years is the use of cold neutrons to measure the nanostructure and microstructure of materials by SANS and neutron reflectometry. The applications have been across-theboard, in areas ranging from soft matter (e.g., polymers and complex fluids, ) to biology (e.g., membranes, proteins) to magnetic solids and devices. Here the NCNR has developed perhaps the best overall set of measurement capabilities worldwide. Moreover, NIST scientists have created new measurement techniques to allow higher resolution, higher intensity SANS measurements. These include multi-beam focusing methods and the use of multiple lenses (developed with Bell Laboratories) to improve resolution and provide higher intensity for smaller length-scale features. Scientists at the NCNR, notably John Barker, have also developed the premier ultra-high resolution 
SANS (USANS), which extends the size range of neutron microstructure measurements by a factor of almost 100, and is having high impact on industrial research.

NIST is also widely acknowledged as an international leader over the past 20 years for studies of surface and interfacial structures (e.g., of polymer thin films, biomembranes, and magnetic multilayers) by neutron reflection, and for measurement advances and theoretical methods to assure the accuracy and uniqueness of structures derived from reflectivity data. For example, the NCNR reflectivity team has developed new approaches for the control of sample environments in order to greatly reduce background, and was the first to achieve $10^{-8}$ neutron reflectivities, which provide more precise and better resolved surface structures. They have further extended interfacial structure determination by using new supermirror transmission and ${ }^{3} \mathrm{He}$ polarizers. NCNR scientists have also made a major contribution to enable direct studies of a number of interfacial systems, including biological membrane structures, by solving the phase problem inherent in reflection measurements. The NCNR reflectivity team is also developing new methods for more powerful and sensitive reflectivity measurements in the second cold neutron guide hall under construction. These will be discussed in the final section of this review.

As mentioned earlier, in the area of neutron diffraction NCNR staff members have made a number of advances in measurement techniques for structure determination. These include the first neutron measurements (with Navy and Army researchers) of stress/strain relationships in solids, which set the stage for several decades of progress in depth-dependent residual stress measurements, with many critical applications in the processing, properties and safety of industrial and defense products. NCNR scientists also developed a "flat-cone" diffractometer, which was the key to one of the first neutron measurements of protein structure. Over the years NCNR staff members have also contributed state-of-the art advances in refinement techniques and computer packages to assure accuracy and efficiency in crystallographic determination of materials structure.

In the last 3 decades the NCNR has also been highly creative in developing new measurement and instrumentation concepts for inelastic neutron scattering studies of the dynamics of materials. As described previously, NIST and U. Maryland staff successfully developed a high-flux cold neutron backscattering spectrometer using the phase-space transform method. NCNR scientists also developed a Filter Analyzer Spectrometer (FANS) which achieved extraordinary sensitivity for studies of neutron vibrational spectroscopy, including broad applications in catalysts, hydrogen storage materials, and metal-hydrogen systems. In recent years, a team of researchers from NIST and John's Hopkins University developed a cold-neutron spectrometer (The Multiple Analyzer Neutron Spectrometer-MACS) which, using a large double focusing monochromator, has unsurpassed cold neutron intensity, and opens up new measurement capabilities for studying small samples of new magnetic solids and many other materials. Similar capabilities have been achieved with a new thermal neutron spectrometer which also uses a large double focusing monochromator and multi-analyzers and detectors. 


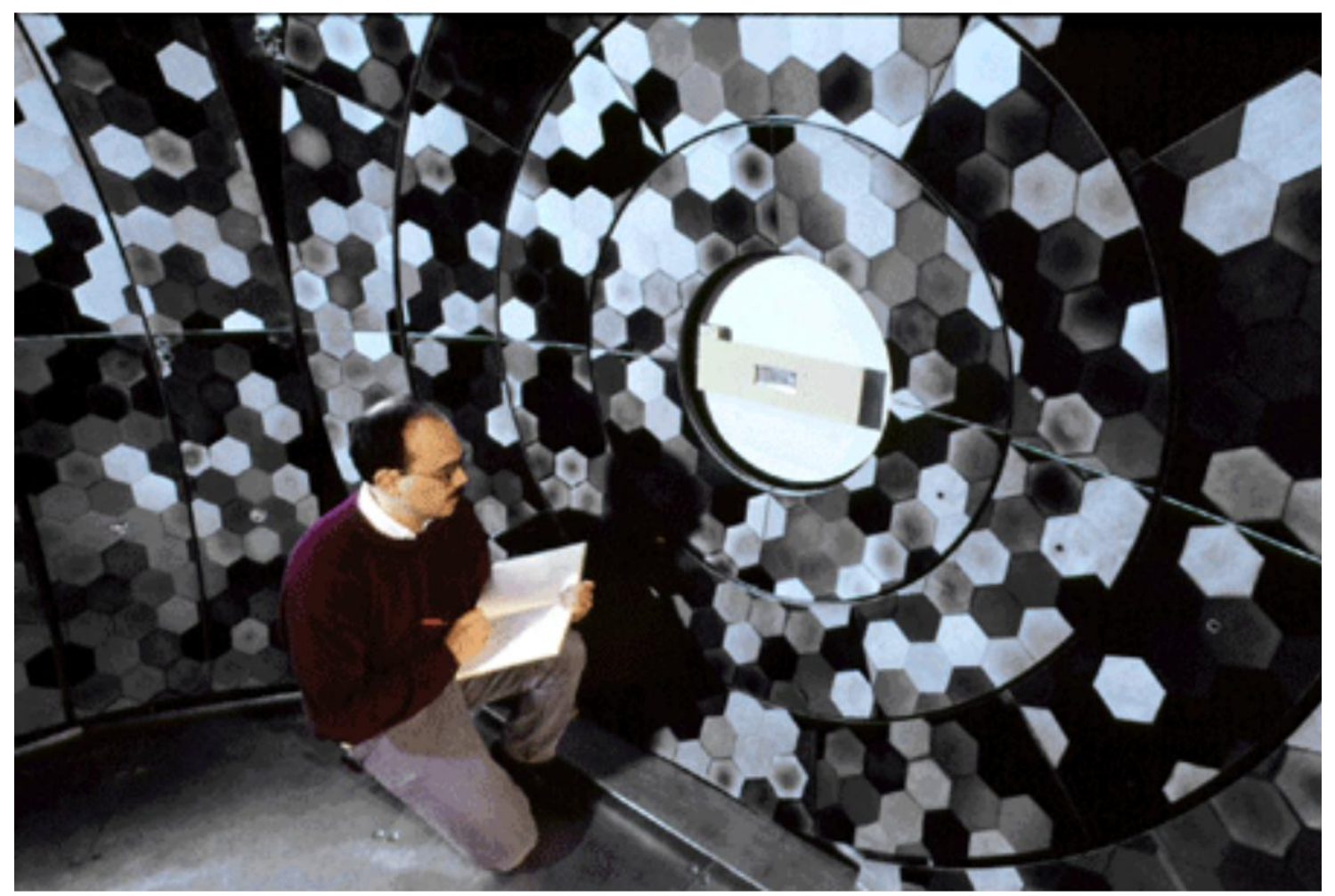

NCNR's Dan Neumann checks the large array of single crystal silicon wafers that forms the focusing analyzer of the High Flux Backscattering Spectrometer he helped design.

As noted earlier, there have also been major contributions to neutron measurement science by other NIST Laboratories. For example, the Nuclear Methods Group of the Chemical Science and Technology Lab has been one of the international leaders in the application of neutron activation techniques for chemical and materials analysis, including an active role in producing standard reference materials for industry and science. This group has been particularly creative and successful in the development of neutron beam methods for materials analysis. They have refined the method of prompt gamma analysis (for extremely sensitive detection of elements - especially hydrogen which release a gamma ray upon neutron absorption). These advances have made major contributions to NIST (and NIST user) programs in chemistry, materials science and physics. They have also pioneered the use of focused beams to enable microprobe analysis of small samples. As mentioned earlier, a similar success has been achieved by Nuclear Methods scientists in the development of cold-neutron depth profiling of thin films. These methods, opened up at NIST, have led to even greater advances at neutron centers in Europe and Japan. 


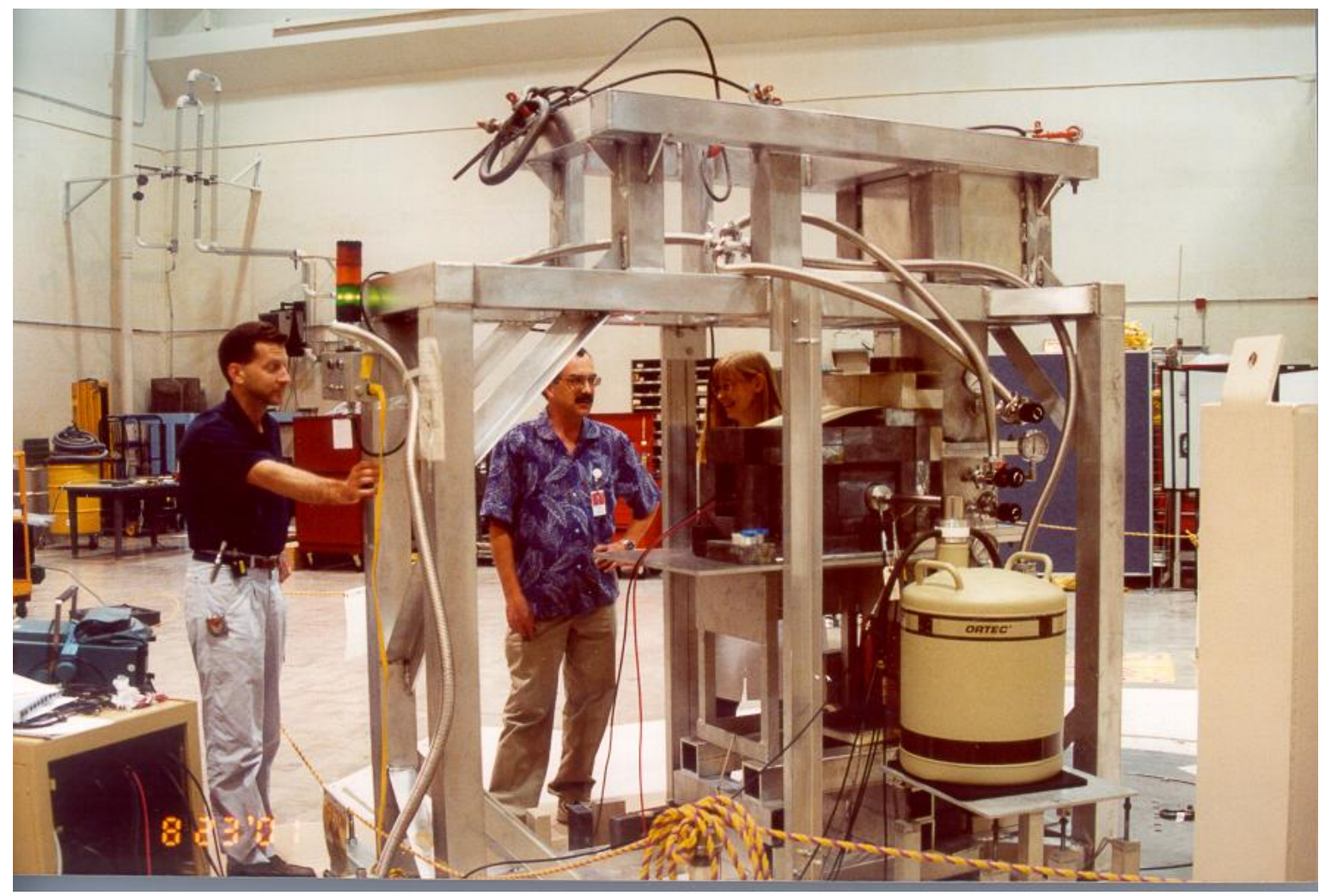

Elizabeth Mackey (partially hidden, right) of the NIST Nuclear Methods Group discusses a chemical analysis experiment on the thermal beam prompt-gamma ray spectrometer at the NBSR with David Anderson (center), FDA scientist in residence at NIST, and engineer Paul Liposky.

Finally, it should be noted that the Neutron Interactions and Dosimetry Group in the Physics Laboratory (with various organizational names) has been carrying out research and dosimetry activities at the NBSR for 40 years. Most particularly, since the development of the cold neutron guide hall, this Group has been an international leader in developing fundamental neutron measurement capabilities. They have designed and constructed the world's premier neutron interferometry facility and continue to apply it to fundamental measurement advances, from high precision measurements of neutron coherent scattering amplitudes, to the development of phase contrast radiography. In collaboration with General Motors, the Neutron Interactions Group has developed a stateof-the-art facility for the imaging of hydrogenous systems, such as fuel cells, including major advances in resolution and detection efficiency. Group scientists have also carried out an outstanding program for development of ${ }^{3} \mathrm{He}$ spin filters to produce high efficiency polarized beams for materials structure research with neutrons. 


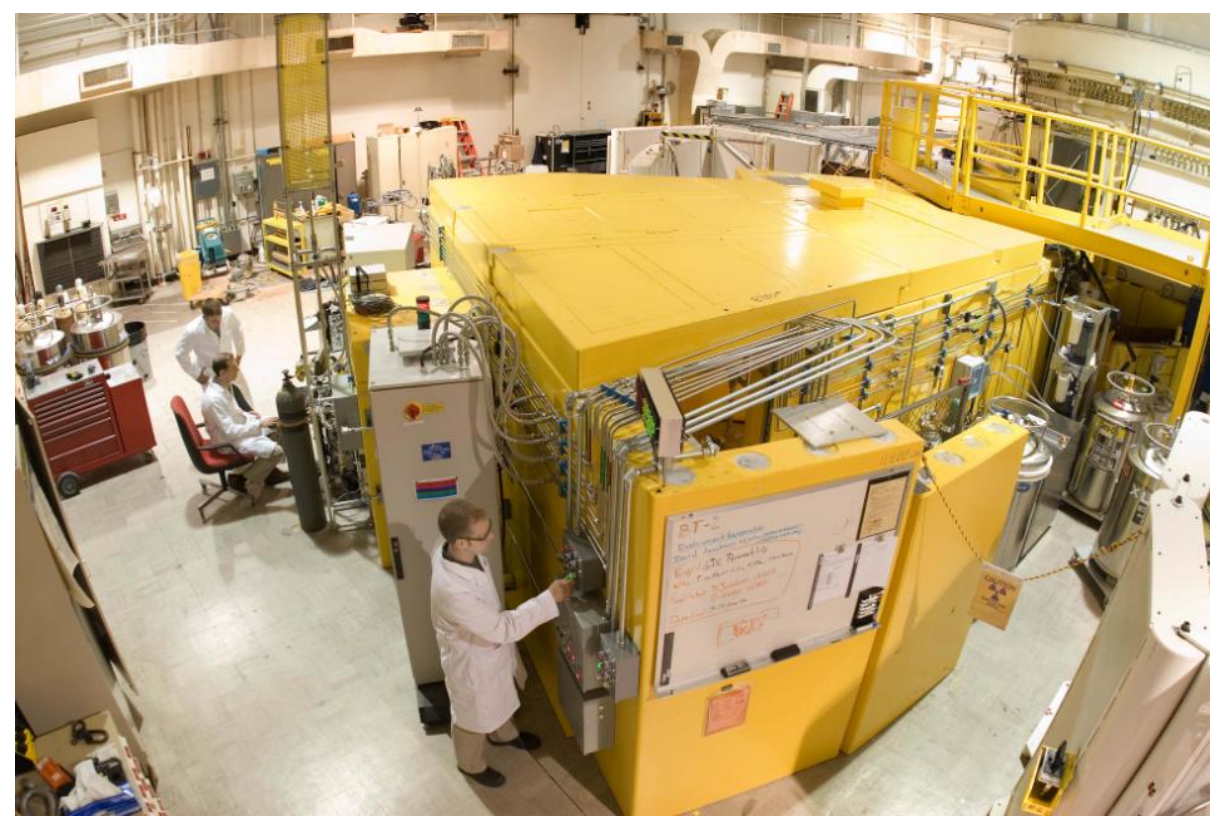

NCNR's David Jacobson stands before the Neutron Imaging Facility that has played a unique role in revealing the flow of product water during the operation of fuel cells being developed by the automotive industry for alternative vehicles. NCNR's Dan Hussey (seated) and Eli Baltic are at the controls at the left. This facility was developed in a partnership between NIST and GM, and is available for use by other U.S. researchers.

\section{Other Perspectives}

Before looking to the future, we shall discuss two important factors in the development of the NCNR. First we review the impact of the support and engagement of NBS/NIST and DOC management over the years. Next we present an overview of the functioning of the NCNR as a national user facility.

\section{$\underline{\text { Role of NIST/NBS and Department of Commerce Management }}$}

One of the key aspects of any large venture in science and engineering, such as development of the NCNR, is the support and involvement of upper management in providing overall planning, oversight and resources, hopefully without "micromanagement" tendencies. In this regard the management environment and support received by the NBSR and the NCNR have been, by and large, extraordinary. This relatively benign and supportive management has extended over eleven NIST/NBS directors, along with comparable changes in DOC leadership, from the inception of the NBSR project over 50 years ago to the current leading role of the NCNR as a national facility.

Among the civilian agencies which have large portfolios in science, engineering and technology, the DOC is perhaps the most unusual. In spite of having in the National Oceanic and Atmospheric Administration (NOAA), NIST and the U.S. Patent office over $\$ 6 \mathrm{~B}$ in major technical activities to oversee, the DOC's central mission is to advance U.S. 
economic development through a variety of responsibilities, including technology enhancement. Other civilian departments and agencies which support science and technology and major laboratories and facilities, such as DOE, NSF and NIH, have central administrations that are largely composed of scientists and engineers. Perhaps the more eclectic mission of the DOC, and the fact that NIST and NOAA are line-item funded units in the DOC budget, has provided more operational autonomy over the years, aside from issues of security and fiscal oversight. Certainly the Director of NIST and the NOAA Administrator have a somewhat greater level of independence than the Directors of the DOE National Laboratories, who by Departmental structure and program funding systems are more subject to management by DOE headquarters.

Whatever the reason, Allen Astin, who was NBS Director from 1954 to 1969, made the central decision (with substantial assistance from his staff) to build the NBSR, and managed to convince three separate DOC Secretaries and Congress to provide funding for its development and staffing. During this same period, Astin also managed to obtain support for two other large ventures, the $100 \mathrm{MeV}$ Electron Accelerator and the Joint Institute for Laboratory Astrophysics (JILA) in Boulder, and to move NBS to a new large site in Gaithersburg, Maryland - all a testament to his low-keyed, but highly effective judgment and leadership. Almost without exception, the ten other NBS/NIST Directors who have followed Astin in the last 40 years have made important, sometimes decisive, contributions to the progress of the NCNR, or at least have done no harm to the enterprise. For example, Ernest Ambler, who was Director during the decisive years from 1974 to 1989, was not originally enthusiastic about the NBS reactor, but ultimately provided the support and leadership which advanced the capabilities of the NBSR and helped make the Cold-Neutron Research Facility possible. He presented the FY'79 initiative to DOC to double the power of the NBSR, which was a necessary step for all future improvements at the reactor. As previously noted, in 1979 he chose the proposal by the NBSR to develop one of the first small angle neutron scattering facilities in the U.S. as one of the first three projects to be funded under the new "Competence" program approved by Congress. Finally Ambler strongly supported the major initiative in FY '85 to develop the CNRF, which ultimately was funded in FY' 87.

Also extremely important to the success of the NBSR and NCNR has been the timely support and efforts of NBS/NIST leadership below the Director's level, and occasionally the direct help of DOC officials. For example, Jordan Baruch, the Assistant Secretary of Commerce for Technology, was very helpful in the success of the FY '79 initiative to double the power of the NBSR. Jack Hoffman, the Director of the Institute for Materials Research, was highly supportive of both the $20 \mathrm{MW}$ upgrade and the Competence award in 1979 to develop SANS. Hoffman was an internationally recognized polymer physicist, who understood the great impact of neutrons for polymer research. As previously mentioned, a few years later Bob Mehrabian, Director of the Center for Materials Science, was a vigorous and timely supporter of the proposal to DOC for the Cold Neutron Research Facility.

Perhaps the most essential efforts in advancing the development of the NIST Center for Neutron Research over a period of two decades were made by Ray Kammer, first as Deputy to Directors Ernest Ambler and Arati Prabhakar and last as NIST Director. Kammer's support during the planning, funding and construction phases of the Cold Neutron Research Facility was critical to its success and later achievements. Among his many contributions was his personal role in assuring the enthusiastic support 
of the Deputy Commerce Secretary Clarence Brown during the 1984-1987 period, when the fate of the project was in the balance. Lyle Schwartz, the Director of the Materials Science and Engineering Laboratory also strongly supported the CNRF during this critical period and approved the change in status (particularly for budget purposes) of the Reactor Radiation Division to the NIST Center for Neutron Research in 1997.

After the Ambler era, NIST Directors continued to directly advance the progress of the NCNR. John Lyons (1989-1993) was an enthusiastic supporter during the early years of the CNRF. As Director of the National Engineering Laboratory, he had (in 1986) testified to Congress that the CNRF project was important enough that he would accept losses in his own Laboratory to assure approval for its funding. Arati Prabhakar (1993-1996), whose main attention was given by necessity to the new Advanced Technology Program, which was given very high priority by the Clinton Administration, was enthusiastic about the CNRF and approved Ray Kammer's continuing focus on its success.

Later NIST Directors and Acting Directors also took actions which made great contributions to the accomplishments of the NCNR. Acting Director Karen Brown strongly supported a budget initiative in FY 2000, which ultimately provided funds for the modernization of NCNR instrumentation. Director Arden Bement, who recognized the broad importance of NCNR in American science, arranged a celebration of the achievements of the facility in 2002 on the Guide Hall floor with the Deputy Secretary of DOC, the President's Science advisor, the Director of the NSF, and high-level representation from DOE, NIH, ExxonMobil Corporation, and others in attendance. In 2005, Acting Director Hratch Semerjian approved the action which led to the NCNR becoming a major operating unit of NIST. And finally, in 2006 Director Bill Jeffrey vigorously supported the successful $\$ 100 \mathrm{M}$ proposal to develop a second NCNR guide hall with next-generation measurement capabilities. 


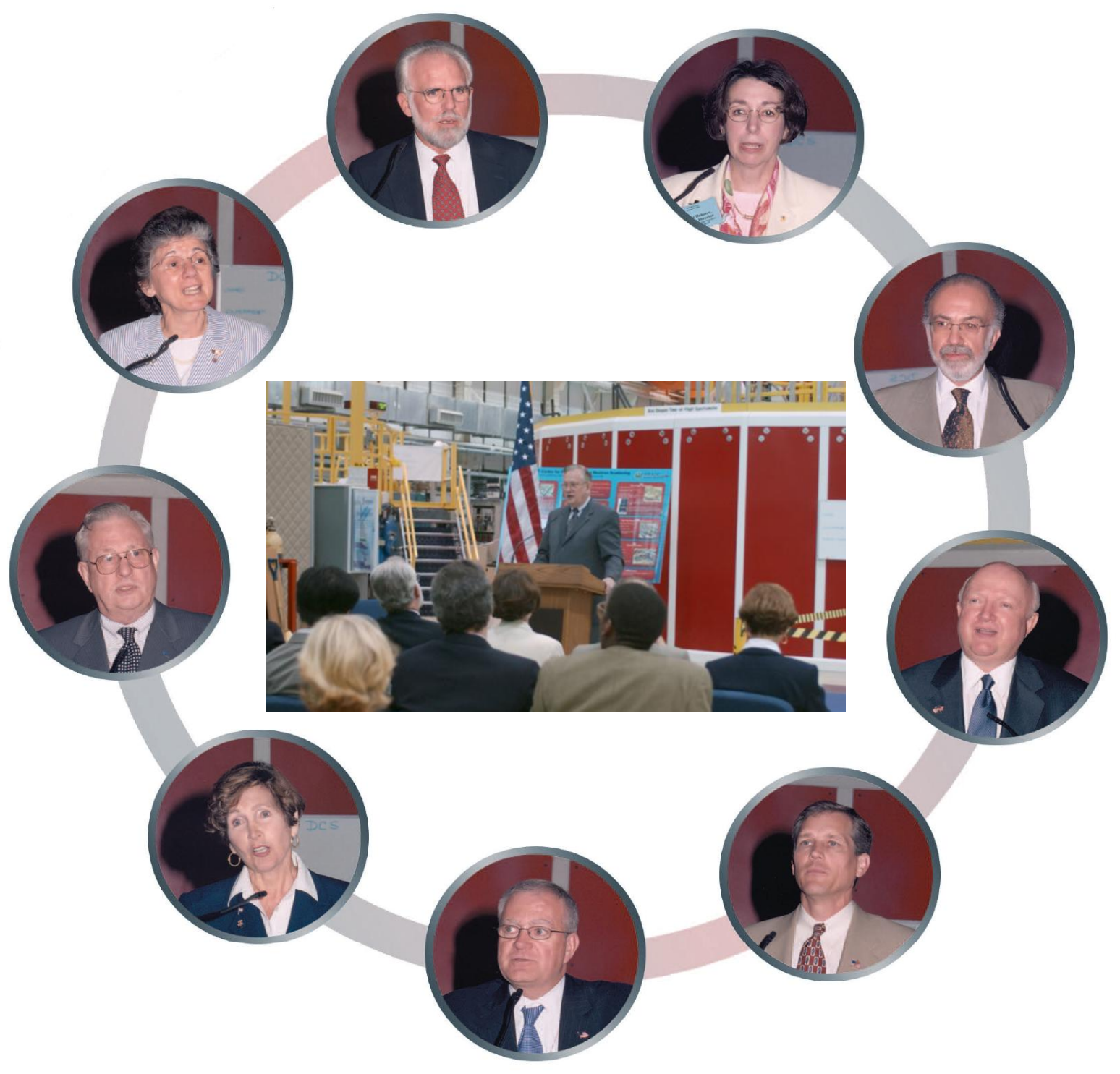

NIST Director Arden Bement (center) addresses attendees at the 2002 celebration of the NCNR and its accomplishments. Among those in attendance, moving clockwise from bottom center, were John Marburger, Director of the White House Office of Science and Technology Policy; Representative Constance Morella, R-Maryland, $8^{\text {th }}$ Congressional District; Arden Bement; Rita Colwell, Director of NSF; Michael Marron, Director of Biomedical Technology NCRR at the NIH; Patricia Dehmer, Associate Director of Office of Basic Energy Sciences at the DOE; Roger Cohen, Manager of Strategic Planning Programs at Exxon-Mobil Research and Engineering Co.; Samuel Bodman, Deputy Secretary of Commerce; and Philip Bond, Undersecretary of Commerce for Technology/ Chief of Staff Department of Commerce. 
It should also be noted that during the critical period between 1985 and 1995 the Director of the NBS/NIST Budget Office, Tom Gary, and a cadre of superb budget analysts (e.g., Joanne Beck, Joyce Brown, and Susan Austin) were an invaluable resource working with Ebbie Maxwell and Denise Sullivan, who were the NCNR Budget Officers during this time.

This long history of strong, timely, and often proactive support of the NBSR and NCNR by DOC and NIST upper management was obviously critical to its achievements as a national resource. In fact without this direct and active support, the NCNR would not have succeeded.

\section{User Facility Operation: Outreach and Training}

The evolution of the NCNR as the nation's premier user facility for neutron research is also worthy of some discussion. As noted earlier, the Intense Pulsed Neutron Source (IPNS) at Argonne was the first U.S. neutron source that operated as a national "user" facility (starting in 1981), with neutron instruments largely scheduled for use on the basis of reviewed experimental proposals by scientists and engineers. It should be noted that all of the major neutron sources in the U.S. had also welcomed outside "users" before that time, but mainly in a collaborative mode, based on mutual interests and on agency missions.

The CNRF came on line in a user mode in 1991 and grew rapidly in the next decade in both available instruments and research participants. The decision was made when the CNRF was funded to design a user mode which differed somewhat from the systems at IPNS and the ILL in Grenoble, France. The NIST system generally reserves two-thirds of the time on "user" instruments for proposal-based experiments and onethird for NIST research, collaborative or otherwise, which matches the NIST mission and the ability of instrument scientists to advance their capabilities and careers. This division of instrument scheduling time is (at least officially) different from the IPNS and ILL models, which dedicate about $90 \%$ of available time to proposal-based research.

Another decision made early on was that only those instruments at the NBSR and CNRF which had adequate funding to support instrument scientists and technical staff were run in a "user" mode. Somewhat different arrangements for allocating instrument time were also created for participating research team instruments, which involved capital and operating funding by outside groups, and for the CHRNS; and a scheduling system requiring full-cost recovery was devised to allow proprietary research by industrial organizations.

A more subtle, but key factor fostering the success of the NCNR as a user facility was the system established in the early days of the NBS reactor which required all scientific staff to "give back" to the facility. Thus all NBS/NIST researchers were expected to contribute some of their efforts to support improvements in research capabilities to serve the broader community. This cooperative tradition helped the NCNR to move more easily and effectively into a national user mode.

Very important, in fact essential, to the success of the CNRF/NCNR as a national user facility was the system devised to inform the science and engineering community of the opportunity to make research proposals and to assure fair and timely evaluation of these proposals and feedback to the proposers. Bill Kamitakahara, a physicist with 
neutron research experience at Iowa State University and Oak Ridge National Laboratory and other neutron sources, and experience as a staff scientist at both DOE and NSF came to NIST in 1990 to develop and implement the proposal system. As a results of Bill's hard work and dedication, the NCNR has organized biannual meetings of experts to assign instrument time based on the ranking of proposals, each of which receives at least three external reviews. Many thousands of proposals have been reviewed (currently about 800 per year), and up to this time the NCNR has been able to serve three times the number of researchers per year compared to any other U.S. neutron facility, past or present. The NIST system has received high praise over the years from research participants, as has the software for instrument operation and for data analysis and evaluation.

As befits its role as a user facility, the NCNR has for two decades engaged in various outreach activities, including an annual hands-on workshop for 30 to 40 young scientists and students to learn and directly experience cold-neutron research by experiments using the state-of-the art SANS, reflectivity and cold neutron spectroscopy instrumentation in the guide hall. This program has been a major success, and over $70 \%$ of the scientists and engineers who receive training return to the NCNR to perform neutron research as their careers advance.

A vital part of the "user" experience at the NCNR is training in the safe and effective use of NCNR laboratories and their equipment for sample preparation and manipulation, under the guidance of Yamali Hernandez, Leader of User Services, and her team. The Health Physics team at the NCNR also plays a key role in assuring safe neutron research and has developed over the years a benign, but thorough, set of procedures and instruction for all NCNR users.

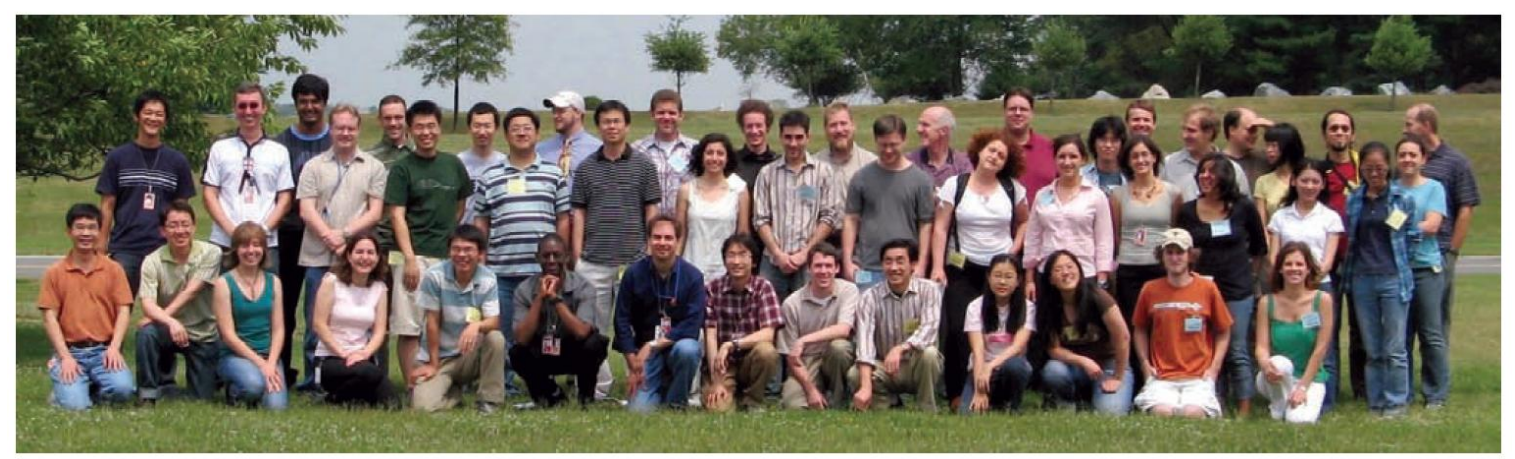

Student participants and NIST staff at the 2007 Summer School and Workshop on Cold Neutron Spectroscopy. 


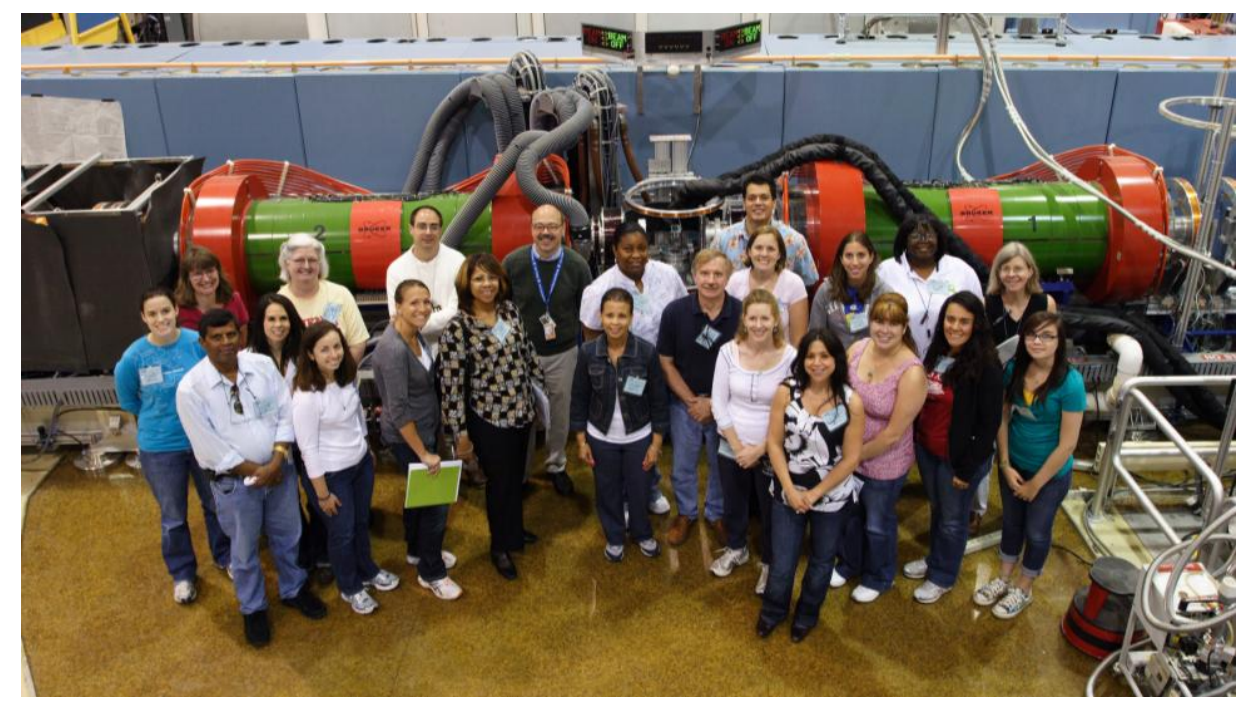

Science teachers and NCNR/CHRNS staff during the NCNR Summer Institute for Middle School Science Teachers, 2009.

Thus the NCNR has over the years developed a highly successful system to guide and facilitate the research performed by thousands of scientists and engineers who have utilized the facilities at the Center. There is more to be done, however, to increase the productivity of the scientific community in making use of the facility. There are three segments to this effort that are under development. The first is to provide ever improving measurement capabilities commensurate with our reactor source. The second is to make available ever friendlier software for data reduction and analysis. The third is to make archived data available to the community. The first part is well underway in the NCNR expansion. Instruments such as CANDOR, vSANS, and MAGIk are being built to make efficient use of cold neutrons in a way that is focused on serving the community that has grown up with the NCNR, particularly for soft matter and biology. The second aspect that began with the DAVE (Data Analysis and Visualization Environment) project and continues with the DANSE (Distributed Data Analysis for Neutron Scattering Experiments) project is to focus on software developments that invite the creation of an expanding community by making it easy for researchers from less traditional disciplines, such as earth science, to profit from the facility. The theme of serving the science/technology community is, of course, directly in line with the mission of the Department of Commerce of which NIST and the NCNR are a part. The third segment, presenting archived data, is also underway. Currently the NCNR raw data archive system includes all instruments in the scattering suite. In addition to a highly available file server, the system has a searchable catalogue which matches the raw data to the experiment responsible for its production. To promote better access of facility users to raw data, the archived data are mirrored to a web server (http://www.ncnr.nist.gov/ncnrdata). Users wishing to keep their experiment data private for the 18 month fair use period may opt out of the mirror process. Beyond that period, archived data becomes "public" and may be mined by the community for use in other studies. 


\section{Future Prospects}

\section{New Capabilities in the Second Guide Hall}

The decision in 2006 to fulfill the cold neutron potential of the NCNR by proposing to the DOC the development of a second guide hall was a great success for Pat Gallagher and the rest of the NCNR staff. In FY 2007 the DOC and Congress approved the first funding of the $\$ 100 \mathrm{M}$ project, including a new, 1500 square meter guide hall with an expanded office/technical wing, a second cold neutron source, an optimized guide tube network and five next generation instruments for cold neutron research, with some capacity for future growth. As shown below, the second guide hall project not only provides totally new instrumentation, but allows the rearrangement of existing and new instruments to provide maximum flexibility and neutron intensity for instruments in both guide halls.

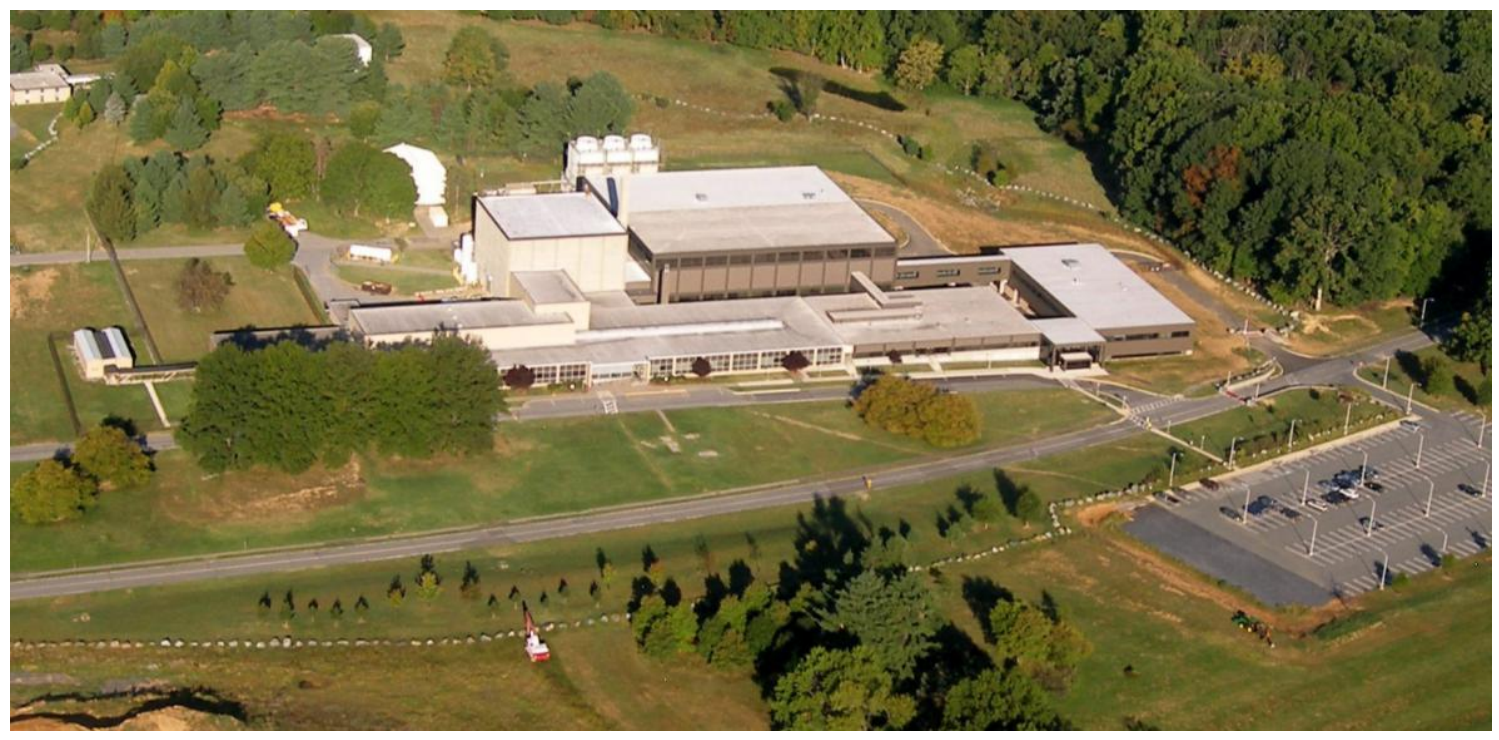

Aerial view of the NCNR in September, 2010, showing the expanded guide hall (lighter roof color at the back) and the new K-wing office complex on the far right.

The array of new instruments at the NCNR, which will come on line between 2012 and the end of 2014 will open up great new science and measurement opportunities for American researchers, particularly in the areas of soft matter research, magnetism, fundamental physics, and materials structure and imaging. The MACS machine, to be placed on its own dedicated, high-brightness cold neutron source, will be the highest flux cold neutron crystal spectrometer in the world for studies of low energy excitations in solids. The CANDOR "white beam" reflectometer/diffractometer will provide well over an order of magnitude increase in measured intensity for low wave-vector reflection and diffraction studies of all classes of thin films and multilayers, while the MAGIk instrument uses new methods to "tag" multiple incident cold neutron beams, combined with position sensitive detectors to greatly increase sensitivity and data rates, particularly for off-specular scattering which reveals the in-plane structure of thin films. 


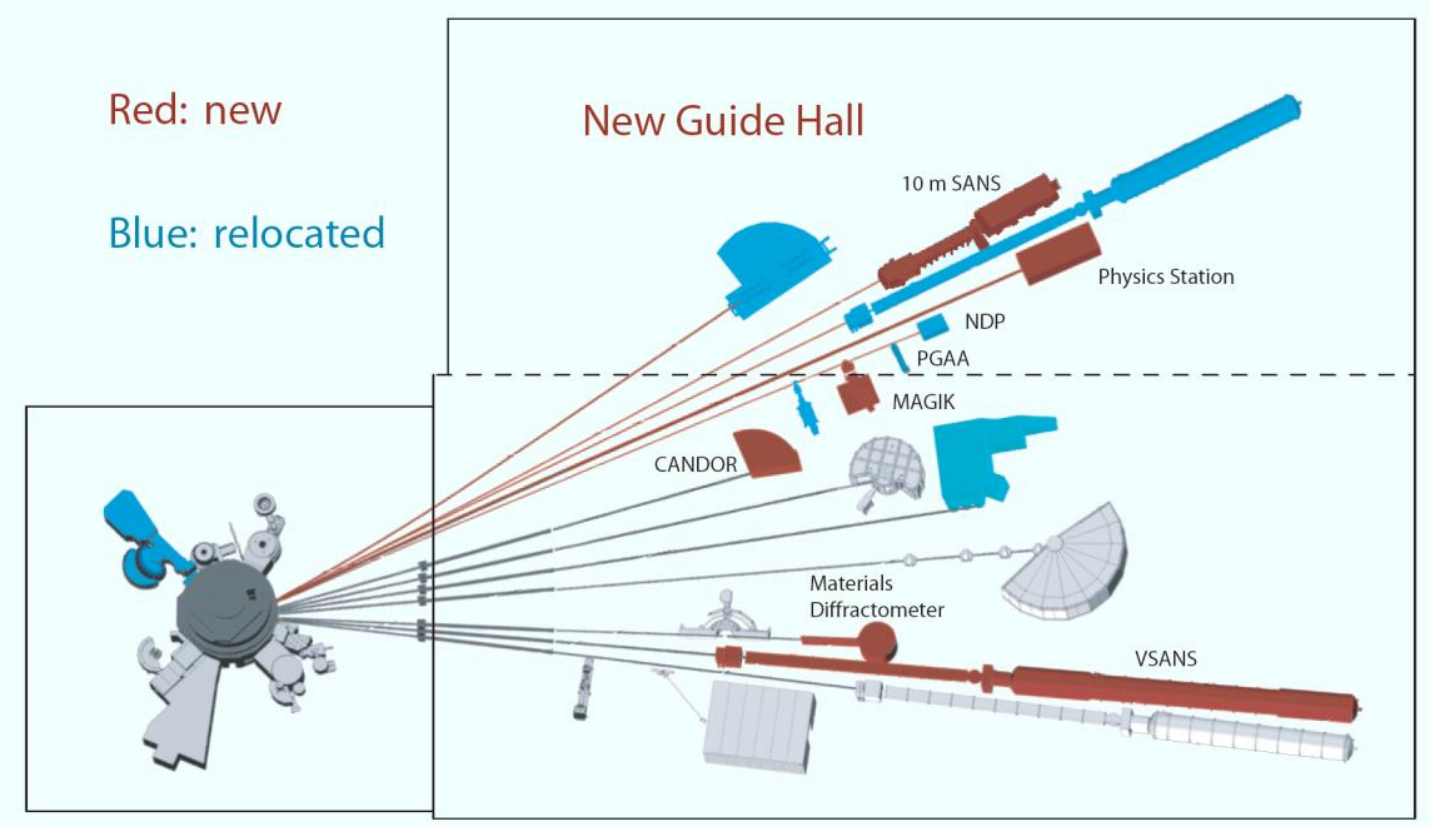

Schematic array of the cold neutron instruments expected to be operational in the expanded NCNR guide hall at the end of 2014.

The $40 \mathrm{~m}$ vSANS instrument for very small angle neutron scattering will extend the wave vector range for conventional SANS down to $10^{-4} \AA^{-1}$ while maintaining an ample cold neutron flux for measurement sensitivity. In a complementary way the new $10 \mathrm{~m}$ SANS will provide a very high intensity medium resolution instrument for small samples and time-sliced measurements. When these new state-of-the-art facilities are combined with existing NCNR SANS capabilities, NIST will maintain its position as the leading and most flexible U.S. resource for neutron studies of nanostructures, under an array of environmental conditions, in both hard and soft matter, including biological systems.

The last new instrument for materials structure research will be the subthermal neutron Materials Diffractometer, which will allow diffraction measurements at least two orders of magnitude faster than is possible on the NCNR high resolution diffractometer, with a range of incident wavelengths from $2.5 \AA$ to $6 \AA$ and wave vector transfers up to 4 $\AA^{-1}$. This is accomplished by using tunable, broad $(\approx 3 \%)$ wavelength resolution, along with an array of modern, high resolution area detectors. This instrument will open up a wide range of structure research, including e.g., in situ studies of solid state chemical reactions, glass transition mechanisms, and the evolution of magnetic structures. And of course measurements for much smaller samples will be enabled.

The new fundamental physics beam line, fed by a sophisticated focusing super mirror guide assembly, will have an order of magnitude increase in cold neutron intensity compared to the existing guide hall facility, along with a carefully controlled magnetic field environment, polarization capability, and optimized space for special projects. This 
new facility will provide an experimental station for critical neutron-based studies of weak interaction physics. In addition this beam line will be used to create the world's first state-of-the-art instrumentation dedicated to neutron phase-contrast imaging of devices and materials. First demonstrated for neutrons at NIST a decade ago, this method can provide up to three orders of magnitude in sensitivity compared to normal radiographs.

\section{$\underline{\text { Future Prospects for the NCNR and for U.S. Neutron Research }}$}

The NCNR is well positioned to continue to build on its success of the past 40 years. The NBS reactor has recently been approved by the Nuclear Regulatory Commission for 20 more years of operation. As noted, the Administration and Congress have approved and funded the construction of a second cold neutron guide hall, an expansion of related offices and facilities, and a modernization of key components of the research reactor. The improved network of cold neutron guides and the next generation of small angle neutron scattering, neutron reflectivity, neutron diffraction and fundamental neutron physics instrumentation will keep the NCNR at the forefront in the U.S. and internationally in many critical areas of science and technology which rely on these neutrons. The flourishing cooperative agreement with the U. of Maryland, and the recent agreements with the Indiana University (2005) and the U. of Delaware (2007), along with many other collaborative projects, will allow the NCNR to stay abreast of national needs for cold neutron research opportunities and instrumentation, particularly in the soft matter sciences. The NCNR is also fortunate to have in place first-rate young leaders and scientists for the future, along with continuing and growing strong research relationships with NIST laboratories and the broader scientific and engineering community.

In the coming years the U.S. position in neutron science will be enhanced, as the DOE responds to the difficult period at its neutron facilities over the past two decades. In particular, the decision by the DOE to concentrate their neutron resources at Oak Ridge National Laboratory in Tennessee, after the shutdown of both the HFBR at Brookhaven in 1999 and IPNS at Argonne in 2008, will have a great impact on the field. This is a point of departure for the DOE, which has previously developed its multidisciplinary user facilities (e.g., neutron sources, synchrotron sources, and nanotechnology centers) at diverse locations.

The \$2B Spallation Neutron Source, currently ramping up in both power (1.4 MW) and experimental stations (25 instruments), is the highest power pulsed neutron source in the world. This new facility offers exciting new scientific capabilities, particularly where the very high peak flux in neutron bursts can be fully utilized. A second target station for broader bursts of neutrons is also in the planning phase. And the High Flux Isotope Reactor has come back on line in recent years, with a cold neutron guide hall and improved thermal beams for inelastic scattering and diffraction. The total operating budget for these facilities is about $\$ 250 \mathrm{M}$ per year $(\approx \$ 300 \mathrm{M}$ when a new target station is implemented). Also in recent years the Los Alamos Neutron Scattering Center has advanced its important capabilities and will, with appropriate funding, continue to provide a productive pulsed neutron source in the years ahead.

All in all the facilities at Oak Ridge could provide close to 40 state of the art neutron beam instruments $(50+$ if the second target station is constructed $)$, the expanded 
NCNR, 30 instruments, and LANL, 10 to 15, if all sources are kept in operation over the next 20 years. It should be noted, however, that Europe, with currently 150 state-of-theart instruments, will still (at least quantitatively) be the world leader in neutron research. New neutron sources in Japan, China, Korea and Australia will also have an increasing impact on the field. In addition, the recently approved development of the European Spallation Source in Sweden will, ten to fifteen years from now, provide European scientists with the highest power spallation source in the world.

\section{Acknowledgments}

The authors thank Laura Williamson for her help in producing the manuscript for this brief history and those who provided or helped locate the visuals used in this review. We also wish to acknowledge the hundreds of scientists, engineers, technicians, and administrative staff who have played such an important role for the past four decades in making the NBSR and the NCNR so successful. The accomplishments reviewed here were in no small part due to all their efforts and dedication.

\section{Bibliography}

"NIST Cold Neutron Research Facility", Special Issue, Journal of Research of the National Institute of Standards and Technology, Vol. 98, No. 1. (1993).

"Materials Research with Neutrons at NIST", R. Cappelletti et al., J. Res. Natl. Inst. Stand. Technol., 106, pp 187-230 (2001).

J. Res. Natl. Inst. Stand. Technol., 106 Special Issue: Crystallography at NBS/NIST, pp. 1044-1173 (2001). See also articles on pp. 921-952, 953-964, 965-975, pp. 1097-1134, and pp. 1155-1173.

“A Unique Institution, The National Bureau of Standards 1950-1069”, Ed. Elio Passaglia, NIST SP 925, (1999).

"Responding to National Needs, The National Bureau of Standards Becomes the National Institute of Standards and Technology", James F. Schooley, NIST SP 955, (2000).

White House Office of Science and Technology Policy: "Report on the Status and Needs of Major Neutron Scattering Facilities and Instruments in the United States" (2002).

The NIST Center for Neutron Research 2010 Accomplishments and Opportunities, NIST SP 1110, http://www.ncnr.nist.gov/AnnualReport/FY2010/AR_2010_large.pdf 
The NIST Center for Neutron Research 2009 Accomplishments and Opportunities, NIST SP 1105, http://www.ncnr.nist.gov/AnnualReport/FY2009/AR2009.pdf

The NIST Center for Neutron Research 2008 Accomplishments and Opportunities, NIST SP 1089, http://www.ncnr.nist.gov/AnnualReport/FY2008/AR2008.pdf

The NIST Center for Neutron Research 2007 Accomplishments and Opportunities, NIST SP 1075, http://www.ncnr.nist.gov/AnnualReport/FY2007/AR2007.pdf

The NIST Center for Neutron Research 2006 Accomplishments and Opportunities, NIST SP 1060, http://www.ncnr.nist.gov/AnnualReport/FY2006/AR2006.pdf

The NIST Center for Neutron Research 2005 Accomplishments and Opportunities, NIST SP 1045, http://www.ncnr.nist.gov/AnnualReport/FY2005/AR2005.pdf

The NIST Center for Neutron Research 2004 Accomplishments and Opportunities, NIST SP 1029, http://www.ncnr.nist.gov/AnnualReport/FY2004/AR2004.pdf

The NIST Center for Neutron Research 2003 Accomplishments and Opportunities, NIST SP 1006, http://www.ncnr.nist.gov/AnnualReport/FY2003/

The NIST Center for Neutron Research 2002 Accomplishments and Opportunities, NIST SP 993, http://www.ncnr.nist.gov/AnnualReport/FY2002_pdf/

The NIST Center for Neutron Research 2001 Accomplishments and Opportunities, NIST SP 977, http://www.ncnr.nist.gov/AnnualReport/FY2001_pdf/

The NIST Center for Neutron Research 2000 Accomplishments and Opportunities, NIST SP 962, http://www.ncnr.nist.gov/AnnualReport/FY2000/

The NIST Center for Neutron Research 1999 Accomplishments and Opportunities, NIST SP 944, http://www.ncnr.nist.gov/AnnualReport/FY1999/

The NIST Center for Neutron Research 1998 Accomplishments and Opportunities, NIST IR 6251, http://www.ncnr.nist.gov/AnnualReport/FY1998/ 

NLT

National Institute of Standards and Technology

Technology Administration, U.S. Department of Commerce

August 2011 